UNIVERSIDADE DE SÃO PAULO

ESCOLA DE ARTES, CIÊNCIAS E HUMANIDADES

PROGRAMA DE PÓS-GRADUAÇÃO EM TÊXTIL E MODA

RENAN GUAZZELLI AFFONSO

MÉTODO PRÁTICO PARA A MEDIÇÃO E COMPARAÇÃO DA EMISSIVIDADE DE RAIOS INFRAVERMELHOS EM DIFERENTES TECIDOS CONTENDO BIOCERÂMICA 


\section{MÉTODO PRÁTICO PARA A MEDIÇÃO E COMPARAÇÃO DA EMISSIVIDADE DE RAIOS INFRAVERMELHOS EM DIFERENTES TECIDOS CONTENDO BIOCERÂMICA}

Dissertação apresentada à Escola de Artes, Ciências e Humanidades da Universidade de São Paulo para obtenção do título de Mestre em Ciências, Programa de PósGraduação em Têxtil e Moda.

Versão corrigida contendo as alterações solicitadas pela comissão julgadora em 28 de junho de 2016. A versão original encontra-se em acervo reservado na Biblioteca da EACH/USP e na Biblioteca Digital de Teses e Dissertações da USP (BDTD), de acordo com a Resolução CoPGr 6018, de 13 de outubro de 2011.

Linha de Pesquisa: Materiais e Processos Têxteis

Orientador: Prof. Dr. João Paulo Pereira Marcicano 
Autorizo a reprodução e divulgação total ou parcial deste trabalho, por qualquer meio convencional ou eletrônico, para fins de estudo e pesquisa, desde que citada a fonte.

Affonso, Renan Guazzelli

Método prático para a medição e comparação da emissividade de raios infravermelhos em diferentes tecidos contendo biocerâmica /

Renan Guazzelli Affonso ; orientador, João Paulo Pereira Marcicano.

- São Paulo, 2016

107 f. : il

Dissertação (Mestrado em Ciências) - Programa de PósGraduação em Têxtil e Moda, Escola de Artes, Ciências e

Humanidades, Universidade de São Paulo, em 2016

Versão corrigida

1. Tecnologia têxtil. 2. Tecidos (Indústria têxtil). 3.

Materiais cerâmicos. 4. Espectroscopia infravermelha. 5.

Fluorescência. 6. Marcicano, João Paulo Pereira, orient. II.

Título.

CDD 22.ed. -677 
Nome: AFFONSO, Renan Guazzelli

Título: Método prático para a medição e comparação da emissividade de raios infravermelhos em diferentes tecidos contendo biocerâmica

Dissertação apresentada à Escola de Artes, Ciências e Humanidades da Universidade de São Paulo para obtenção do título de Mestre em Ciências, Programa de PósGraduação em Têxtil e Moda.

Linha de Pesquisa: Materiais e Processos Têxteis

Aprovado em:

\section{Banca Examinadora}

Prof. Dr(a). Instituição:

Julgamento: Assinatura:

Prof. Dr(a).

Instituição:

Julgamento:

Assinatura:

Prof. Dr(a).

Instituição:

Julgamento:

Assinatura:

Prof. Dr(a).

Instituição:

Julgamento:

Assinatura: 


\section{AGRADECIMENTOS}

Agradeço aos meus pais e irmã, que sempre me apoiaram e incentivaram a seguir meus estudos, e que me suportaram nos bons e maus momentos.

Ao meu orientado João Paulo Pereira Marcicano por toda ajuda na realização deste trabalho.

À Prof ${ }^{\mathrm{a}}$ Dra. Marcilei Aparecida Guazzelli da Silveira, pois sem seu apoio e empenho em me auxiliar neste estudo, este trabalho não teria sido realizado.

À Dra. Roseli F. Gennari, que mais uma vez me auxiliou com as medições das amostras no espectrofotômetro de raios infravermelhos, além de sanar muitas dúvidas que surgiram ao longo do trabalho.

À Prof ${ }^{a}$ Dra. Marcia A. Rizzutto, por toda ajuda na elaboração dos ensaios de fluorescência de raios $\mathrm{X}$, e também pela ajuda na análise dos resultados obtidos.

Às Prof ${ }^{a}$ s Dra.s Camilla Borelli e Regina Aparecida Sanches, pelas valiosas dicas e orientações durante as etapas prévias para a obtenção deste título.

E por fim agradeço à minha amiga e colega Fernanda Gomes de Vasconcelos por sempre me apoiar, incentivar e me acompanhar não somente nas aulas, mas em todos os momentos, sempre me ajudando na hora das dificuldades. 
O único lugar onde o sucesso vem antes do trabalho é no dicionário. Albert Einstein 


\section{RESUMO}

\section{AFFONSO, Renan Guazzelli, Método prático para a medição e comparação da}

emissividade de raios infravermelhos em diferentes tecidos contendo biocerâmica. 2016 . 107 f. Dissertação (Mestrado em Têxtil e Moda) - Escola de Artes, Ciências e Humanidades, Universidade de São Paulo, São Paulo, 2016. Versão corrigida.

Por décadas a radiação infravermelha tem sido usada de forma estética e terapêutica, e é caracterizada por ter a propriedade de penetrar na pele. O surgimento de novas tecnologias permitiu a criação de têxteis funcionais, entre eles os tecidos contendo biocerâmica, que absorvem o calor do corpo, ativando a biocerâmica presente e emitindo raios infravermelhos longos, que penetram na pele ativando a microcirculação sanguínea. Porém, tecidos desse tipo só tiveram eficiência comprovada por testes clínicos, que são métodos caros e demorados, ou por analogia baseada no tipo de construção. O objetivo deste estudo foi elaborar um método prático para medir a emissividade de tecidos contendo biocerâmica, utilizando um espectrofotômetro de raios infravermelhos, comparar a emissividade desses tecidos, além de realizar uma análise de fluorescência de raios $\mathrm{X}$ a fim de descobrir os elementos químicos presentes nos tecidos, para confirmar quaisquer diferenças de emissividade entre os mesmos. Concluiu-se que é possível medir a emissividade de tecidos contendo biocerâmica através do aquecimento das amostras, simulando a ação do tecido junto ao corpo, e posteriormente realizando ensaios em um espectrofotômetro de infravermelhos por transformada de Fourier, onde picos de emissão foram encontrados em cada tecido analisado, o que possibilitou o cálculo da emissividade (expressa em contagens de área) através do ajuste de uma curva gaussiana em cada pico de emissão. Através da fluorescência de raios $\mathrm{X}$ foram encontrados diferentes elementos químicos na composição das amostras, podem ser a causa da diferença de emissividade entre os tecidos.

Palavras-chave: Tecidos contendo biocerâmica. Espectroscopia de Infravermelhos. Fluorescência de raios $\mathrm{X}$. 


\begin{abstract}
AFFONSO, Renan Guazzelli, Practical method for Infrared rays emissivity measurement and comparison in different fabrics containing bioceramics. 2016. 107 p. Dissertation

(Masters in Textile and Fashion) - Escola de Artes, Ciências e Humanidades, Universidade de São Paulo, São Paulo, 2016. Corrected version.

The infrared radiation has been used on aesthetic and therapeutic way for decades, and is characterized for being able to penetrate deeply underneath the skin. New technologies appeared, enabling the development of functional textiles, among them textiles containing bioceramics that absorb the body heat, activating the bioceramic on it and emitting far infrared rays, which penetrate into the skin, activating the blood microcirculation. However, the efficiency of this sort of fabrics was proven only by clinical tests, which are very expensive and time consuming, and by construction analogy. The main objective of this study was to develop a practical method for measuring fabrics containing bioceramics emissivity, using an infrared spectrophotometer, comparing the fabrics emissivity, besides doing an $\mathrm{X}$ ray fluorescence analysis in order to discover the chemical elements that composes the fabrics, to confirm any emissivity differences between them. It was concluded that it is possible to measure the emissivity of fabrics containing bioceramics by heating the samples, simulating the action of the fabric on the body, and subsequently performing tests on a Fourier transform infrared spectrophotometer, where emission peaks were found on the fabrics, that enabled the emissivity calculation (expressed in area counts) by adjusting a Gaussian curve at each emission peak. By the $\mathrm{X}$ ray fluorescence different chemical elements were found on the fabrics composition, which can be the reason for the emissivity difference between them.
\end{abstract}

Key words: Fabrics containing bioceramics. Infrared spectroscopy. X ray fluorescence. 


\section{LISTA DE TABELAS}

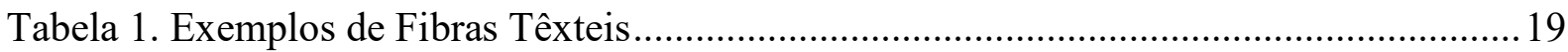

Tabela 2. Estatística anual de fibras artificiais manufaturadas em 2015 (ton/ano).................23

Tabela 3. Estatística anual de fibras sintéticas manufaturadas em 2015 (ton/ano). ................ 24

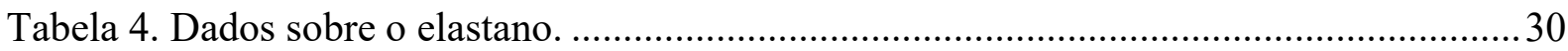

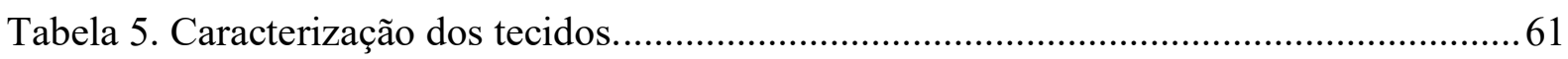

Tabela 6. Resultado dos cálculos obtidos através do ajuste da curva gaussiana para o primeiro pico de emissão do tecido com biocerâmica incorporada à matriz polimérica do fio, quando

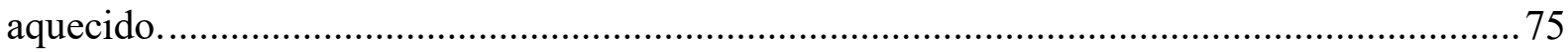

Tabela 7. Resultado dos cálculos obtidos através do ajuste da curva gaussiana para o segundo pico de emissão do tecido com biocerâmica incorporada à matriz polimérica do fio, quando aquecido.

Tabela 8. Resultado dos cálculos obtidos através do ajuste da curva gaussiana para o terceiro pico de emissão do tecido com biocerâmica incorporada à matriz polimérica do fio, quando aquecido.

Tabela 9. Resultado dos cálculos obtidos através do ajuste da curva gaussiana para o primeiro pico de emissão do tecido com biocerâmica impregnada, quando aquecido.

Tabela 10. Resultado dos cálculos obtidos através do ajuste da curva gaussiana para o segundo pico de emissão do tecido com biocerâmica impregnada, quando aquecido.

Tabela 11. Resultado dos cálculos obtidos através do ajuste da curva gaussiana para o pico de emissão do tecido com deposição de biocerâmica, quando aquecido.

Tabela 12. Comparativo de contagens de área para cada pico de emissão dos diferentes tecidos em função com número de onda e comprimento de onda.

Tabela 13. Nomes dos elementos químicos encontrados nas medições com o sistema FRX. . 90 Tabela 14. Áreas relativas a cada elemento encontrado no espectro da amostra de tecido com biocerâmica incorporada à matriz polimérica do fio.

Tabela 15. Áreas relativas a cada elemento encontrado no espectro da amostra de tecido com biocerâmica impregnada.

Tabela 16. Áreas relativas a cada elemento encontrado no espectro da amostra de tecido com deposição de biocerâmica.

Tabela 17. Áreas relativas a cada elemento encontrado no espectro da amostra de tecido sem biocerâmica.

Tabela 18. Áreas relativas a cada elemento encontrado no espectro das diferentes amostras analisadas, com filtro no sistema FRX. 


\section{LISTA DE FIGURAS}

Figura 1. Efeito do Tecido Contendo Biocerâmica em Contato com a Pele............................ 15

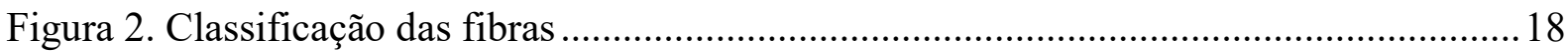

Figura 3. Consumo de fibras no Mundo e no Brasil...............................................................20

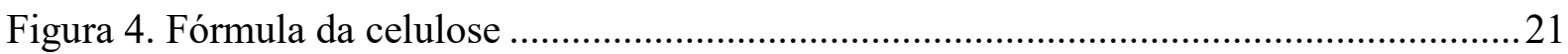

Figura 5. Seqüência para obtenção do poliéster ................................................................25

Figura 6. Corte Transversal e Vista Longitudinal da Fibra de Poliamida. ...............................26

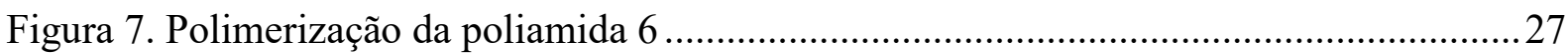

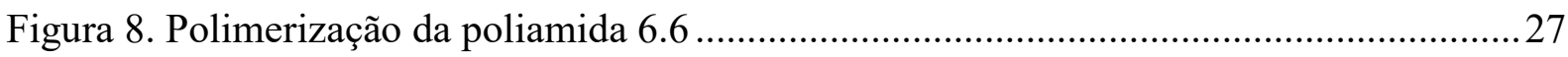

Figura 9. Diferença na disposição dos grupos amina nas poliamidas 6 e 6.6 ......................... 28

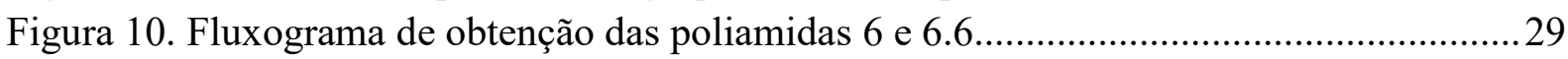

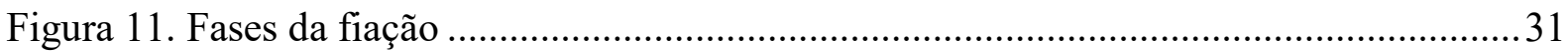

Figura 12. Processo de fiação da poliamida por fusão ........................................................... 33

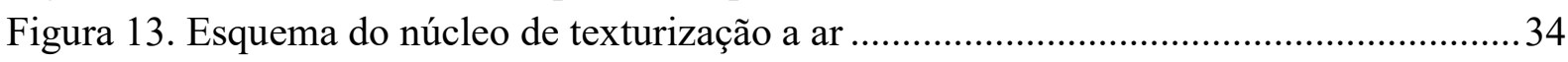

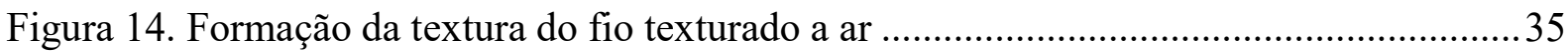

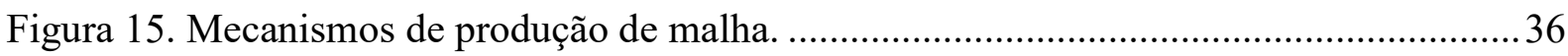

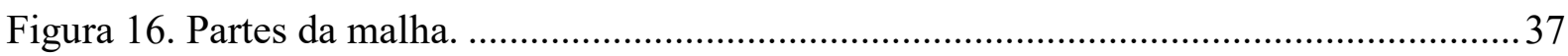

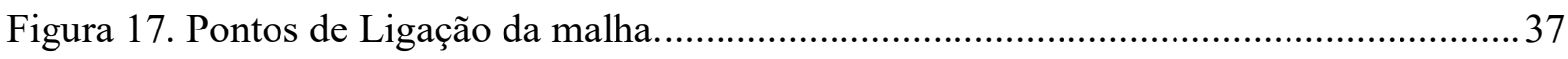

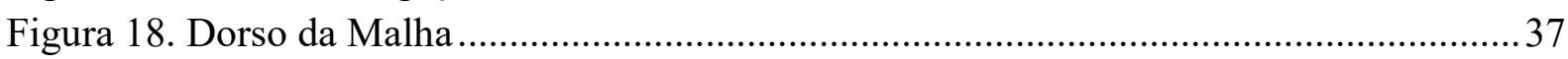

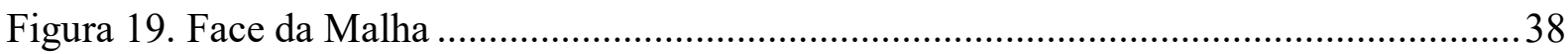

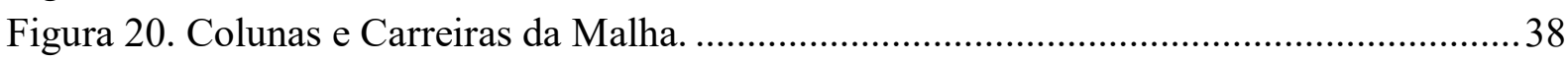

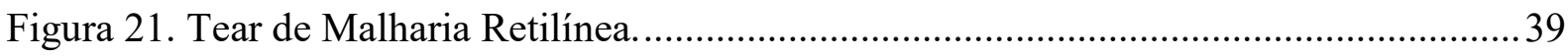

Figura 22. Tear de Malharia Circular de Grande Diâmetro. .................................................... 40

Figura 23. Diferença entre ligamentos de malha de trama e urdume ..................................... 41

Figura 24. Extensão da radiação infravermelha dentro do espectro eletromagnético. ..............43

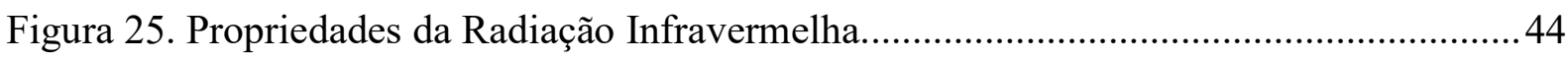

Figura 26. Porcentagem de absorção e penetração na pele humana correspondendo com o

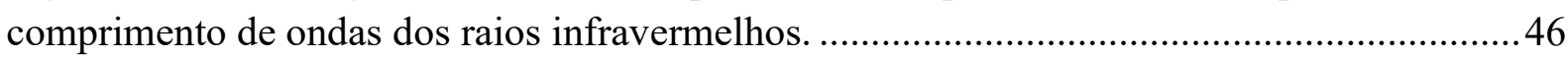

Figura 27. Incorporação da biocerâmica na matriz plomérica do fio. ......................................50

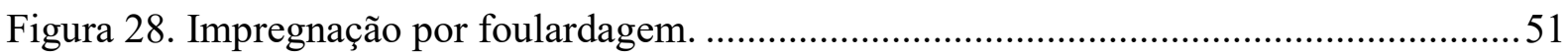

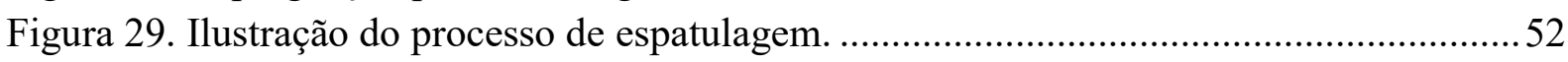

Figura 30. Esquema do espectrofotômetro de infravermelhos utilizado para medição das

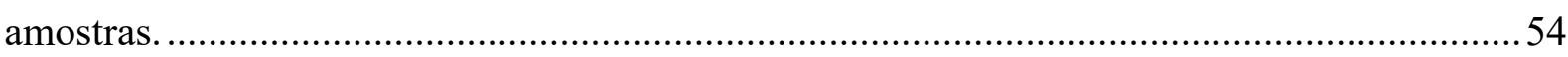

Figura 31. Diagrama simplificado do sistema óptico de um espectrômetro FTIR...................57

Figura 32. Fluxograma do experimento para a medição das amostras no espectrofotômetro

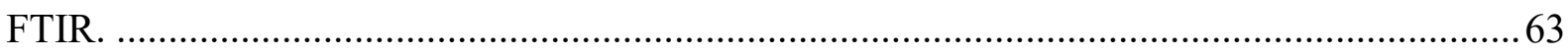

Figura 33. Espectrofotômetro utilizado no experimento e interior do espectrofotômetro. .......64 Figura 34. Chapa metálica utilizada para aquecer as amostras com o porta amostras utilizado no experimento.

Figura 35. Sistema de Fluorescência de Raios X utilizado no experimento. ...........................67

Figura 36. Espectro de emissão do tecido sem biocerâmica aquecido e não aquecido.............68 
Figura 37. Espectro de emissão do tecido sem biocerâmica, aquecido e não aquecido, com deslocamento.

Figura 38. Espectro de emissão do tecido com biocerâmica incorporada à matriz polimérica do fio, aquecido e não aquecido, com deslocamento.

Figura 39. Espectro de emissão do tecido com biocerâmica impregnada, aquecido e não aquecido, com deslocamento.

Figura 40. Espectro de emissão do tecido com deposição de biocerâmica, aquecido e não aquecido, com deslocamento.

Figura 41. Parâmetros para cálculo da área embaixo da curva gaussiana ajustada a cada pico de emissão do espectro infravermelho.

Figura 42. Curva Gaussiana ajustada ao primeiro pico do espectro de emissão do tecido com biocerâmica incorporada à matriz polimérica do fio, quando aquecido.

Figura 43. Curva Gaussiana ajustada ao segundo pico do espectro de emissão do tecido com biocerâmica incorporada à matriz polimérica do fio, quando aquecido.

Figura 44. Curva Gaussiana ajustada ao terceiro pico do espectro de emissão do tecido com biocerâmica incorporada à matriz polimérica do fio, quando aquecido.

Figura 45. Curva Gaussiana ajustada ao primeiro pico do espectro de emissão do tecido com biocerâmica impregnada, quando aquecido

Figura 46. Curva Gaussiana ajustada ao segundo pico do espectro de emissão do tecido com biocerâmica impregnada, quando aquecido

Figura 47. Curva Gaussiana ajustada ao pico do espectro de emissão do tecido com deposição de biocerâmica, quando aquecido.

Figura 48. Contagem de área de cada pico para os diferentes tipos de tecido, quando aquecido.

Figura 49. Gráfico de contagens de raios X emitidos pelo tecido com biocerâmica incorporada à matriz polimérica do fio.

Figura 50. Gráfico de contagens de raios $\mathrm{X}$ emitidos pelo tecido com biocerâmica impregnada.

Figura 51. Gráfico de contagens de raios $\mathrm{X}$ emitidos pelo tecido com deposição de biocerâmica.

Figura 52. Gráfico de contagens de raios X emitidos pelo tecido sem biocerâmica.

Figura 53. Gráfico de contagens de raios X emitidos pelo tecido com biocerâmica incorporada à matriz polimérica do fio, com filtro.

Figura 54. Gráfico de contagens de raios $\mathrm{X}$ emitidos pelo tecido com biocerâmica impregnada, com filtro.

Figura 55. Gráfico de contagens de raios $\mathrm{X}$ emitidos pelo tecido com deposição de biocerâmica, com filtro.

Figura 56. Gráfico de contagens de raios $\mathrm{X}$ emitidos pelo tecido sem biocerâmica, com filtro. 


\section{SUMÁRIO}

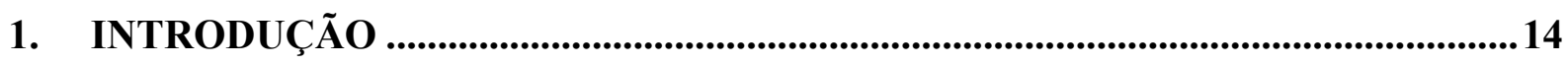

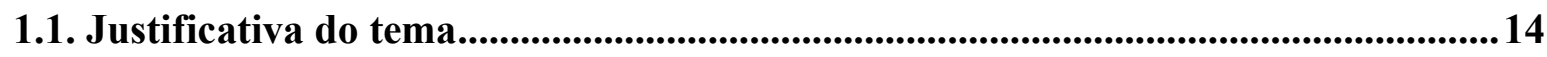

1.2. Importância do trabalho ...................................................................................16

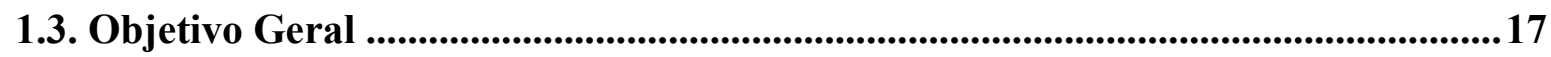

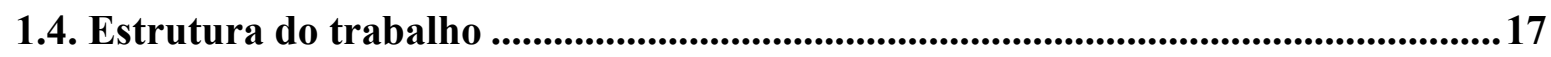

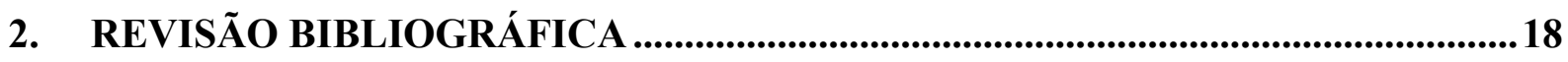

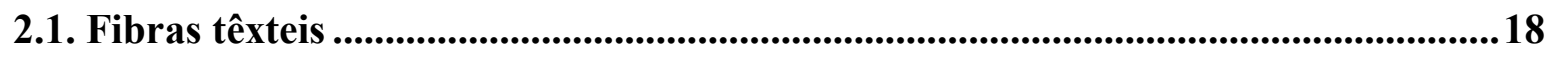

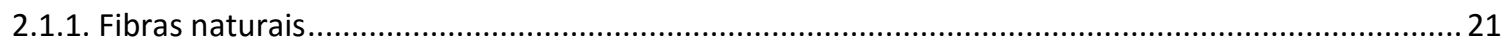

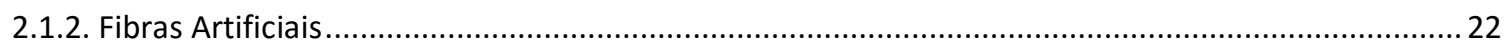

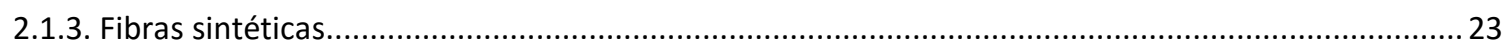

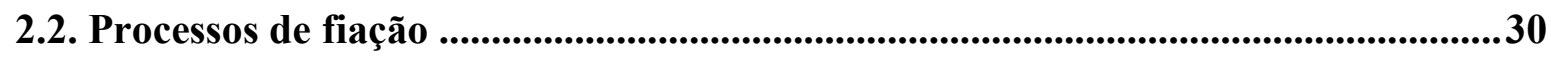

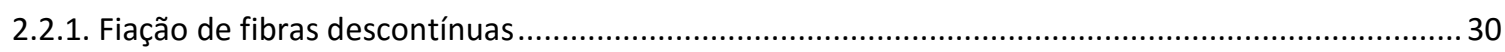

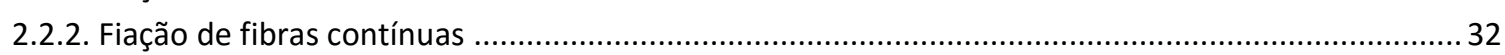

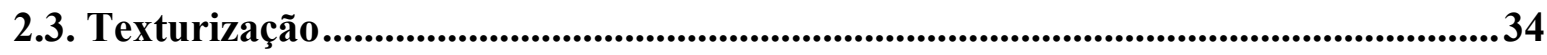

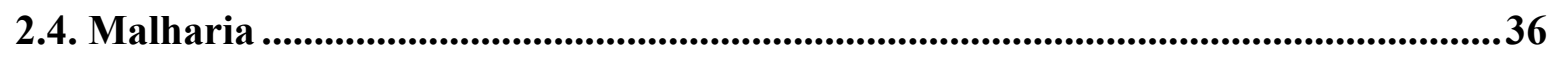

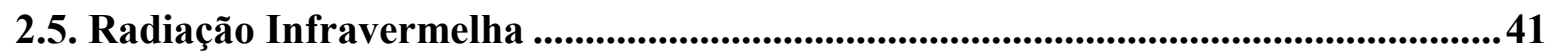

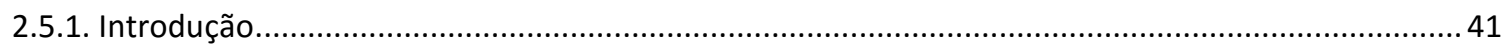

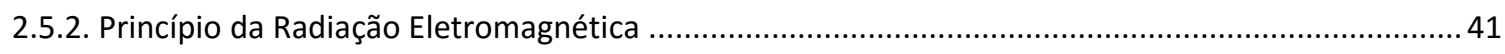

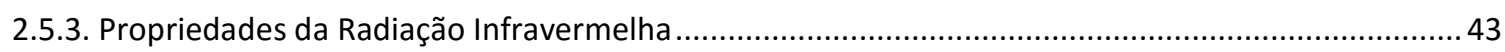

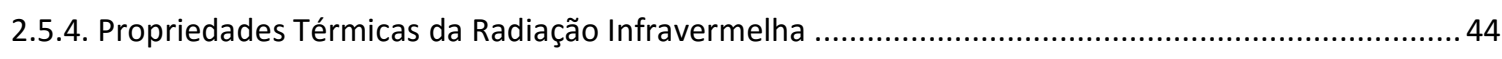

2.5.5. Ação Biológica da Radiação Infravermelha ......................................................................... 45

2.6. Têxteis com radiação infravermelha....................................................................46

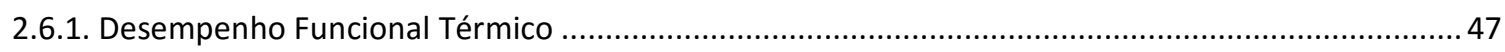

2.7. Princípio da Incorporação de Radiação Infravermelha em Têxteis ......................48

2.7.1. Materiais Especiais Utilizados para Incorporar o Efeito de Radiação Infravermelha em Têxteis ...... 49

2.7.2. Métodos de Aplicação de Materiais Cerâmicos em Têxteis ........................................................... 49

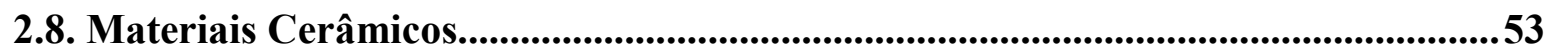

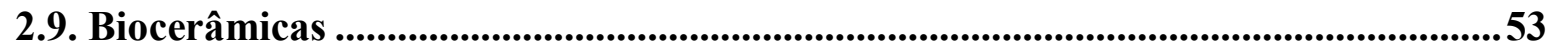

2.10. Espectrofotômetro de Infravermelhos...................................................................54

2.11. Espectroscopia FTIR - Infravermelhos por Transformada de Fourier ..............55

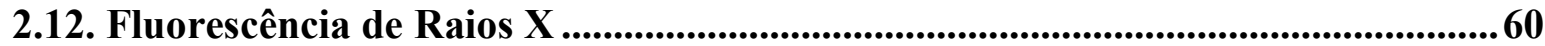




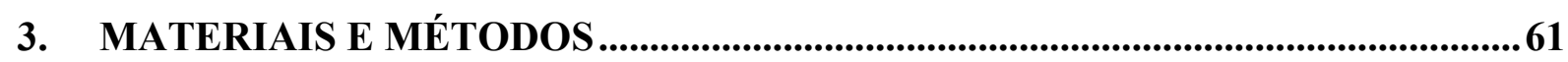

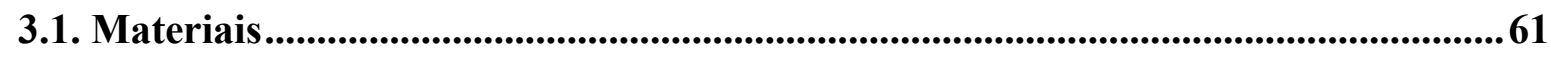

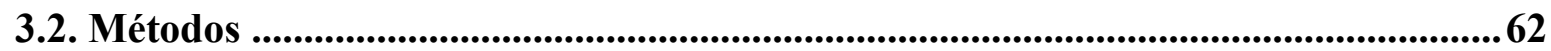

4. RESULTADOS E DISCUSSÃO DOS ENSAIOS.............................................68

4.1. Resultados da Espectrofotometria de Raios Infravermelhos ...............................68

4.2. Resultados da Fluorescência de Raios X .........................................................88

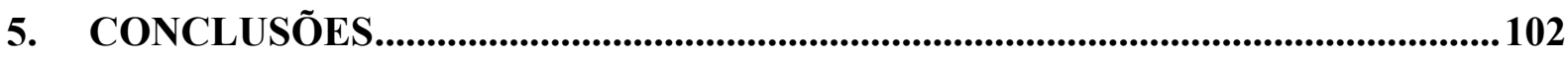

6. SUGESTÃO DE TRABALHOS FUTUROS......................................................... 102

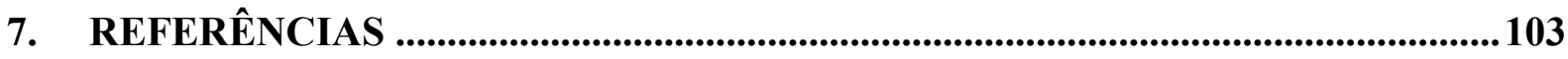




\section{INTRODUÇÃO}

Segundo Conrado (2004) os comprimentos de onda do espectro eletromagnético são utilizados pelo homem no seu dia-a-dia há muito tempo, sendo em sua maioria invisíveis aos olhos, como por exemplo, a radiação infravermelha, que é usada na terapia médica, principalmente no tratamento de reumatismos, artrites e sinusites.

Estudos analisando as propriedades de alguns materiais cerâmicos mostraram que eles possuem efeito foto-térmico, ou seja, apresentam a propriedade de emitir radiação infravermelha quando aquecidos (CONRADO, 2000).

Com base nos estudos dos materiais cerâmicos, para auxiliar no tratamento médico,

tecidos contendo biocerâmica começaram a ser desenvolvidos primeiramente na Ásia (BASTOS, 2013) na forma de acessórios terapêuticos como luvas, cintas, ataduras, bermudas, entre outros. Segundo Karachi (2008) este tipo de tecido é um grande desenvolvimento de inovação têxtil.

\subsection{Justificativa do tema}

A radiação infravermelha é uma energia não ionizante, que vem do espectro eletromagnético e está compreendida na faixa de comprimentos de onda $(\lambda)$ de 0,7 a $1000 \mu \mathrm{m}$, sendo que a faixa de 0,7 a $3 \mu \mathrm{m}$ é classificada de infravermelho próximo, a faixa de 3 a $6 \mu \mathrm{m}$ de infravermelho médio e a faixa de 6 a $1000 \mu \mathrm{m}$ de infravermelho longo (DOVER, PHILLIPS, ARNDT, 1989).

Têxteis especiais compostos com cerâmicas que têm fortes propriedades de absorção de infravermelhos foram desenvolvidos. Os raios infravermelhos são transmitidos à pele pelo tecido, assim a pele absorve esses raios causando a sensação de calor (SHYR, XU, YAO, 2007). A fabricação desses artigos é feita com a utilização de pó de materiais cerâmicos, como o Carbeto de Zircônio $(\mathrm{ZrC})$. Esse pó é incorporado ao material têxtil para utilizar o efeito de radiação infravermelha das cerâmicas (PARK, SHIM, SHIM, 2009). 
Hoje em dia, no mercado, encontram-se artigos têxteis contendo biocerâmica disponibilizados da seguinte forma:

○ Tecido com biocerâmica incorporada à matriz polimérica do fio.

○ Tecido com biocerâmica impregnada.

○ Tecido com deposição de biocerâmica em sua superfície.

Conforme estudo feito por Conrado (2000) esses tecidos funcionam basicamente da seguinte forma: O calor emitido pelo corpo é absorvido pelo material cerâmico, que é excitado, refratando raios infravermelhos longos para o corpo. Esses raios penetram na pele e interagem com o corpo, estimulando a microcirculação e o metabolismo celular, aumentando a circulação sanguínea periférica (WAINWRIGHT, 2010).

Figura 1. Efeito do Tecido Contendo Biocerâmica em Contato com a Pele.

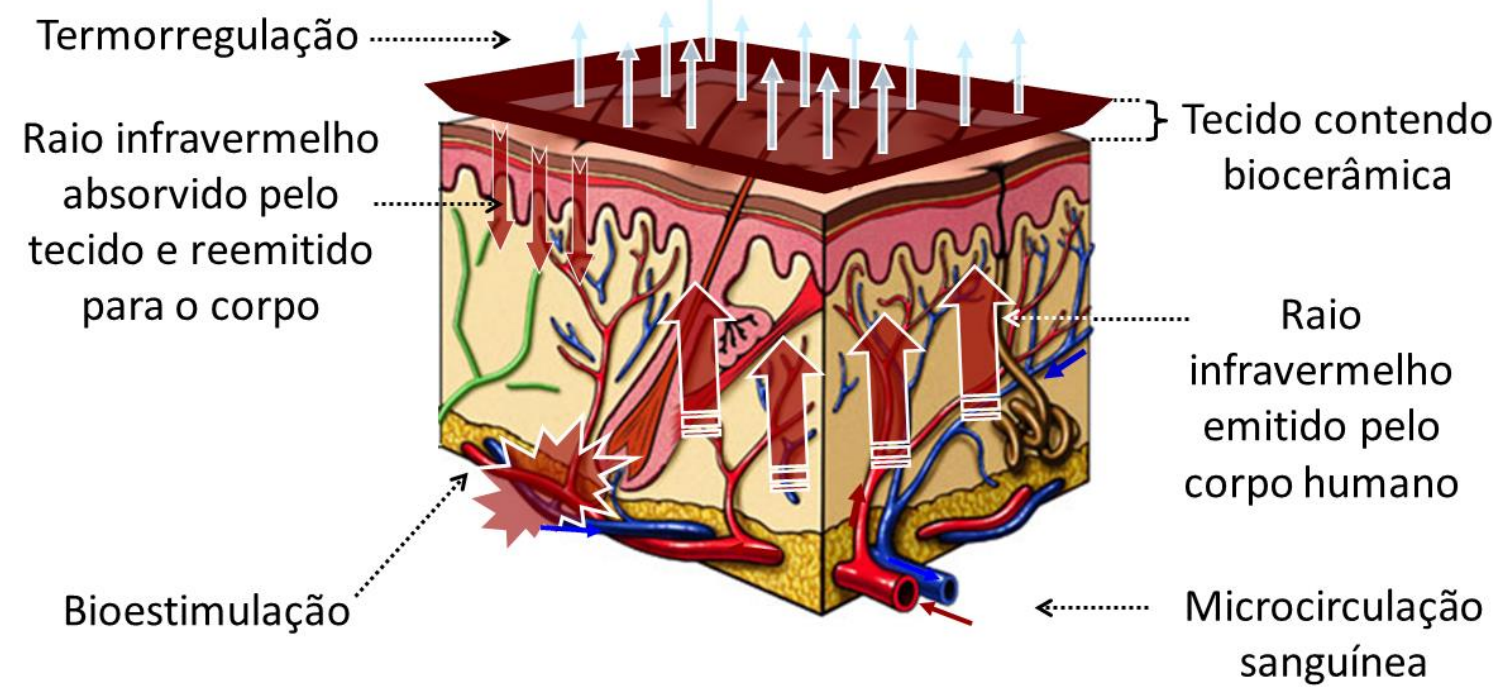

Aumento da microcirculação sanguínea periférica

Fonte: Bastos (2013).

A irradiação com infravermelho emitido pela biocerâmica favorece a divisão celular e a síntese de proteínas como o colágeno e a elastina. Isso melhora a circulação sanguínea e a oxigenação dos tecidos corporais, promovendo uma redução da dor no local em contato com a biocerâmica (BEZERRA, CONRADO, 2003). 
Os materiais cerâmicos esquentam as substâncias ao seu redor de forma homogênea devido a uniformidade da radiação infravermelha que eles possuem, causando um movimento molecular (PARK, SHIM, SHIM, 2009).

\subsection{Importância do trabalho}

O interesse atual em têxteis biofuncionais é focado basicamente no uso para dar suporte a terapias médicas e prevenções dermatológicas. Os têxteis interagem com a pele de uma maneira muito intensiva. Os têxteis podem influenciar na pele, através da interação entre a pele e o material têxtil (ELSNER, HIPLER, 2006).

As biocerâmicas emitem raios infravermelhos longos, cujos principais efeitos compreendem a melhora da circulação, um aumento da imunidade, a reparação e regeneração dos tecidos corporais e o gerenciamento dos líquidos do corpo (INOUE, KABAYA, 1989).

A possibilidade da confecção de roupas para uso diário contendo biocerâmica permite uma estimulação contínua por parte dos raios infravermelhos emitidos pelo tecido, fazendo com que tratamentos médicos que utilizam a radiação infravermelha possam ser realizados em casa ou no trabalho (CONRADO, 2000). Já existem no mercado brasileiro alguns produtos com este tipo de efeito.

A avaliação da emissividade desses tecidos é muito importante, porém existem poucas referências disponíveis relacionadas a esse tema (SHYR, XU, YAO, 2007). A eficiência de artigos contendo biocerâmica foi comprovada apenas com testes clínicos ou por analogia baseada no tipo de construção (ligamentos, gramatura, entre outros). Estes métodos são muito demorados e caros (ANDRADE, KAYSER, 2012), não havendo até então uma forma prática para medir a emissividade de tecidos com esse tipo de característica. 


\subsection{Objetivo Geral}

Elaborar um método prático (procedimento) para medir a emissividade de raios infravermelhos de tecidos contendo biocerâmica e comparar os diferentes tipos de tecido contendo biocerâmica, encontrando a emissão característica de cada um.

\subsection{Estrutura do trabalho}

O trabalho será dividido em seis capítulos: Introdução, Revisão Bibliográfica, Materiais e Métodos, Resultados e discussões, Conclusão e Sugestões de Trabalhos Futuros.

O capítulo 1 - Introdução: apresenta uma ideia geral sobre o que será tratado no trabalho, contendo objetivos, justificativa, importância do trabalho, pergunta e hipótese, além do plano de organização do trabalho.

O capítulo 2 - Revisão Bibliográfica: trata principalmente de radiação infravermelha, tecidos com características de emissão de raios infravermelhos, espectroscopia de infravermelhos por transformada de Fourier e Fluorescência de Raios X.

O capítulo 3 - Materiais e Métodos: são descritos todos os materiais e equipamentos e metodologias utilizados no trabalho.

O capítulo 4 - Resultados e Discussão dos Ensaios: Serão descritos e analisados todos os resultados obtidos.

O capítulo 5 - Conclusão: serão apresentadas as conclusões obtidas no trabalho, verificando a hipótese proposta no capítulo de introdução.

Finalmente, o capítulo 6 - Sugestão de Trabalhos Futuros: serão sugeridas novas possibilidades para continuidade e aperfeiçoamento do trabalho. 


\section{REVISÃO BIBLIOGRÁFICA}

\subsection{Fibras têxteis}

Segundo o Conmetro (2008) uma fibra têxtil é toda matéria natural, de origem vegetal, animal ou mineral, assim como toda matéria artificial ou sintética, que por sua alta relação entre seu comprimento e seu diâmetro, e ainda, por suas características de flexibilidade, suavidade, elasticidade, resistência, tenacidade e finura está apta as aplicações têxteis.

A indústria têxtil utiliza vários tipos de fibras diferentes como matéria-prima. Algumas dessas fibras têm sido usadas desde as civilizações mais antigas até hoje, e outras foram ganhando importância nos últimos anos (CORBMAN, 1975).

A classificação geral das fibras está resumida na figura 2:

Figura 2. Classificação das fibras

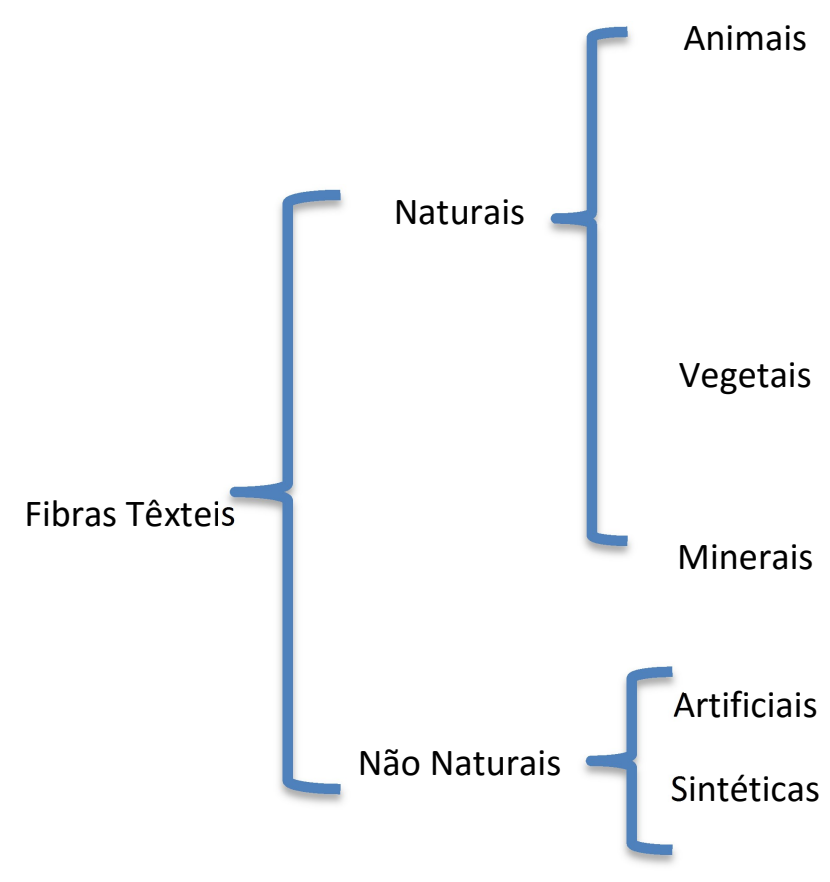

Fonte: Renan Guazzelli Affonso, 2015. 
Sendo assim alguns exemplos de cada tipo de fibra podem ser encontrados na tabela 1:

Tabela 1. Exemplos de Fibras Têxteis

\begin{tabular}{|c|c|c|}
\hline \multirow{3}{*}{ ANIMAIS } & Secreção & S - Seda \\
\hline & Pelos & $\begin{array}{l}\text { WP - Alpaca } \\
\text { WA - Angorá } \\
\text { WS - Cashmere } \\
\text { WO - Lã }\end{array}$ \\
\hline & Minerais & A - Amianto \\
\hline \multirow{4}{*}{ VEGETAIS } & Semente & $\begin{array}{l}\text { CO - Algodão } \\
\text { CP - Paina }\end{array}$ \\
\hline & Caule & $\begin{array}{l}\text { CH - Cânhamo } \\
\text { CJ - Juta } \\
\text { CL - Linho } \\
\text { CR - Rami }\end{array}$ \\
\hline & Folhas & $\begin{array}{l}\text { CB - Abacá } \\
\text { CS - Sisal }\end{array}$ \\
\hline & Frutos & CC - Côco \\
\hline ARTIFICIAIS & $\begin{array}{l}\text { CA - Acet } \\
\text { AL - Algin } \\
\text { CLY - Lioc } \\
\text { CMD - M } \\
C V \text { - Visc }\end{array}$ & \\
\hline SINTÉTICAS & $\begin{array}{l}\text { PAC - Acr } \\
\text { EL - Elast } \\
\text { PA - Polia } \\
\text { PES - Poli } \\
\text { PE - Polie } \\
\text { PP - Polip }\end{array}$ & $\begin{array}{l}\text { da } \\
\text { er } \\
\text { no } \\
\text { ileno }\end{array}$ \\
\hline
\end{tabular}

Fonte: Renan Guazzelli Affonso, 2015 
A figura 3 mostra uma comparação entre o consumo de fibras no mundo e o consumo de fibras no Brasil, através de um gráfico, onde as fibras estão divididas em naturais, artificiais e sintéticas. Nota-se que em geral, no mundo, as fibras mais consumidas são as sintéticas, enquanto que no Brasil as mais consumidas são as naturais.

Figura 3. Consumo de fibras no Mundo e no Brasil

\section{Mundo}

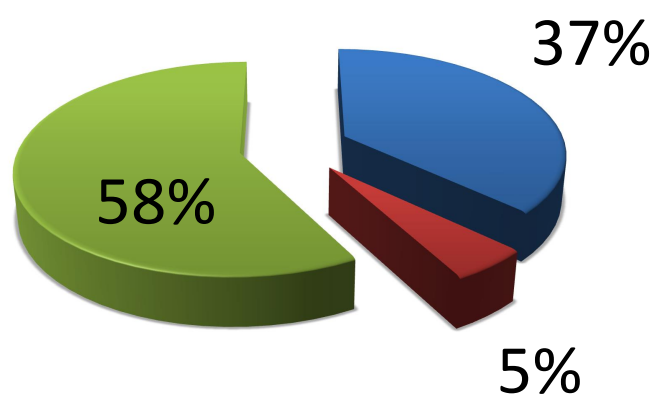

Brasil

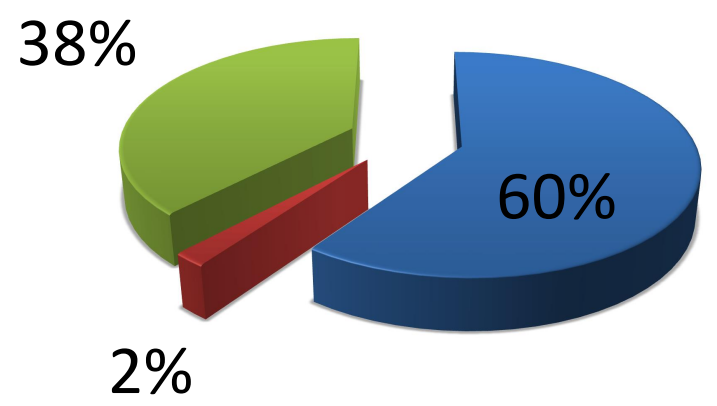

Fonte: ABRAFAS, 2013. 


\subsubsection{Fibras naturais}

Segundo Alfieri (2012a) as fibras naturais são aquelas preparadas pela natureza, ou seja, já são encontradas prontas. Elas são compostas, em sua maioria, por celulose.

A celulose é um polímero de cadeia longa, composta por um único monômero, o hidrato de carbono (carboidrato), conhecido como polissacarídeo. O polissacarídeo é uma macromolécula formada pela união de diversos monossacarídeos.

O nome de grau de polimerização (G.P.) é dado ao número de repetições destes monossacarídeos, sendo que o grau de polimerização da celulose depende da fonte de extração da mesma, bem como dos processos de purificação e beneficiamento a que será submetida durante todo o processamento industrial até o uso final como material têxtil. A figura 4 mostra a fórmula química da celulose.

Figura 4. Fórmula da celulose

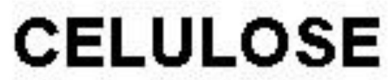

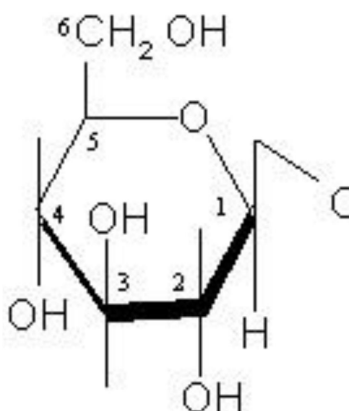

GLICOSE

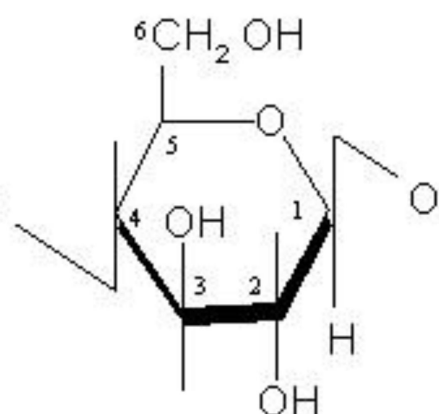

GLICOSE

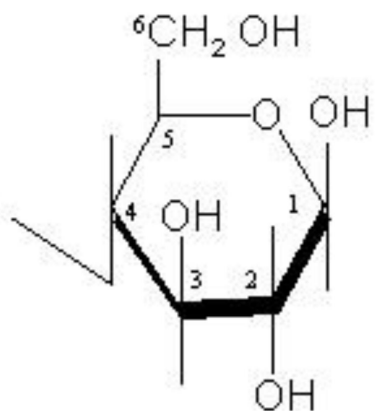

GLICOSE

Fonte: Klock, et al., 2005.

A celulose contém grupos hidroxilas livres, que são responsáveis pela grande quantidade de pontes de hidrogênio, ligações que mantém a coesão de toda estrutura molecular da fibra.

As moléculas de celulose formam pequenos feixes de cadeias moleculares, que se combinam em grupos para compor as fibras da celulose. 
As fibras celulósicas apresentam regiões organizadas onde as moléculas estão em completo arranjo cristalino e regiões desorganizadas, onde as moléculas encontram-se em estado amorfo.

As regiões amorfas comandam a capacidade de absorção das fibras, isto porque dificilmente as moléculas de água conseguem romper o grande número de ligações de intercadeias existentes nas regiões cristalinas. Assim, somente nas regiões amorfas, onde as moléculas estão orientadas ao acaso e onde ocorrem menos ligações entre as macromoléculas a água pode penetrar (ALFIERI, 2012a).

\subsubsection{Fibras Artificiais}

São aquelas produzidas pelo homem através da transformação química de matériasprimas naturais ou da sua solubilidade através da ação de agentes químicos.

Estas fibras podem ser derivadas, por um lado, da celulose de várias plantas (árvores, algodão, etc.) ou, por outro, de proteínas.

As mais conhecidas são as fibras de viscose, modal e acetato, que são nomes genéricos de fibras químicas de celulose.

O processo de produção de fibras artificiais celulósicas consiste, essencialmente, na regeneração desta numa solução da celulose com agentes químicos, que varia entre o pH ácido e o alcalino. Após transformar a celulose nesse derivado solúvel, este derivado é transformado em fibras ou filamentos e regenerado novamente para celulose.

Já as fibras de origem proteica passam por um processo mais complexo, que implica a adição de uma enzima.

Abaixo segue uma figura que representa a rota de fabricação das fibras de viscose e acetato, onde a partir de lâminas de celulose, o raiom acetato e o raiom viscose seguem rotas distintas. A viscose passa por banho de soda cáustica e, em seguida, por subprocessos de moagem, sulfurização e maturação, para finalmente, ser extrudada e assumir a forma de filamento contínuo ou fibra cortada (ABRAFAS, 2016).

O acetato passa inicialmente por banho de ácido sulfúrico, diluição em acetona, extrusão e, finalmente, por operação de evaporação da acetona. 
As fibras artificiais têm a vantagem de poderem ser modificadas ao longo do seu processo de fabricação, de acordo com a funcionalidade que se pretende alcançar.

A tabela 2 mostra a produção de fibras artificiais no Brasil no ano de 2015.

Tabela 2. Estatística anual de fibras artificiais manufaturadas em 2015 (ton/ano).

\begin{tabular}{|c|c|c|c|c|c|c|c|}
\cline { 2 - 8 } \multicolumn{1}{c|}{} & $\begin{array}{c}\text { CAPACID. } \\
\text { INSTALADA }\end{array}$ & PRODUÇÃO & $\begin{array}{c}\text { VENDAS } \\
\text { DOME. (1) }\end{array}$ & $\begin{array}{c}\text { EXPORT. } \\
\mathbf{( 2 )}\end{array}$ & $\begin{array}{c}\text { TOTAL VENDAS } \\
\mathbf{( 1 + 2 )}\end{array}$ & IMPORT. & $\begin{array}{c}\text { CONSUMO } \\
\text { APARENTE }\end{array}$ \\
\hline RAION VISCOSE & 0 & 0 & 0 & 0 & 0 & 12.166 & 12.166 \\
\hline RAION ACETATO & 17.700 & 11.355 & 7.434 & 3.766 & 11.200 & 36 & 7.625 \\
\hline TOTAL (T / ANO) & 17.700 & 11.355 & 7.434 & 3.766 & 11.200 & 12.202 & 19.791 \\
\hline
\end{tabular}

Fonte: ABRAFAS, 2016.

\subsubsection{Fibras sintéticas}

As fibras sintéticas são aquelas produzidas a partir de resinas derivadas do petróleo. As mais conhecidas e utilizadas são: poliéster, poliamida, polipropileno, acrílico e elastano.

Todas as fibras sintéticas são produzidas na forma de filamentos contínuos a partir de polímeros derretidos que passam através de pequenos orifícios (fieiras). Após isso há a possibilidade dos filamentos serem cortados para que as fibras possam ser fiadas com outros tipos de fibra (fibras sintéticas com naturais, sintéticas com artificiais, ou até mesmo sintéticas com sintéticas).

As fibras sintéticas são formadas por polímeros, que são compostos de moléculas que contém unidades estruturais que se repetem diversas vezes em cada molécula, assim uma única molécula pode conter centenas de unidades que se repetem, por isso recebem o nome de macromoléculas (SADOV, KORCHAGIN, MATETSKY, 1973).

Muitos processos têm sido desenvolvidos para a aplicação de textura em fios de filamentos, seja na forma de volume ou elasticidade. Esses processos, chamados de texturização, são desenvolvidos para diminuir o grau de alinhamento e paralelização entre os filamentos, e introduzir um aspecto estrutural que pode ser comparado com fios fiados. 
O que distingue um polímero na sua forma de fibra é a sua orientação em uma direção particular. Suas propriedades físicas são altamente influenciadas pela organização das cadeias poliméricas, ou macromoléculas, em suas regiões cristalinas e amorfas, e a relação destas regiões entre si (ALFIERI, 2012a). A produção de fibras sintéticas no Brasil pode ser analisada na tabela 3 .

Tabela 3. Estatística anual de fibras sintéticas manufaturadas em 2015 (ton/ano).

\begin{tabular}{|c|c|c|c|c|c|c|c|}
\cline { 2 - 8 } \multicolumn{1}{c|}{} & $\begin{array}{c}\text { CAPACID. } \\
\text { INSTALADA }\end{array}$ & PRODUÇÃO & $\begin{array}{c}\text { VENDAS } \\
\text { DOME. (1) }\end{array}$ & $\begin{array}{c}\text { EXPORT. } \\
-\mathbf{2}\end{array}$ & $\begin{array}{c}\text { TOTAL } \\
\text { VENDAS } \\
(\mathbf{1}+\mathbf{2})\end{array}$ & IMPORT. & $\begin{array}{c}\text { CONSUMO } \\
\text { APARENTE }\end{array}$ \\
\hline POLIAMIDA & 74.607 & 35.865 & 35.067 & 3394,21 & 38.461 & 51.923 & 74.087 \\
\hline $\begin{array}{c}\text { FILAMENTO } \\
\text { TÊXTIL }\end{array}$ & 58.607 & 24.278 & 24.411 & 1.703 & 26.114 & 33.331 & 55.907 \\
\hline $\begin{array}{c}\text { FILAMENTO } \\
\text { INDUSTRIAL }\end{array}$ & 16.000 & 11.587 & 10.656 & 1.691 & 12.347 & 18.592 & 18.180 \\
\hline ELASTÔMEROS & 24.000 & 22.800 & 17.600 & 6.481 & 24.081 & 1.833 & 18.152 \\
\hline POLIÉSTER & 24.000 & 22.800 & 17.600 & 6.481 & 24.081 & 1.833 & 18.152 \\
\hline $\begin{array}{c}\text { FILAMENTO } \\
\text { TÊXTIL }\end{array}$ & 302.000 & 168.240 & 167.529 & 5621,68 & 173.151 & 244.113 & 406.731 \\
\hline $\begin{array}{c}\text { FILAMENTO } \\
\text { INDUSTRIAL }\end{array}$ & 108.200 & 60.680 & 60.680 & 805,823 & 61.486 & 153.033 & 212.908 \\
\hline FIBRA CORTADA & 17.400 & 7.830 & 7.430 & 827,451 & 8.257 & 36.574 & 43.577 \\
\hline $\begin{array}{c}\text { FIBRA CORTADA } \\
\text { Reciclada }\end{array}$ & 176.400 & 99.730 & 99.419 & 3988,41 & 103.407 & 54.505 & 150.246 \\
\hline ACRÍLICO & 35.000 & 0 & 0 & 0 & 0 & 12.574 & 12.574 \\
\hline $\begin{array}{c}\text { TOTAL (T / } \\
\text { ANO) }\end{array}$ & 435.607 & 226.905 & 220.196 & 15.497 & 235.693 & 310.443 & 511.544 \\
\hline
\end{tabular}

Fonte: ABRAFAS, 2016.

O poliéster é uma das fibras sintéticas mais utilizadas no mundo, sendo o polietilenotereftalato o principal poliéster usado para fins têxteis. Este poliéster é obtido na maioria dos casos a partir da policondensação do dimetiltereftalato e do dietileno glicol, sob vácuo e alta pressão. 
A figura 5 apresenta de forma simplificada a obtenção do poliéster.

Figura 5. Seqüência para obtenção do poliéster

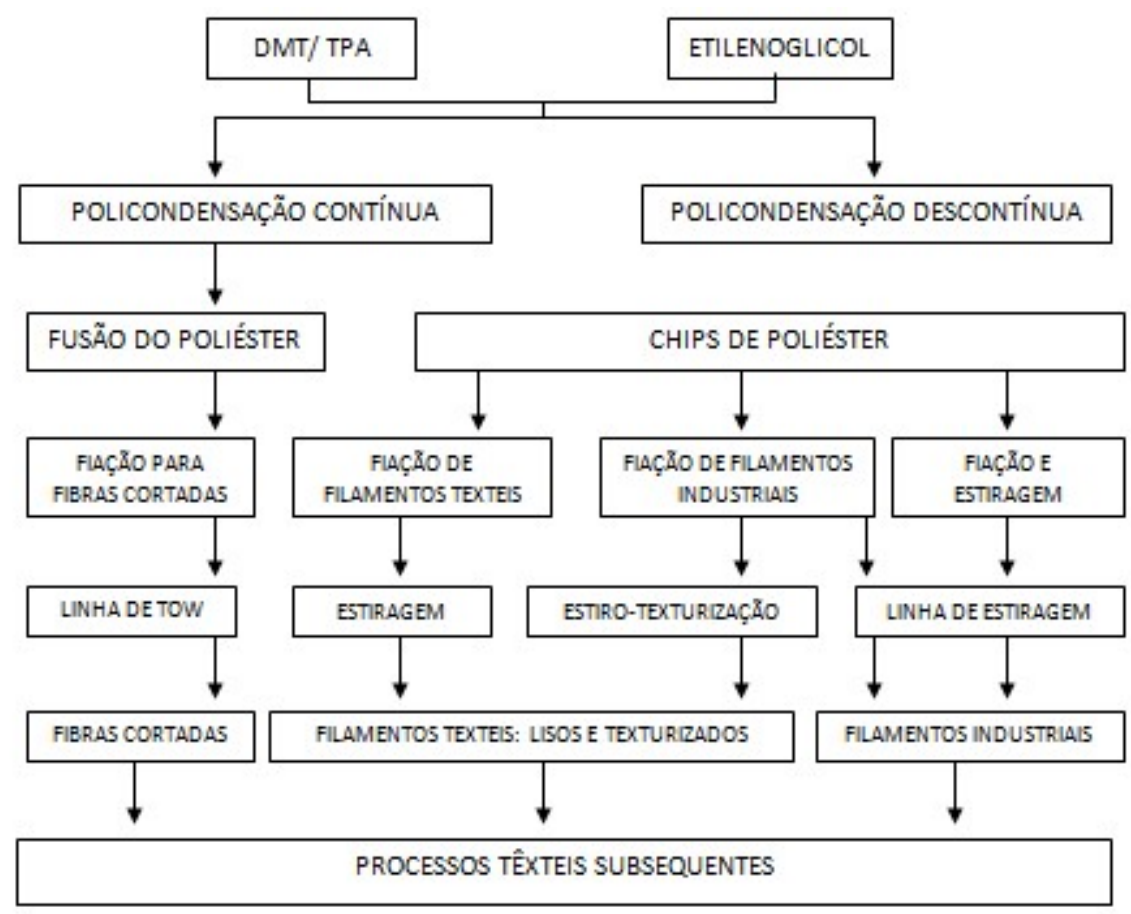

Fonte: Neto, 1996.

\subsubsection{Poliamida}

A palavra "nylon" é um termo genérico que designa um grupo de componentes químicos relacionados classificados como poliamidas (CORBMAN, 1975).

Corbman (1975) afirma que a responsabilidade pela descoberta, ou invenção, da poliamida pertence a DuPont $\mathbb{R}^{1}$, mais especificamente ao Dr. Wallace H. Carothers e sua equipe de químicos orgânicos do departamento de química da empresa. Isso ocorreu durante um longo programa de exploração química dentro da empresa Du Pont no ano de 1928.

Os filamentos de poliamida podem ser fabricados como opacos, semi-opacos e brilhantes, como ocorre também com outras fibras químicas. Isso é possível com a adição de dióxido de titânio na composição da fibra (o dióxido de titânio deixa a fibra mais opaca).

\footnotetext{
${ }^{1}$ DuPont ${ }^{2}$ é uma marca comercial registradas da E. I. du Pont de Nemours and Company.
} 
A figura 6 mostra a vista transversal e longitudinal da fibra de poliamida.

Figura 6. Corte Transversal e Vista Longitudinal da Fibra de Poliamida.

Corte Transversal

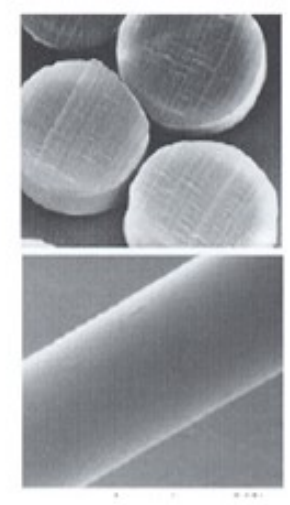

Redonda

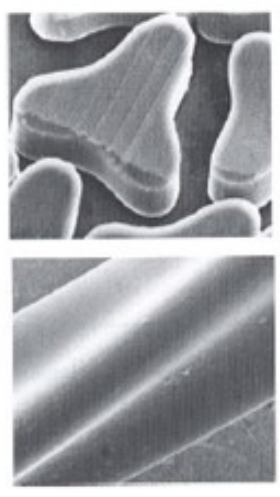

Trilobal

Fonte: Alfieri, 2012.

A poliamida 6 é obtida pela polimerização da caprolactama, que é o produto da condensação interna do ácido E-aminocapróico. Já a caprolactama pode ser obtida por muitos processos, sendo os mais comuns os que partem do benzeno, fenol ou ciclohexano.

Segundo Alfieri (2012a), a poliamida 6.6 é um polímero linear obtido pela reação entre uma diamina de 6 carbonos, a hexametilenoamina e o ácido adípico, e ocorre em duas etapas:

$1^{\circ}$ ) Ácido adípico reage em quantidades estequiométricas com a diamina produzindo o sal de nylon e água. Este sal de nylon, o adipato de hexametileno diamina, é solúvel em água e funde ao redor de $190-191^{\circ} \mathrm{C}$. É de cor branca e aspecto cristalino.

$2^{\circ}$ ) Uma solução de sal de poliamida a $60-65 \%$ em água e contendo ainda estabilizador e catalisador é aquecida a $275^{\circ} \mathrm{C}$ em autoclaves de polimerização sob gás inerte (N2) atingindo uma pressão de aproximadamente 15 atmosferas. A polimerização prossegue então, pelo alivio gradativo na pressão interna da autoclave e conseqüentemente, a eliminação da água formada na reação. 
A figura 7 e a figura 8 apresentam um exemplo do processo de polimerização da poliamida 6 e da poliamida 6.6 , respectivamente.

Figura 7. Polimerização da poliamida 6
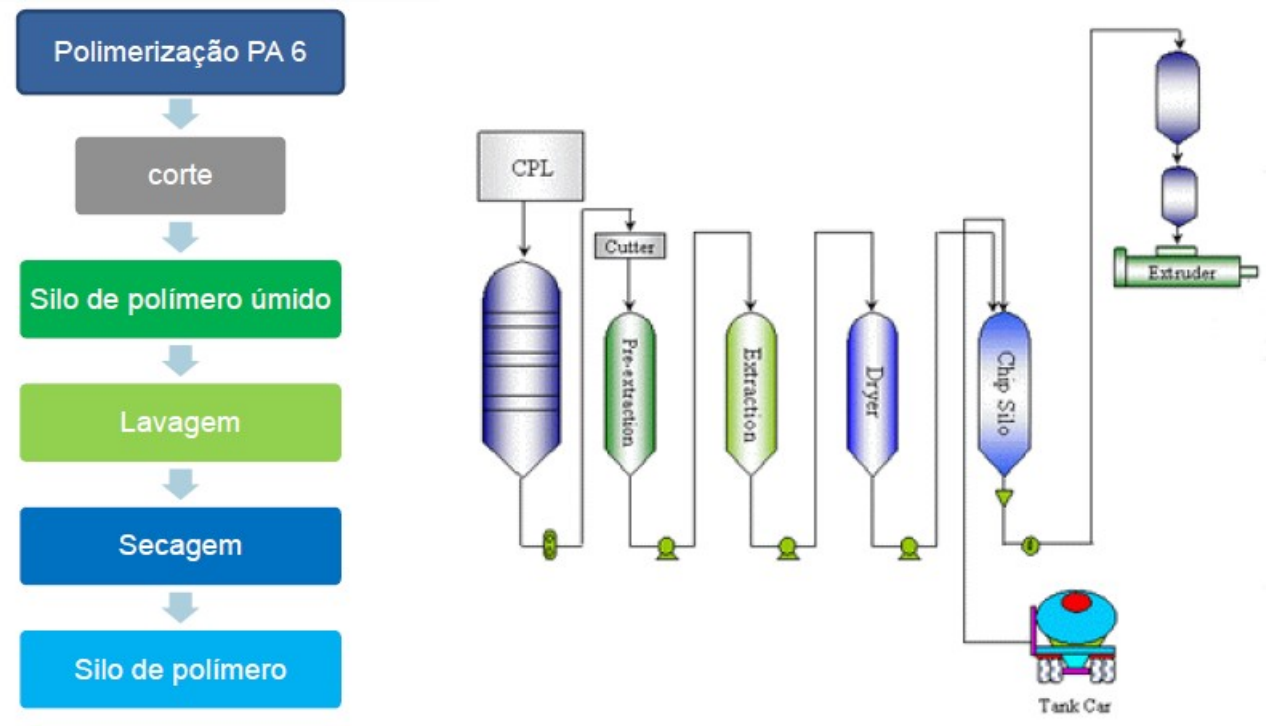

Fonte: Alfieri, 2012.

Figura 8. Polimerização da poliamida 6.6
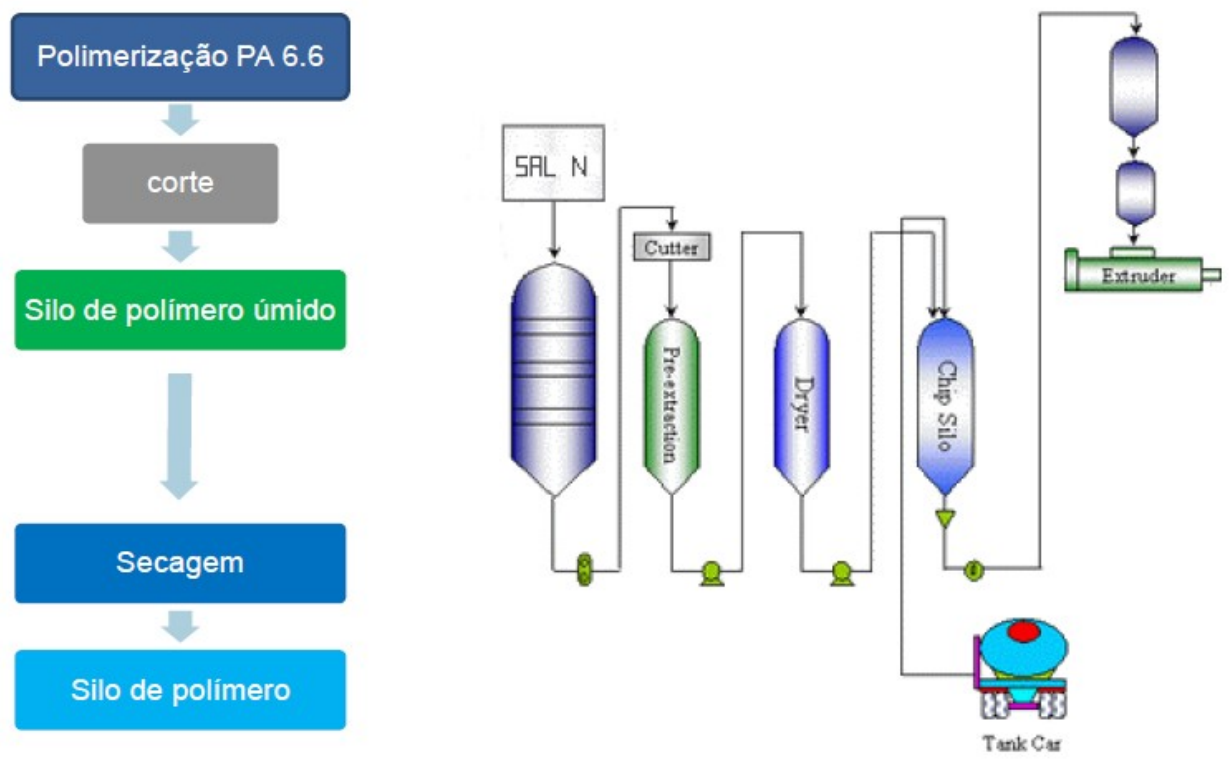

Fonte: Alfieri, 2012a.

Do ponto de vista químico, a maior diferença entre poliamida 6 e a poliamida 6.6 é o fato dos grupos amida estarem dispostos ao longo da cadeia de maneira diferente, como mostrado na figura 9 . 
Figura 9. Diferença na disposição dos grupos amina nas poliamidas 6 e 6.6
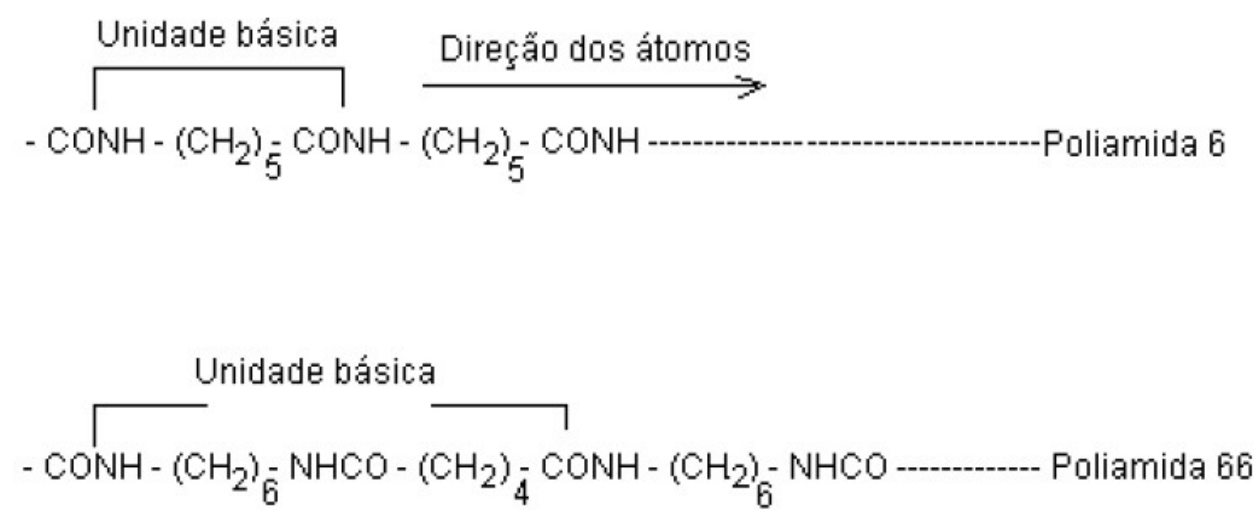

Fonte: Alfieri, 2012a.

Desta diferença de disposição dos átomos, na formação dos grupos amídicos, é que resultam alguns aspectos importantes. O mais importante deles é a implicação no teor cristalino no final das duas fibras, para a poliamida 6 , em média, 35 a 40\%, já na poliamida $6.6,55^{\mathrm{a}} 60 \%$ (NETO, 1996).

O processo de fabricação dos fios de poliamida se dá resumidamente da seguinte forma: A matéria prima (polímero) é disponível em forma de chips. Esses chips são fundidos em uma extrusora. Em seguida o polímero é expelido sob pressão, sendo dosado por bombas de engrenagem, saindo pelas fieiras (pequenos furos por onde o polímero derretido passa), formando assim os filamentos.

Logo que deixam as fieiras, os filamentos se solidificam ao receber um leve jato de ar em fluxo laminar. Após isso os filamentos são estirados (isso orienta a estrutura molecular do fio) e enrolados em bobinas. 
A figura 10 mostra o fluxograma de obtenção das poliamidas 6 e 6.6, incluindo o processo de fiação das mesmas.

Figura 10. Fluxograma de obtenção das poliamidas 6 e 6.6

Poliamida 6

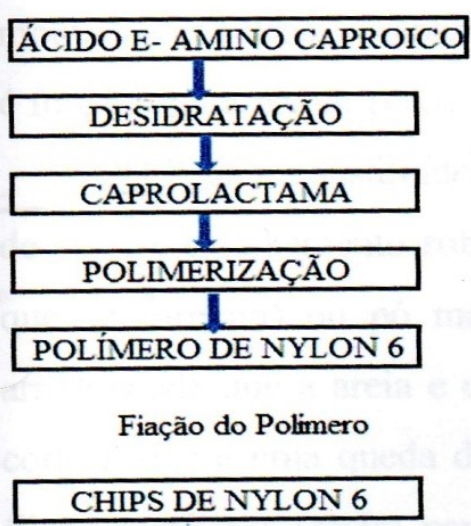

Poliamida 6.6

HEXAMETILENO DIAMINA

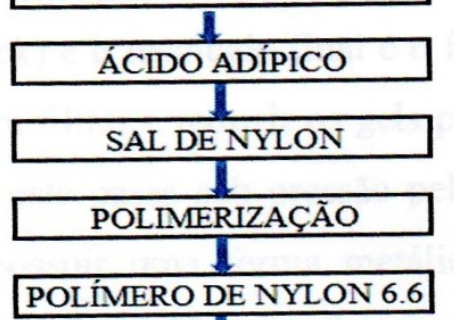

CHIPS DE NYLON 6.6

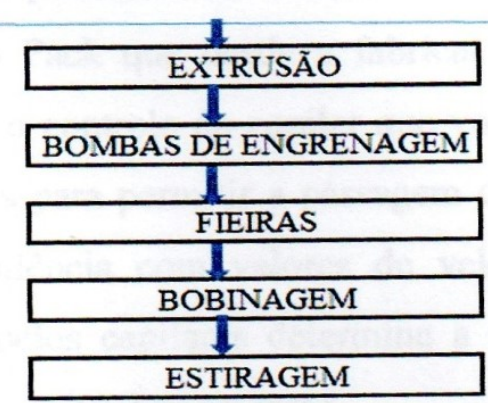

Fonte: Neto, 1996.

\subsubsection{Elastano}

O elastano é uma fibra elastomérica, produzida por polímeros lineares segmentados constituídos de pelo menos 85\% de poliuretano. Segundo Alfieri (2012a) um polímero segmentado é um copolímero a blocos no qual se alternam ao longo da cadeia molecular, unidades de diferentes composições.

Esta fibra contém praticamente uma estrutura 99\% amorfa com baixo grau de ordem, além de ser uma molécula flexível. Também é uma fibra com alta recuperação elástica, e é usada principalmente na a produção de tecidos de malha. 
A tabela 4 apresenta algumas informações específicas sobre o elastano, como tenacidade, comprimento de ruptura e alongamento à ruptura.

Tabela 4. Dados sobre o elastano.

\begin{tabular}{|c|c|}
\hline \multicolumn{2}{|c|}{ Elastano } \\
\hline Tenacidade (g/den) & $0,6-1,3$ \\
\hline Comprimento de ruptura $(\mathrm{km})$ & $5,4-11,7$ \\
\hline Alongamento à ruptura $(\%)$ & $420-700$ \\
\hline
\end{tabular}

Fonte: Alfieri, 2012a.

\subsection{Processos de fiação}

A fiação pode ser definida como uma sequencia de operações que transforma uma massa de fibras têxteis, inicialmente desordenadas, em um conjunto de grande comprimento. Este possui na sua seção, dezenas de fibras, mais orientadas do que na forma inicial que se apresentaram, presas entre si por meio de uma torção conferida ao longo deste comprimento (CORBMAN, 1975).

Entre os tipos de fiação, podem-se destacar dois tipos: a fiação de fibra descontínua onde se inclui o algodão, a lã, linho, viscose, rami, modal, etc., e a fiação de fios contínuos por extrusão onde se inclui o elastano, poliamida, polipropileno, poliéster, etc.

\subsubsection{Fiação de fibras descontínuas}

O processo de fiação descontínua é composto basicamente por três fases: A primeira fase é a de abertura e limpeza, onde as fibras provenientes dos fardos são abertas e flocadas ao mesmo tempo em que partículas estranhas (restos de folhas e sementes, por exemplo) presentes são eliminadas. 
A segunda fase é a preparação à fiação, onde a limpeza da fibra ganha continuidade, além de iniciar um processo de orientação e redução da massa fibrosa por unidade de comprimento.

A terceira fase é a fiação propriamente dita, onde a finura final é estabelecida, além da aplicação de uma torção para dar coesão à massa fibrosa, através de um filatório

A figura 11 apresenta a sequência de fases da fiação.

Figura 11. Fases da fiação

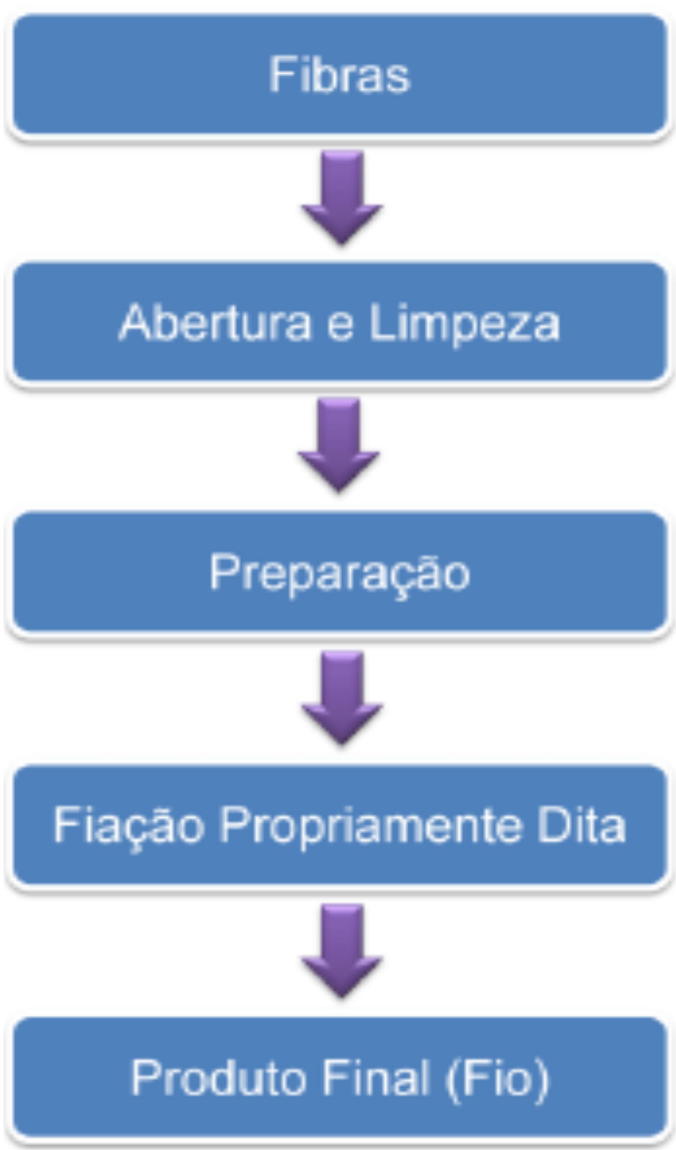

Fonte: Renan Guazzelli Affonso, 2015.

Existem alguns fatores individuais das fibras que influenciam na qualidade final do fio, são estes: comprimento e espessura das fibras e o estado de limpeza das mesmas. Sendo assim, no caso da fibra de algodão é necessário retirar os restos de folhas e materiais vegetais encontrados (PAIVA, EMANUEL, MAGNO, 2010). No caso da lã, precisa-se realizar uma lavagem. Já as fibras sintéticas geralmente dispensam qualquer tipo de limpeza prévia. 
No processo de fiação descontínua destacam-se dois fluxos diferentes: a fiação por anéis e a fiação por rotor (ou fiação open-end). A fiação à anel é denominada fiação convencional enquanto os outros processo são denominados não convencionais, como por exemplo: Jet Spinner, Vortex, etc.

\subsubsection{Fiação de fibras contínuas}

Existem diversos processos de fabricação de fibras contínuas, porém todos têm o mesmo princípio: a matéria-prima, apresentada de forma sólida, é transformada em um líquido viscoso por dissolução em solventes, emulsificação ou fusão. Este líquido viscoso sofre uma transformação e, após esta transformação, torna-se um fio.

$\mathrm{Na}$ primeira fase, as forças que unem as macromoléculas são anuladas deixando-as livres. Na segunda fase, a de extrusão, as causas que provocam a eliminação das forças intermoleculares são eliminadas e as macromoléculas unem-se novamente, formando um sólido em forma de fio (CORBMAN, 1975).

Em alguns processos de fabricação de fios obtêm-se produtos (fios) com as moléculas orientadas. Entretanto, em outros processos, o fio é obtido numa forma imprópria para o uso têxtil com as moléculas dispostas em forma desordenada, sendo necessária a realização de uma estiragem, a fim de orientar suas moléculas e conferir propriedades convenientes para seu uso na indústria têxtil.

Os vários processos de fabricação se subdividem em: fiação a úmido, fiação a seco, fiação por fusão, fiação por dispersão, transformação de um filme em fios e filamentos,

No presente trabalho será tratado apenas da fiação por fusão. 


\subsubsection{Fiação por fusão}

Segundo Hearle, Hollick e Wilson (2001), o processo de fiação por fusão pode ser executado em dois modos:

- Quando o fio a ser produzido é de titulagem elevada. O polímero derretido é extrudado por uma fieira posta verticalmente em água fria a alguns centímetros da superfície. O fio resfria bruscamente pelo choque de temperatura (por causa da presença de água) e se solidifica na forma dada pela fieira. Neste processo são produzidos fios técnicos de poliamida, poliéster e polipropileno para aplicações como linhas de pesca, cordões para raquete de tênis, etc.

- Quando o fio a ser produzido é de titulagem baixa. O polímero derretido é extrudado dentro de uma cela de fiação, passando pela fieira, e encontrando uma corrente fria de ar transversal ao seu percurso. Isso provoca seu resfriamento e solidificação (CORBMAN, 1975). Os principais exemplos são as poliamidas, poliéster e polipropileno.

A figura 12 apresenta um esquema da produção de um fio de poliamida feito pelo processo de fiação por fusão.

Figura 12. Processo de fiação da poliamida por fusão

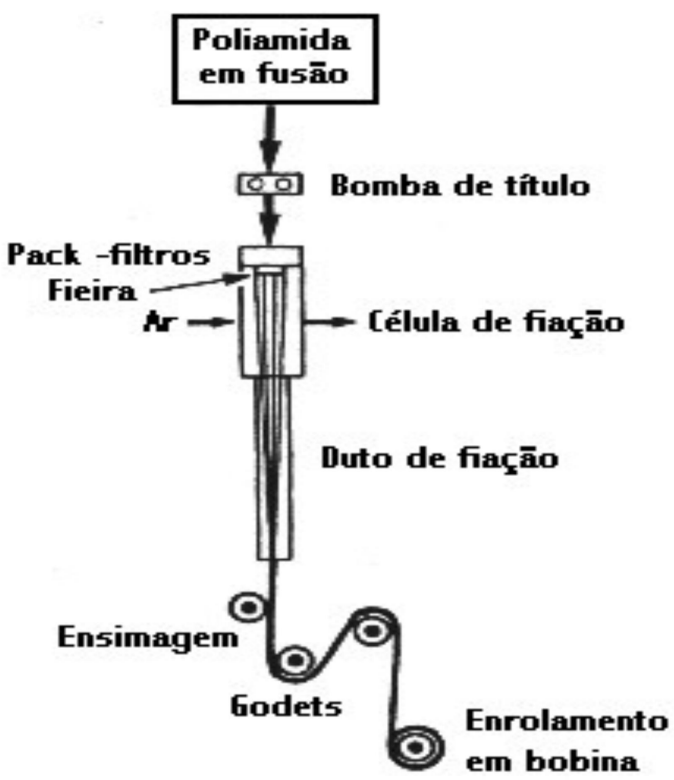

Fonte: Alfieri, 2012a. 


\subsection{Texturização}

Texturização é um processo de transformação que consiste em aumentar o volume e/ou a elasticidade de fios contínuos (sintéticos ou artificiais), utilizando geralmente da sua termoplasticidade, criando distorções permanentes nos fios de filamentos em forma de frisos, hélices, alças, loops, etc.

Existem alguns tipos de texturização. Os principais são a texturização a ar e a texturização por falsa torção.

O fio texturizado a ar apresenta pouca elasticidade e uma textura com pilosidade similar ao dos fios fiados. Ele é produzido passando um fio multifilamentos numa câmara onde um forte fluxo de ar embaraça os filamentos entre si dando origem à textura. A figura 13 apresenta o esquema de texturização a ar, sinalizando a entrada do ar comprimido no núcleo de texturização a ar, entrelaçando os filamentos do fio.

Figura 13. Esquema do núcleo de texturização a ar

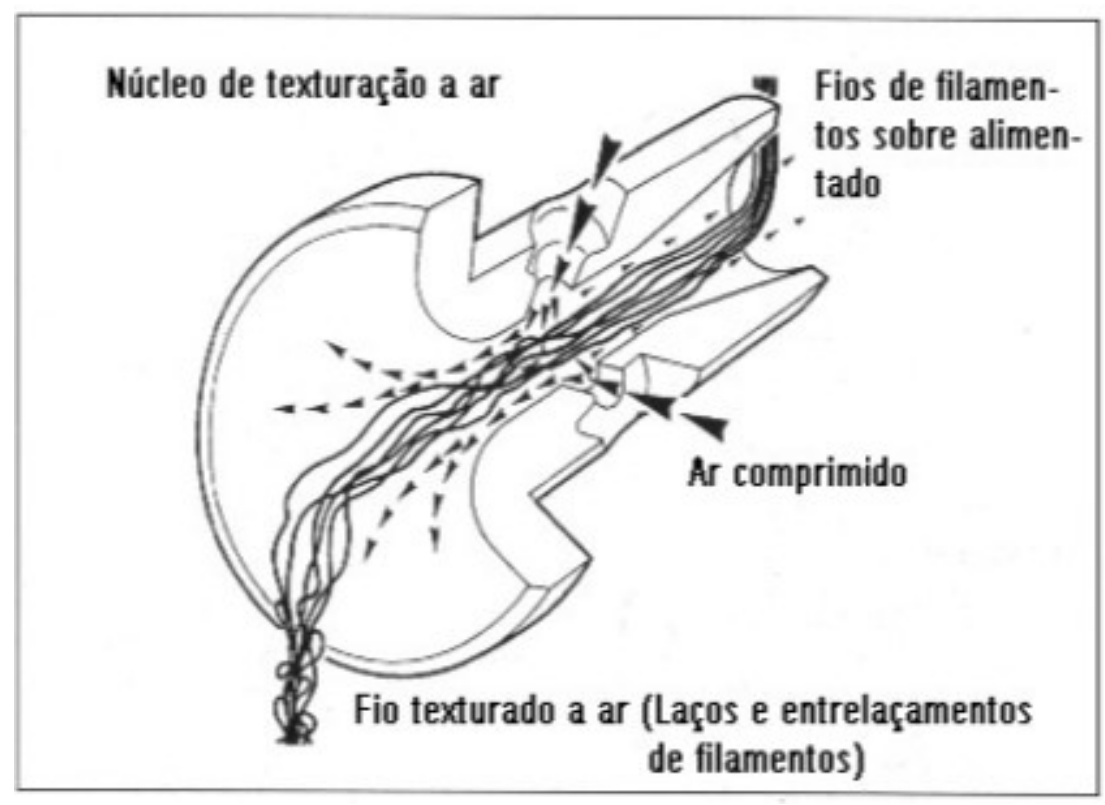

Fonte: Alfieri, 2013. 
A figura 14 mostra o aspecto do fio produzido através da texturização a ar.

Figura 14. Formação da textura do fio texturado a ar

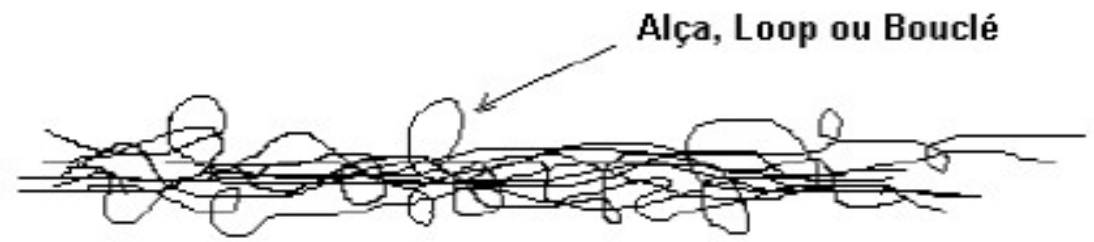

FIO TEXTURADO A AR

Fonte: Alfieri, 2013.

$\mathrm{Na}$ texturização por falsa torção os fios são texturizados por processos termomecânicos que deformam os filamentos produzindo ondulações irregulares. Neste processo, o fio multifilamento contínuo liso é torcido, fixado por ação do calor e destorcido com o mesmo número de voltas (HEARLE, HOLLICK, WILSON, 2001).

As espiras dos filamentos que foram fixadas se destorcem encavalando-se. Assim os fios adquirem mais elasticidade, maciez, pois são mais compressíveis, têm melhor isolamento térmico, porque retém mais ar em sua estrutura e transmitem melhor o vapor de água e suor pela micro porosidade. 


\subsection{Malharia}

Malharia é a produção de tecidos de malha. Dentro da atividade têxtil, o segmento de malharia é um dos mais antigos, tendo origem no processo manual de tricotagem, o qual surgiu entre os árabes e as tribos nômades que teciam a lã de seus rebanhos à mão, com agulhas de pontas reviradas. Estes tecidos são caracterizados pelo entrelaçamento de fios têxteis, sendo este sempre no mesmo sentido, podendo ser todos na horizontal (trama) ou na vertical (urdume) (ROMERO et al, 1996). Por apenas utilizar um conjunto de fios ligados por laçadas (através de agulhas), o tecido de malha possui características de flexibilidade e elasticidades que não podem ser obtidas no tecido plano.

A produção dos tecidos de malha pode ser dividida em 3 diferentes mecanismos, apresentados na figura 15 .

Figura 15. Mecanismos de produção de malha.

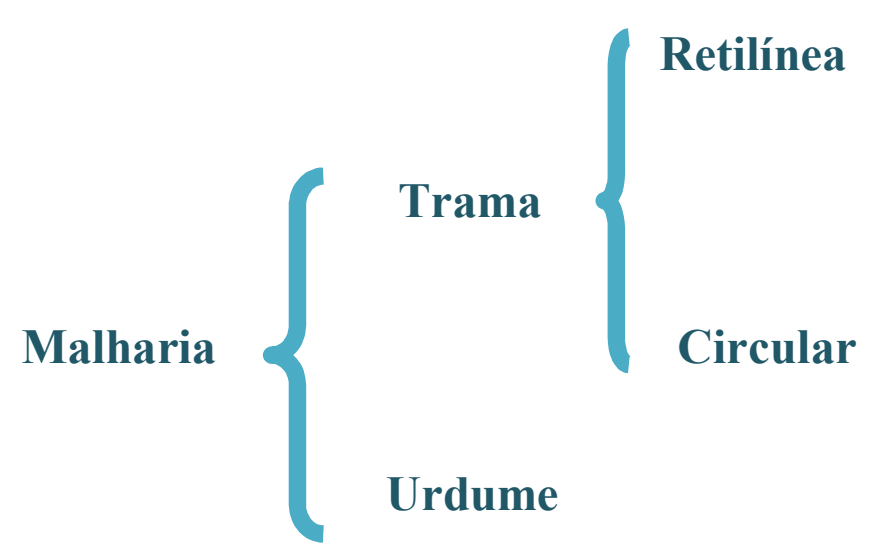

Fonte: Renan Guazzelli Affonso, 2015.

Uma malha é formada por uma cabeça, duas pernas e dois pés. No ponto onde as pernas se transformam em pés existem dois pontos de contato com a malha anterior, que são denominados pontos de ligação. A figura 16 mostra as partes de uma malha. 
Figura 16. Partes da malha.

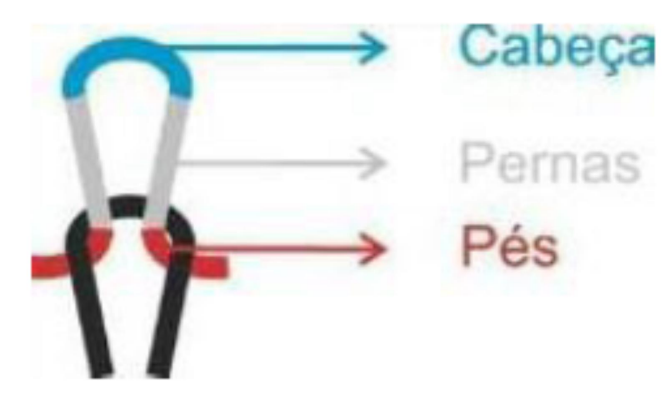

Fonte: Macedo, 2009.

Na figura 17 estão sinalizados os pontos de contato entre duas malhas.

Figura 17. Pontos de Ligação da malha.

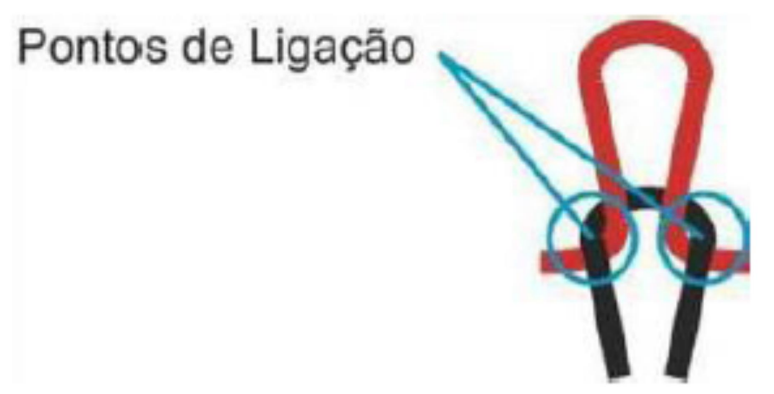

Fonte: Macedo, 2009.

Se os pés das malhas estão por cima dos pontos de ligação e as pernas estão por baixo deles, então este é o dorso da malha ou avesso do tecido. A figura 18 apresenta o lado avesso do tecido de malha.

Figura 18. Dorso da Malha

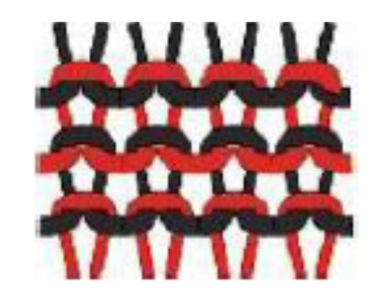

Fonte: Macedo, 2009. 
Se ao contrário, os pés estiverem por baixo e as pernas por cima nos seus pontos de ligação, então esta é a face frontal da malha ou lado direito do tecido. A figura 19 mostra o lado direito do tecido de malha.

Figura 19. Face da Malha

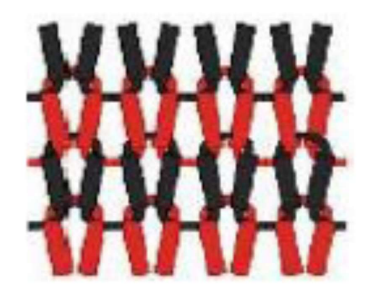

Fonte: Macedo, 2009.

Segundo Spencer (2001), no tecido de malha existem dois elementos principais que caracterizam este tipo de tecido: a carreira de malhas, que é uma série de laçadas sucessivas de um mesmo fio, que cruzam o tecido transversalmente. Todas as laçadas (malhas) de uma carreira são formadas pelo mesmo fio. A coluna de malhas, que é uma série de laçadas de fios diferentes, fica na direção do comprimento do tecido. Todas as malhas de uma mesma coluna são formadas numa mesma agulha e o número de colunas influencia na determinação da largura do tecido.

A figura 20 identifica, em vermelho, as colunas e as carreiras de um tecido de malha.

Figura 20. Colunas e Carreiras da Malha.

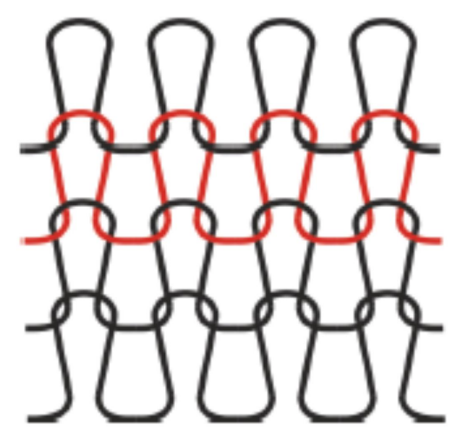

Carreira de Malhas

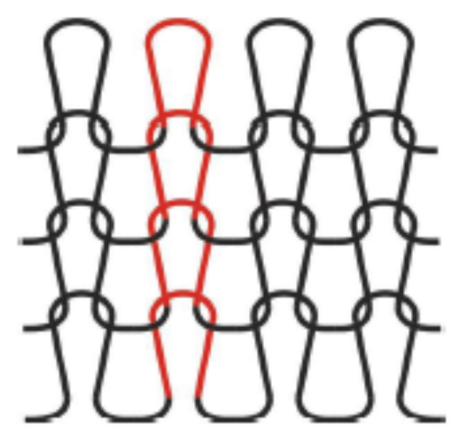

Coluna de Malhas

Fonte: Macedo, 2009. 
A malharia de trama retilínea produz tecidos de malha com gramaturas mais altas, e é principalmente utilizada na fabricação de artigos de inverno e geralmente tem baixa produção.

A figura 21 mostra uma máquina de malharia retilínea.

Figura 21. Tear de Malharia Retilínea.

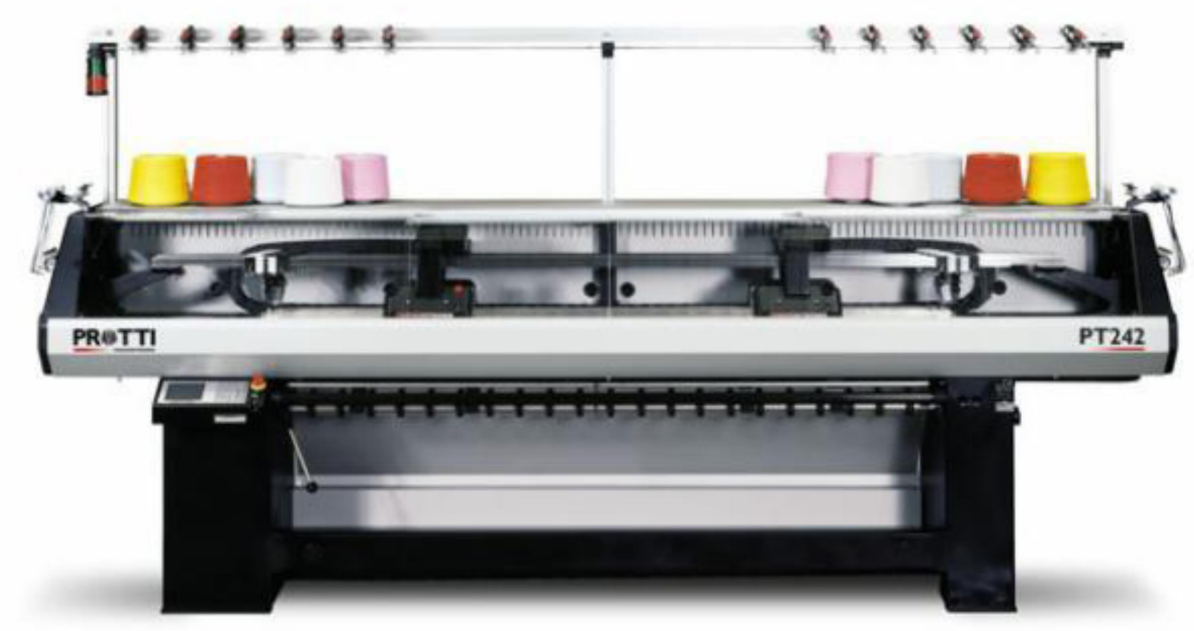

Fonte: Macedo, 2009.

A malharia circular mantém todos os princípios da malharia retilínea, podendo produzir diversos ligamentos. A principal diferença está na sua elevada produção em relação à malharia retilínea, pois as máquinas circulares possuem maior número de sistemas.

As ligações básicas são a meia malha (Jersey), o Piquet, o moleton e o rib. A máquina pode ser monofrontura ou duplafrontura, podendo ser divididas em máquinas de pequeno diâmetro e grande diâmetro.

A figura 22 apresenta uma máquina de malharia circular de grande diâmetro, largamente utilizada na indústria. 
Figura 22. Tear de Malharia Circular de Grande Diâmetro.

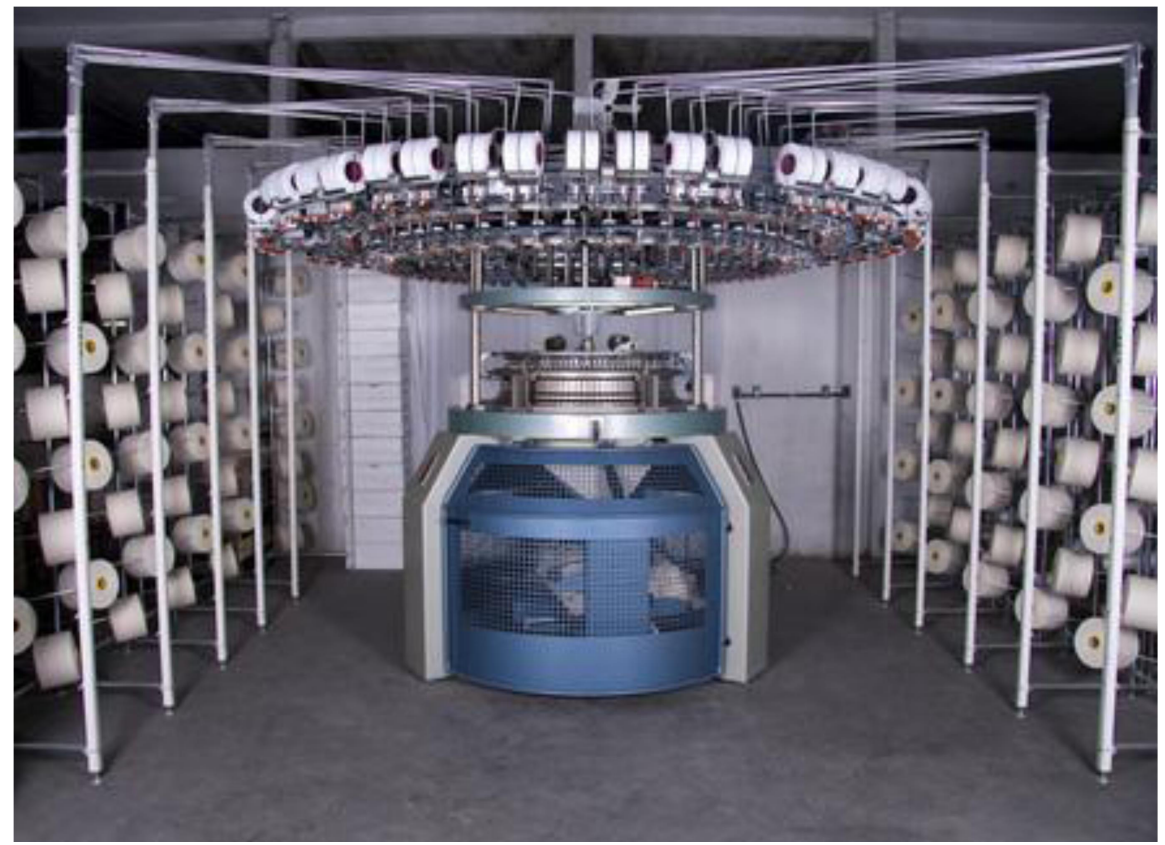

Fonte: Macedo, 2009.

Malharia de urdume é o nome dado a produção de tecidos a partir do processo de fabricação dos quais os fios são provenientes de rolos de urdume. Os fios são preparados carretéis de urdume, que entram nas máquinas Raschel ou Kettenstuhl. Eles passam por agulhas que estão presas em barras que fazem o entrelaçamento com os fios. Durante o processo de tricotagem, cada um dos fios de urdume é frisado de maneira a formar uma linha vertical a que se dá o nome de coluna, que se entrelaça com outras colunas adjacentes para formar o tecido (SPENCER, 2001). Artigos feitos em malharia de urdume normalmente usam elastano e são indesmalháveis.

A máquina Raschel é normalmente utilizada para tecer rendas e similares e a Kettenstuhl para tecidos que são utilizados em lingeries, automobilísticos, filtros, etc. Estas máquinas podem ser monofrontura ou duplafrontura. 
A figura 23 ressalta, em preto, a diferença entre os ligamentos de malha de urdume e de trama.

Figura 23. Diferença entre ligamentos de malha de trama e urdume

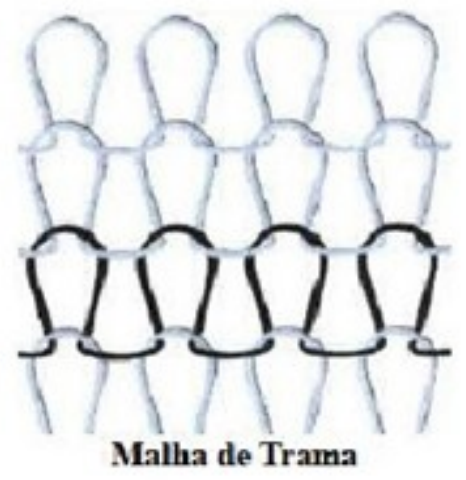

Fonte: http://pt.scribd.com/doc/50890062/malharia

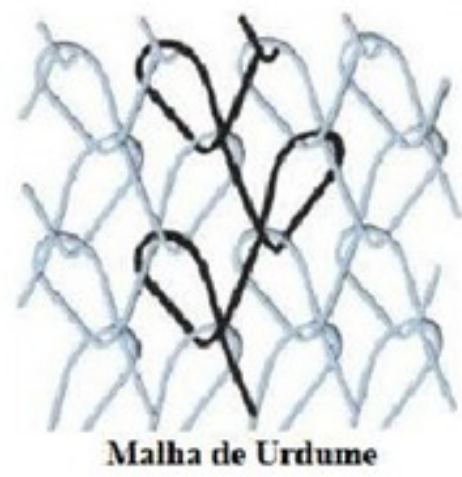

Malha de Urdume

\subsection{Radiação Infravermelha}

\subsubsection{Introdução}

Diferentemente da convecção e da condução, não é necessária a existência de um meio na transferência de calor por radiação para transmissão, pois a transferência de energia acontece pela propagação de ondas eletromagnéticas. Consequentemente, a transferência de calor por radiação acontece na forma de ondas eletromagnéticas, sobretudo na região da radiação infravermelha (HU, 2006; DYER, 2011).

Segundo Li (2001), a taxa de transferência de calor por radiação através da roupa depende da média da temperatura do ambiente ao redor, da temperatura da superfície da roupa e das características da roupa e do ambiente.

\subsubsection{Princípio da Radiação Eletromagnética}

Segundo Cyan (2012), a transferência térmica de radiação é a consequência de uma troca que inclui emissão e absorção. A radiação eletromagnética compõe ondas que se auto propagam, as quais têm componentes elétricas e magnéticas. A unidade básica de radiação 
eletromagnética é o fóton. Ondas eletromagnéticas, ou raios, são classificados de acordo com seu comprimento de ondas (KNIGHT, 2004; DYER, 2011).

A luz solar é formada por ondas eletromagnéticas, incluindo a radiação Ultra Violeta, a radiação visível e a radiação infravermelha. A energia solar correspondente é de $6,8 \%$ na extensão de raios Ultra Violeta (0,5\% de UVB e 6,3\% de UVA), 38,9\% na extensão visível, enquanto a extensão do espectro infravermelho constitui aproximadamente $54,3 \%$ da irradiação solar total (HU, 2006). Essas ondas eletromagnéticas são definidas como radiação de comprimento de onda visível e invisível. A extensão visível engloba a luz das cores vermelha, laranja, amarela, verde, azul, índigo e violeta. Comprimentos de onda maiores ou menores do que o dessas cores são invisíveis ao homem, incluindo a luz ultravioleta e os raios $\mathrm{x}$ em comprimentos de onda mais curtos, e as microondas e as ondas de rádio em comprimentos de onda maiores (DYER, 2011).

A radiação infravermelha é a parte invisível do espectro eletromagnético depois do fim da região de luz visível. O termo "infravermelho" se refere a uma ampla gama de frequências no espectro eletromagnético, a partir da extremidade superior das frequências utilizadas para a comunicação até a extremidade de baixa frequência do espectro de luz visível, ou seja, está compreendida entre a luz visível e a região de microondas, (HU, 2006; DYER, 2011).

A radiação infravermelha foi descoberta por William Herschel nos anos 1800. Segundo Hu (2006) e Dyer (2011), em 1847 A. H. L. Fizeau e J. B. L. Foucault mostraram que a radiação infravermelha tinha as mesmas propriedades da luz visível, podendo ser refletida, refratada e capaz de formar um padrão de interferência.

O comprimento de onda dos raios infravermelhos varia de 0,75 a $1000 \mu \mathrm{m}$. A radiação infravermelha é dividida em três regiões de espectros: IVL ou IV-C, infravermelho longo (3 a $1000 \mu \mathrm{m})$; IVM ou IV-B, infravermelho médio (1,4 a $3 \mu \mathrm{m})$ e IVC ou IV-A, infravermelho curto ou próximo $(0,76$ a $1,4 \mu \mathrm{m})$. Há uma alternativa que permite essa divisão da seguinte forma: Infravermelho curto $(0,75$ a $1,5 \mu \mathrm{m})$, médio $(1,5$ a 5,6 $\mu \mathrm{m})$ e longo $(5,6$ a $1000 \mu \mathrm{M})$ (LI et al; 2007).

A figura 24 apresenta o espectro eletromagnético e situa a extensão da radiação infravermelha dentro dele, mostrando a faixa de comprimento de onda que ela abrange. 
Figura 24. Extensão da radiação infravermelha dentro do espectro eletromagnético.

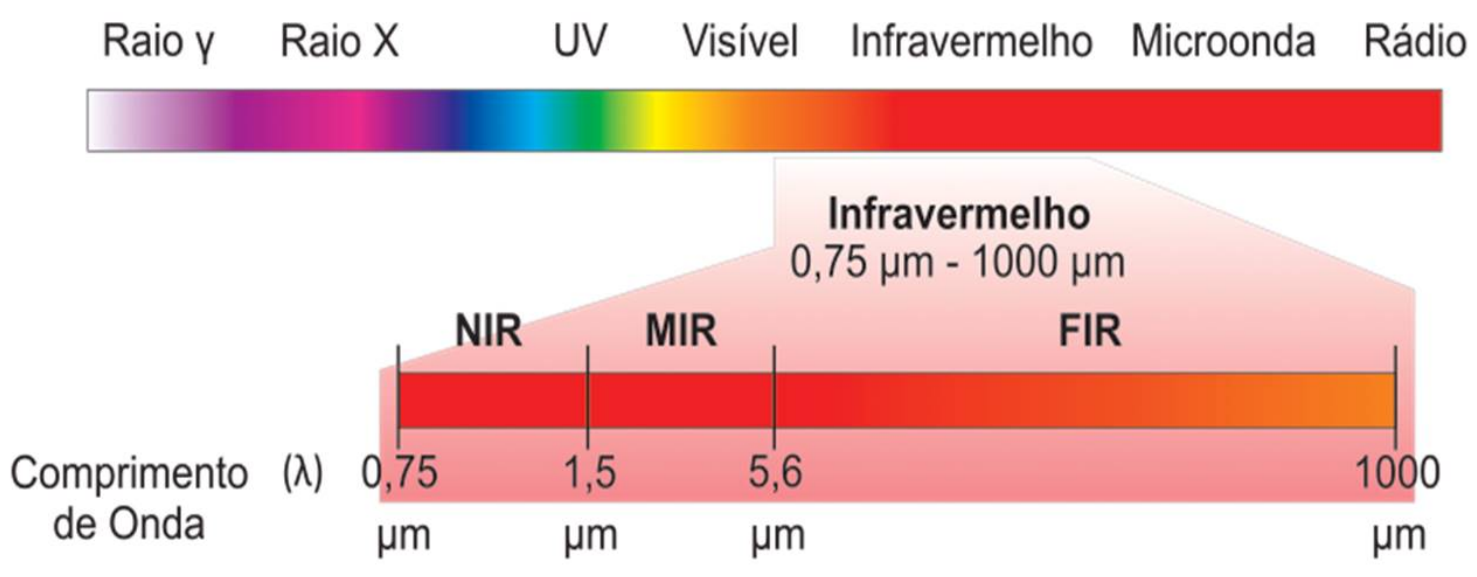

Fonte: Adaptado de Cyan, 2012.

\subsubsection{Propriedades da Radiação Infravermelha}

A radiação infravermelha, ao entrar em contato com um objeto, tem parte da sua energia radiante (que atingiu o objeto) absorvida. Outra parte da energia pode ser refletida e outra diretamente transmitida. Somente a energia absorvida serve para esquentar o objeto que está recebendo a radiação infravermelha. Portanto, as propriedades térmicas da radiação infravermelha têm importância significativa na determinação da transferência de calor de objetos que recebem esse tipo de radiação. Cyan (2012) demonstra a equação da energia incidente total da radiação infravermelha:

Energia incidente Total $=$ Absorvida + Refletida + Transmitida

A figura 25 apresenta as propriedades da radiação infravermelha, sendo elas: absorção, reflexão e transmissão. 
Figura 25. Propriedades da Radiação Infravermelha.

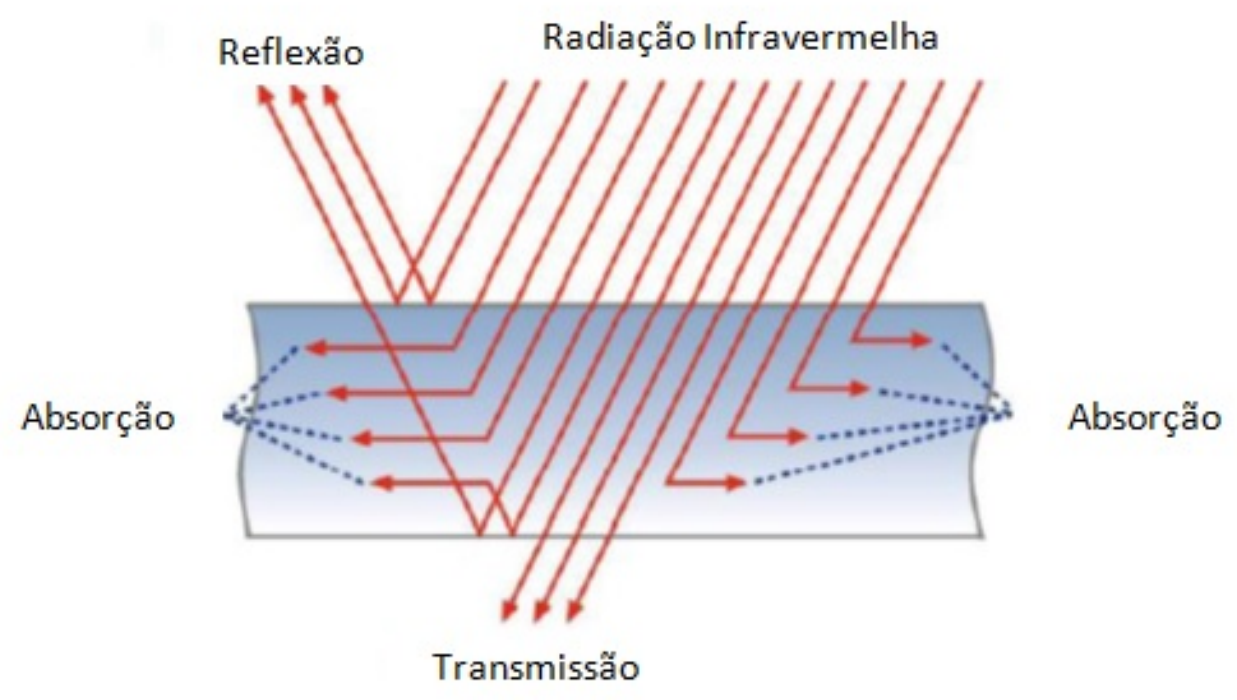

Fonte: Cyan, 2012.

Segundo Cyan (2012), a absorção é a transmissão da energia radioativa para energia térmica armazenada pelas moléculas do material do corpo que está recebendo a radiação infravermelha. Transmissão é a passagem da radiação através de um meio sem mudança na frequência. Reflexão é o retorno da radiação eletromagnética pela superfície do material em que a radiação foi incidida.

Essas propriedades térmicas da radiação infravermelha dependem de alguns fatores. A transmissão da radiação depende da transparência dos materiais; a absorção da radiação depende da natureza física dos materiais; a reflexão da radiação é influenciada pelo acabamento de superfície, o ângulo em que o raio incidente colide sobre a superfície, a distribuição do espectro da radiação incidente, a composição e a estrutura da superfície irradiada (CYAN, 2012).

\subsubsection{Propriedades Térmicas da Radiação Infravermelha}

A radiação infravermelha tem relação direta com propriedades térmicas, uma vez que ela pode ser absorvida e convertida em energia térmica pela maioria dos materiais. A radiação tem uma interação com as moléculas do objeto que atinge (principalmente com moléculas de água), causando mudanças nessas moléculas que podem influenciar a frequência e a 
amplitude de sua oscilação. Durante o processo de absorção, a taxa de oscilação das moléculas do objeto que recebe a radiação aumenta e elas são impulsionadas para um nível de energia mais alto antes de voltar ao normal. Durante o estágio de voltar ao normal (taxa de oscilação inicial), a energia térmica é liberada na forma de calor, o que aquece o objeto (CYAN, 2012).

\subsubsection{Ação Biológica da Radiação Infravermelha}

Segundo Hu (2006), existem evidências de que a radiação infravermelha tem efeitos bioestimulantes em tecidos (tecidos humanos), afetando o estado do metabolismo do organismo na forma de regulação de calor, tendo assim, efeito sobre o corpo humano. Segundo Cyan (2012), exceto quando está na temperatura do zero absoluto $\left(-273,15^{\circ} \mathrm{C}\right)$ toda matéria tem sua vibração, sendo que a velocidade e a frequência da vibração dependem da substância, o seu peso molecular, estrutura molecular, a dimensão da sua estrutura mecânica, etc. À medida que as frequências de ressonância naturais de moléculas de água e substâncias orgânicas estão dentro das frequências de onda do infravermelho distante (comprimentos de onda de 5 a $15 \mu \mathrm{m}$ ), a água e as substâncias orgânicas podem facilmente absorver a energia de radiação infravermelha (HU, 2006). Pesquisas fisiológicas mostram que a maior parte do corpo humano é composta de água (57\% a 69\%), assim a radiação infravermelha longa pode ser absorvida facilmente pelo corpo humano. (CHURCHILL, 2003; HU, J.; 2006).

Cyan (2012), diz em estudo que a habilidade de absorver infravermelhos e a profundidade da penetração na pele humana correspondem com o comprimento de onda dos raios infravermelhos, quanto mais curta a profundidade de penetração, maior é o comprimento de onda do raio infravermelho. Comprimentos de onda curtos na gama de IV-A (infravermelhos A: 1,0 $\mu \mathrm{m}$ ) aproximam-se do tecido subcutâneo, sem elevar a temperatura da superfície da pele significativamente, enquanto que os da gama de IV-C (infravermelhos C: 3,0 a 6,0 $\mu \mathrm{m}$ ) são absorvidos inteiramente nas camadas epidérmicas e levam a um aumento da temperatura da pele, que resulta em sensações térmicas que variam de calor agradável para queimaduras térmicas. Os raios infravermelhos podem penetrar de $0,7 \mathrm{~mm}$ a $30,0 \mathrm{~mm}$ no tecido humano, sendo que algumas pesquisas revelam que os raios IV-A, aplicados localmente, contêm propriedades de penetração suficientes para permitir a transferência de 
calor e condução pela corrente sanguínea para produzir efeitos terapêuticos sobre os tecidos a certa distância a partir do local de irradiação direta.

A figura 26 mostra a porcentagem de absorção de raios infravermelhos em cada camada da pele, de acordo com a faixa de comprimento de onda dos raios.

Figura 26. Porcentagem de absorção e penetração na pele humana correspondendo com o comprimento de ondas dos raios infravermelhos.

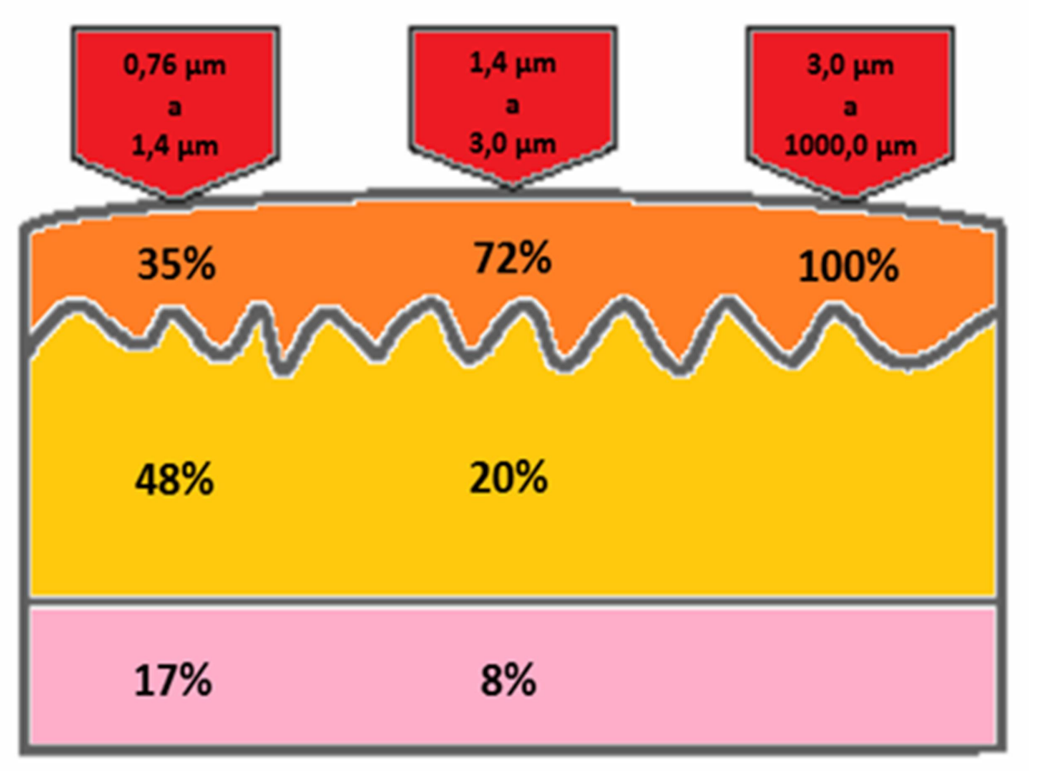

\section{Epiderme}

\section{Derme}

\section{Tecido Subcutâneo}

Fonte: Adaptação de Hu, J; 2006.

Os efeitos dos raios infravermelhos na pele envolvem a vasodilatação dos capilares sanguíneos por radiação infravermelha, aumentando a circulação sanguínea, a produção de suor, e o movimento do ar ambiente (CYAN, 2012).

\subsection{Têxteis com radiação infravermelha}

Quando uma roupa é utilizada, a transferência de calor por radiação acontece na forma de ondas eletromagnéticas, muitas na faixa da região infravermelha (HU et al, 2006). O comprimento de onda dos raios infravermelhos varia de 0,75 a $1000 \mu \mathrm{m}$ e o espectro infravermelho tipicamente associado com os processos fisiológicos humanos varia de 6 a 14 $\mu \mathrm{m}$ (HU, 2006). 
Têxteis que podem fornecer uma funcionalidade a mais ao usuário se destacam dos têxteis convencionais e vêm recebendo atenção especial. Têxteis com radiação infravermelha são caracterizados por ter uma alta absorção e emissão de infravermelhos. Cada vez mais, têxteis voltados a esse tipo de funcionalidade vêm ganhando mercado em diferentes campos, como o terapêutico, o de esportes e o militar (HU, 2006; DYER, 2011).

Uma prática comum na produção de tecidos com radiação infravermelha é a aplicação de alguns materiais especiais na superfície do tecido durante o acabamento. Esses materiais especiais (geralmente materiais cerâmicos) são capazes de criar uma alteração nas propriedades infravermelhas do tecido e, assim, dar algumas funções específicas aos usuários. Além disso, segundo Cyan (2012), os métodos de aplicação desses materiais geram uma influência no desempenho do acabamento. Em última instância, o acabamento afeta as sensações subjetivas humanas.

\subsubsection{Desempenho Funcional Térmico}

Segundo Cyan (2012) o desempenho funcional térmico é um dos critérios críticos para avaliar a performance de uma roupa. Ele está associado com o conforto que se tem ao vestir um artigo têxtil. Conforto é o estado de harmonia psicológica, física e fisiológica entre o ser humano e o meio ambiente (LI, 2001). Os processos que abrangem o conforto humano são: físico, termofisiológico, neurofísiológico e psicológico.

O propósito de vestir um artigo têxtil é o de obter conforto fisiológico e psicológico, e garantir que as condições físicas ao redor de nosso corpo sejam adequados para nossa sobrevivência (HU, 2006). Em seu estudo, Li (2001) diz que o conforto termofisiológico tem uma relação próxima com o balanceamento térmico do corpo humano, que se esforça para manter uma temperatura de aproximadamente $37^{\circ} \mathrm{C}$, sendo que uma variação de $\pm 5^{\circ} \mathrm{C}$ poderia ser fatal. A alteração de temperatura do corpo pode causar uma hipotermia ou uma hipertermia, respectivamente, graças a falta ou o excesso de calor no corpo (CHURCHILL, 2003; OGULATA, 2007). Isso mostra o quão importante o artigo têxtil é para o conforto termo fisiológico. Por isso é muito importante o conceito de desempenho funcional térmico ao avaliar se um artigo têxtil pode fornecer um microclima térmico propício para a sobrevivência humana. 
Conforme Cyan (2012) diz, "não há uma definição exata para o desempenho funcional térmico". Porém, alguns estudos de Luo, et al. (2011) apontam que esse desempenho está ligado à proteção térmica das roupas, que têm relação com a saúde física e a sobrevivência humana, particularmente durante um período de más condições térmicas, o que também pode afetar as sensações humanas subjetivas.

Vários elementos representam um grande impacto no desempenho funcional térmico e são descritos como a termorregulação do corpo humano, a transferência de calor e umidade, o comportamento do material do vestuário, assim como a interação dinâmica entre o ser humano, as roupas e o meio ambiente. Entre esses elementos descobriu-se que as propriedades térmicas dos materiais para vestuário e as características da estrutura da montagem do vestuário são dois fatores influentes essenciais sobre o desempenho funcional térmico (LUO et al, 2011).

Estudos realizados por Ogulata (2007) e Holmér (2008) mostram que o desempenho funcional térmico é um conceito crítico para a avaliação da performance de um artigo têxtil.

Graças à importância e a aceitação de roupas com desempenho funcional térmico, torna-se importante avaliar o efeito dos acabamentos de infravermelhos (acabamentos contendo biocerâmica) baseados no conceito do desempenho funcional térmico. Esse desempenho pode ser tido como um guia para auxiliar na avaliação se o artigo têxtil supre os requisitos do conforto termofisiológico humano (CYAN, 2012).

\subsection{Princípio da Incorporação de Radiação Infravermelha em Têxteis}

Há uma tendência de aplicação de acabamento de infravermelho sobre substratos de tecido para alterar as propriedades de radiação infravermelha, de modo a gerar algumas funções especiais em itens de vestuário (CYAN, 2012).

Pesquisas (HU et al, 2006) apontam tecnologias de revestimento de polímeros (coating), que podem afetar significativamente a propriedades de radiação infravermelha da superfícies de materiais.

Dyer (2011) diz que o princípio básico por detrás dos têxteis de infravermelho longo é que, o tecido é estimulado por energia térmica (calor emitido pelo corpo humano), que 
absorve o calor e o converte por meio de emissão de raios infravermelhos longos, que são dirigidos de volta para dentro do corpo humano, sendo assim, o tecido funciona através do usuário. Outra forma de explicar esse processo é que a camada de material de infravermelho longo ativo atua como um espelho para o corpo humano, com o calor emitido sendo reenviado como infravermelho longo dentro de uma gama específica de comprimentos de onda.

\subsubsection{Materiais Especiais Utilizados para Incorporar o Efeito de Radiação Infravermelha em Têxteis}

Segundo Cyan (2012) o acabamento de tecidos incorporado com alguns materiais causa uma grande influência nas propriedades de infravermelho e, consequentemente, o desempenho de radiação térmica.

Alguns autores relatam que o acabamento com nano partículas (YANG et al, 2008), a utilização de microcápsulas com materiais de mudança de fase incorporadas com nano partículas de prata (SONG et al, 2008), e a adição de partículas de dióxido de titânio (WU et al, 2008) podem alterar as propriedades de radiação infravermelha dos tecidos.

A incorporação de materiais cerâmicos em tecidos, principalmente o Carbeto de Zircônio (mais utilizado para dar esse tipo de acabamento em tecidos) também é capaz de alterar as propriedades de radiação infravermelha dos tecidos (YU et al, 2007).

\subsubsection{Métodos de Aplicação de Materiais Cerâmicos em Têxteis}

Produtos de infravermelhos longos baseados em biocerâmicas estão disponíveis comercialmente na indústria. Biocerâmica é um termo empregado para a cerâmica com funcionalidade biológica, incluindo aquelas que podem emitir raios infravermelhos longos (CYAN, 2012). A cerâmica é, por conseguinte, o componente funcional do têxtil inteligente com esse tipo de acabamento, e a quantidade e meios pelos quais a biocerâmica pode ser incorporada nas fibras determina a emissividade total de raios infravermelhos longos do tecido.

Têxteis com infravermelhos longos são muitas vezes criados através da adição de pó de cerâmica de tamanho nano ou micro em polímeros, antes de serem extrudados e fiados. 
Segundo Cyan, (2012) os pós de biocerâmica podem ser combinados para formar a estrutura de têxteis para proporcionar efeitos de infravermelho longo, incluindo o óxido de magnésio, o carbeto de zircônio, óxido de ferro, carboneto de silício e compostos à base de germânio. Esses materiais retêm o calor emitido pelo corpo e o reemitem na forma de infravermelhos longos, penetrando fundo nas articulações e tecidos próximos aumentando o fluxo de sangue.

Existem diversas maneiras de incorporar biocerâmicas em têxteis, incluindo impregnação, deposição e também a incorporação da mesma na matriz polimérica do fio (que posteriormente formará o tecido) (DYER, 2011).

A incorporação da biocerâmica à matriz polimérica do fio é feita com pós biocerâmicos que são misturados aos polímeros antes de serem fiados, ou seja, o polímero da fibra é derretido e em seguida o pó cerâmico é adicionado ao líquido viscoso (polímero derretido), após isso ele passa pelas fieiras, onde formam os fios.

A figura 27 mostra um esquema visual da incorporação da biocerâmica na matriz polimérica do fio.

Figura 27. Incorporação da biocerâmica na matriz plomérica do fio.

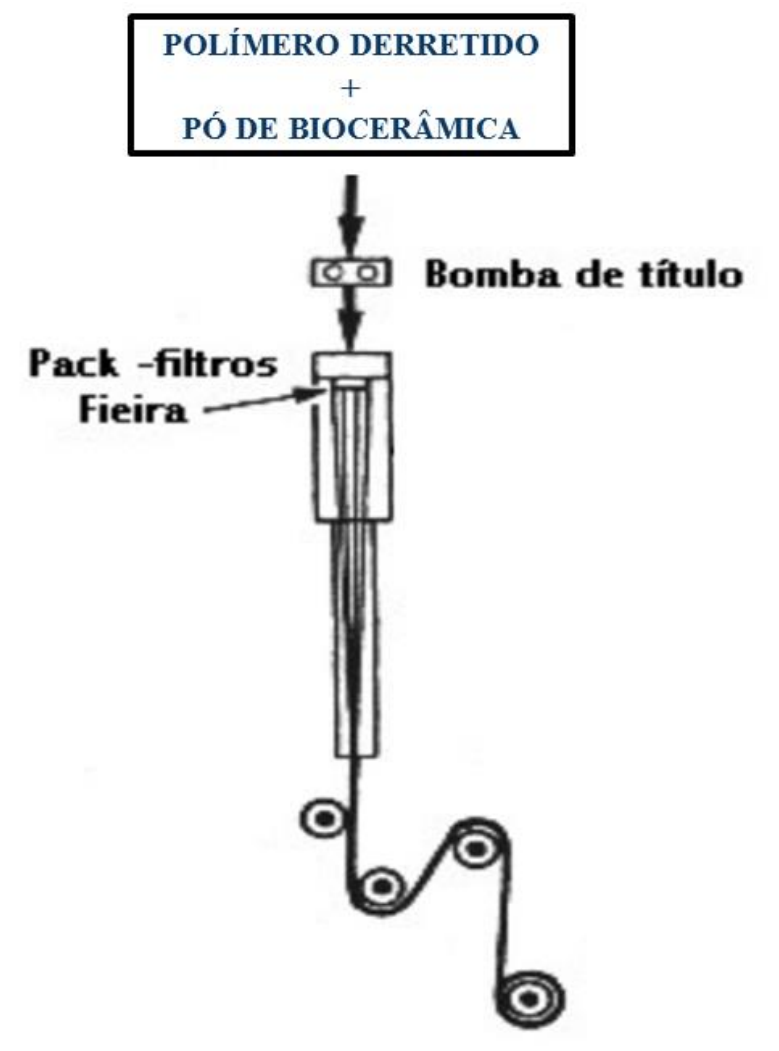


Um dos benefícios em ter biocerâmica incorporada na matriz polimérica do fio é que o efeito não se perde com o uso ou lavagens, tornando a vida útil do artigo muito maior. Porém esse processo só é permitido para fibras não naturais.

A impregnação é feita através de um foulard, que é uma máquina destinada à impregnação de uma grande variedade de substâncias químicas têxteis. Ela funciona da seguinte maneira: o tecido é inserido em uma cuba que contém um líquido ou pasta com um líquido ou pasta viscosa com o acabamento desejado (podem ser corantes, amaciantes, etc., e nesse caso, uma pasta contendo biocerâmica). Após isso acontece a espremagem, onde o acabamento que ficou na superfície do tecido, após este ter mergulhado na cuba, é forçado, através da ação de pressão por parte de cilindros, a penetrar no material têxtil. Após a foulardagem, o tecido é seco e ao mesmo tempo fixado.

A figura 28 apresenta um esquema visual da impregnação por foulardagem.

Figura 28. Impregnação por foulardagem.

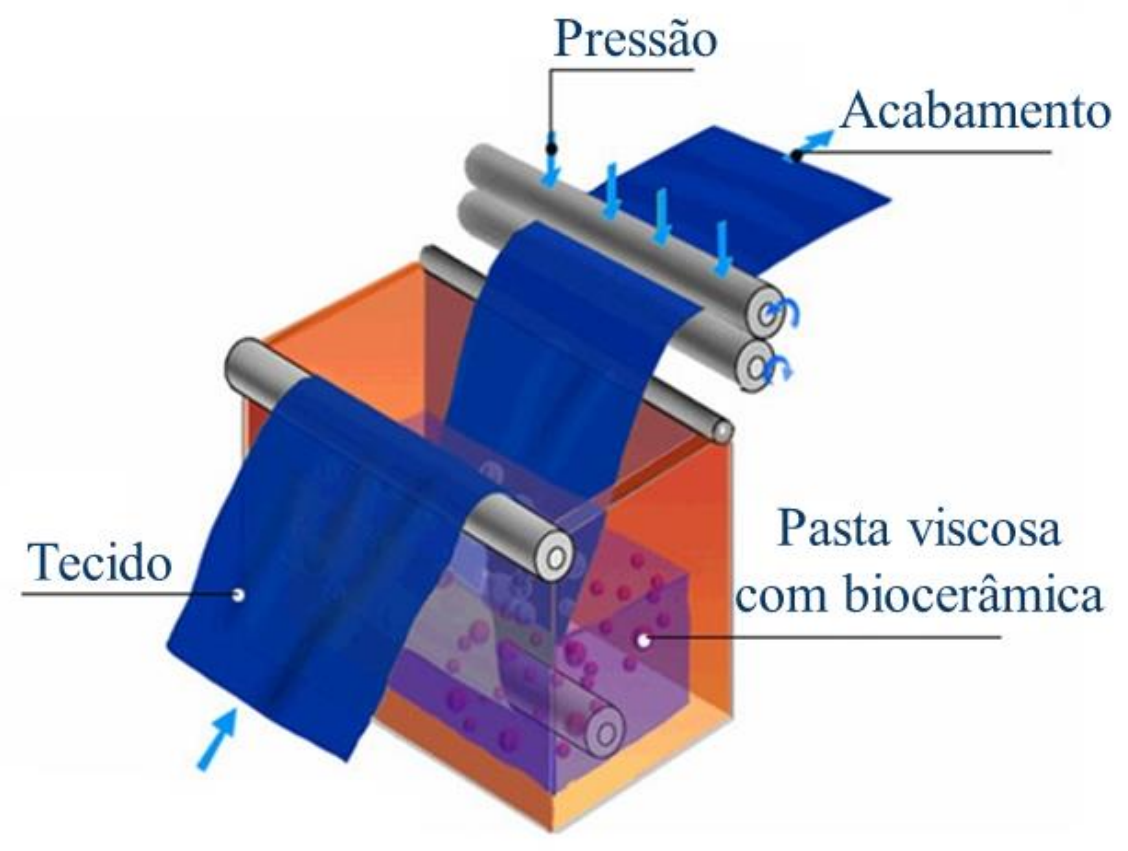

Fonte: Adaptado de Alfieri, 2012b.

A deposição é feita por processos de espalmagem, que segundo Alfieri (2012b) é um "processo que consiste em depositar uma ou mais camadas de um liquido ou pasta sobre um substrato têxtil". 
A técnica de espalmagem mais utilizada é o revestimento direto por espatulagem, onde o material viscoso a ser aplicado sobre o tecido é controlado com uma espátula (racla), que serve para espalha-lo uniformemente sobre toda a largura do tecido, controlando também sua espessura. Após isso o tecido é seco e fixado.

Segundo Cyan (2012) a biocerâmica é moída em micro ou nanopartículas (pó metálico) e é colocada junto com uma resina de polipropileno ou poliuretano para realizar o processo de espalmagem. A figura 29 apresenta um esquema visual do processo de espatulagem.

Figura 29. Ilustração do processo de espatulagem.

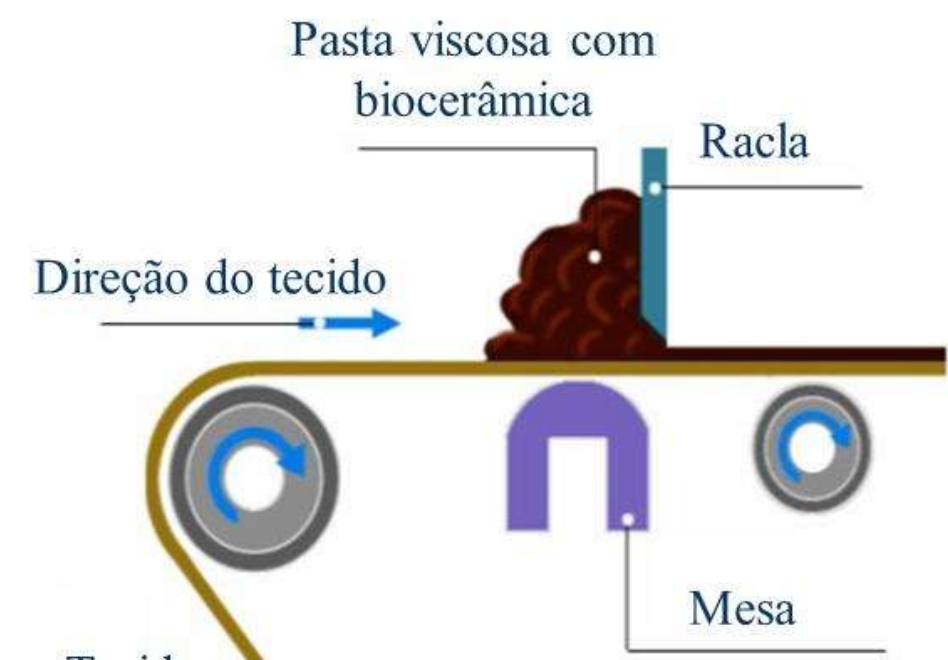

Tecido

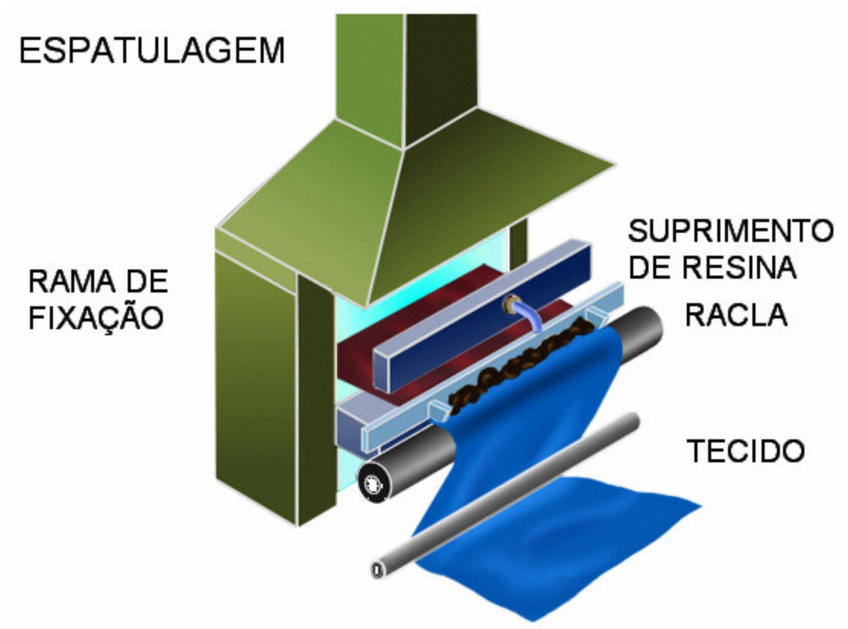

Fonte: Alfieri, 2012b. 
A desvantagem dos métodos de impregnação e deposição é o fato da biocerâmica se desprender do tecido conforme o número de lavagens realizadas, perdendo assim sua eficiência ao longo do tempo. Porém há a possibilidade da utilização desses dois tipos de acabamento em qualquer tipo de fibra.

\subsection{Materiais Cerâmicos}

Os materiais cerâmicos são compostos químicos e soluções que envolvem elementos metálicos e não metálicos (CARTER, NORTON, 2007). A variedade das propriedades mecânicas e físicas dos materiais cerâmicos permite que sejam aplicados para distintas finalidades: tijolos, louças, refratários, materiais magnéticos, dispositivos eletrônicos, fibras, abrasivos, componentes aeroespaciais, etc.

\subsection{Biocerâmicas}

O campo das biocerâmicas é relativamente novo e não existia até os anos 1970 (CARTER, NORTON, 2007).

As biocerâmicas são consideradas biomateriais, e segundo Carter e Norton (2007), biomaterial é qualquer substância, sem ser uma droga ou uma combinação de substâncias sintéticas ou de origem natural, que pode ser usada por qualquer período de tempo, como um todo ou como parte de um sistema, que interage com sistemas biológicos.

Infelizmente não há muitas informações a respeito das biocerâmicas utilizadas em tecidos, pois as mesmas são segredos industriais. Uma das únicas que é mais conhecida é o Carbeto de Zircônio. Como forma de investigação foram analisadas as patentes dos tecidos utilizados neste estudo, porém nenhuma das patentes especificava a biocerâmica utilizada ou dava maiores informações a respeito, tratando do assunto de forma sigilosa. 


\subsection{Espectrofotômetro de Infravermelhos}

Espectrofotômetros de raios infravermelhos são utilizados, normalmente, para gravar espectros na região de 4000 a $650 \mathrm{~cm}^{-1}(2,5$ a $15,4 \mu \mathrm{m})$, ou em alguns casos até $200 \mathrm{~cm}^{-1}$ (EP 6.0 ; 2008). Existem Espectrofotômetros reguláveis para diferentes faixas do espectro infravermelho, sendo possível analisar toda faixa de emissão infravermelha.

Eles consistem de uma fonte de luz adequada (infravermelha), monocromador ou interferômetro e um receptor.

A figura 30 mostra um esquema do interior do espectrofotômetro de infravermelhos utilizado para a realização dos ensaios neste estudo.

Figura 30. Esquema do espectrofotômetro de infravermelhos utilizado para medição das amostras.

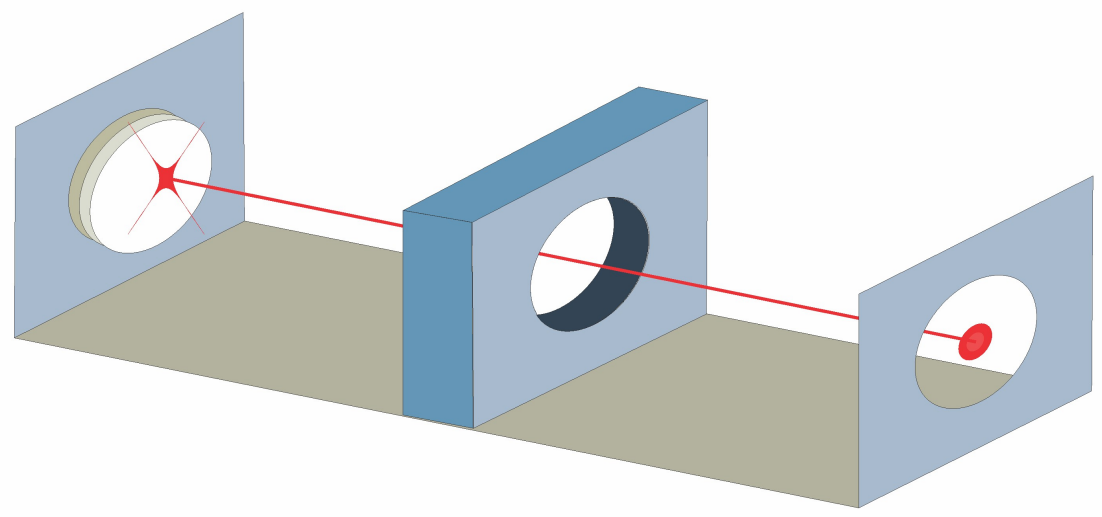

Fonte: Renan Guazzelli Affonso, 2015.

Normalmente o espectro é dado como uma função da transmitância, do coeficiente da intensidade da radiação transmitida e da incidência da radiação, e também pode ser dada em absorbância (como é o caso do espectrofotômetro utilizado) (EP 6.0, 2008).

A absorbância é dada em porcentagem, representando a porcentagem de radiação absorvida pelo receptor do espectrofotômetro. $\mathrm{O}$ aparelho espectrofotômetro de infravermelhos mede a absorbância para cada número de onda (comprimento de onda) variando de $100 \mathrm{~cm}^{-1}$ até $10000 \mathrm{~cm}^{-1}$. Como resultado da medição é obtido um gráfico de absorbância (\%) por número de onda $\left(\mathrm{cm}^{-1}\right)$. 


\subsection{Espectroscopia FTIR - Infravermelhos por Transformada de Fourier}

A espectroscopia no infravermelho é uma técnica utilizada desde 1940 pelos cientistas russos, mas só em 1950 foram comercializados os primeiros espectrômetros dispersivos. Os instrumentos usados são chamados espectrômetros de infravermelho, e a propriedade física medida é a capacidade da substância para absorver, transmitir, ou refletir radiação infravermelha (BALL, 2006).

Um espectrograma (gráfico obtido pelo espectrofotômetro) no infravermelho possui uma apresentação bidimensional das características de uma molécula. Estas características de absorção aparecem no espectrograma como bandas ou picos, e pode ser descrito através de três variáveis: posição, intensidade e formato. Os dois primeiros podem ser expressos em números, enquanto que o terceiro (formato de banda) é usualmente expresso em palavras (SMITH, 1996).

Quatro parâmetros diferentes são usados para descrever posição no espectrograma: energia (ergs), frequência $\left(\mathrm{s}^{-1}\right)$, comprimento de onda $(\mu$ ou $\mu \mathrm{m})$, e número de ondas $\left(\mathrm{cm}^{-1}\right)$. As unidades usadas no espectrograma dependerão do instrumento projetado, e se outra unidade é requerida para um trabalho específico, os dados devem ser apropriadamente convertidos (FIORINI, 2000). Os dados são apresentados em comprimento de onda ou número de ondas, sendo a segunda atualmente preferida.

Fiorini (2000) mostra como as unidades em questão se relacionam e como podem ser convertidas:

Energia e frequência são relacionadas por:

$$
\mathrm{E}=\mathrm{h} . v
$$

Onde:

- $\mathrm{E}=$ energia ( ergs )

- $\mathrm{h}=$ constante de Planck ( $6,67 \times 10^{-27}$ ergs . s )

- $\quad v=$ frequência $\left(\mathrm{s}^{-1}\right)$

Frequência e comprimento de onda são relacionados por:

$$
\lambda . v=\mathrm{c}
$$


Onde:

- $\lambda=$ comprimento de onda $(\mathrm{cm})$

- $\quad v=$ frequência $\left(\mathrm{s}^{-1}\right)$

- $\mathrm{c}=$ velocidade da luz $\left(3 \times 10^{10} \mathrm{~cm} / \mathrm{s}\right)$

Comprimento de onda e número de ondas são relacionados por:

$$
\underline{v}=1 / \lambda
$$

Onde:

- $\lambda=$ comprimento de onda $(\mathrm{cm})$

- $\underline{v}=$ número de onda $\left(\mathrm{cm}^{-1}\right)$

Equação ( 1-3 ) é usualmente escrita como:

$$
\lambda=10000 / v
$$

- Onde $\lambda$ é agora o comprimento de onda em microns ( $\mu$ ), a unidade normalmente usada em medidas na região infravermelho do espectro.

Segungo Fiorini (2000) intensidade é uma medida da quantidade da energia absorvida pela amostra e é determinado pelo eixo y, ou ordenada. Este parâmetro pode ser expresso em números ou palavras. Se a intensidade está em números, pode ser expressa como porcentagem de transmitância ou em unidades de absorção. A energia, ou potência radiante, que é absorvida pela amostra em alguma frequência é Po, e a fração de Po da energia transmitida pela amostra é $\mathrm{P}$, então a transmitância $\mathrm{T}$ pode ser expressa como:

$$
\mathrm{T}=\mathrm{P} / \mathrm{Po}=10^{- \text {a.b.c }}
$$

Onde:

- $\quad$ Po $=$ radiaçao incidente

- $\mathrm{P}=$ radiação transmitida

- $\mathrm{a}=$ constante de absortividade de um componente em $\mathrm{g} / \mathrm{l} \mathrm{em}$ um comprimento

- de onda particular.

- $\mathrm{b}=$ diferença da trajetória óptica da amostra. 
- $\quad \mathrm{c}=$ concentração do componente em no de moles/l.

- e porcentagem de transmitância como:

$$
\% \mathrm{~T}=100 . \mathrm{P} / \mathrm{Po}
$$

Certas vezes, especialmente para análise quantitativa, é desejável expressar esses dados em unidades de absorção em vez de porcentagem de transmitância (SMITH, 1996). A absorção é dada por:

$$
\mathrm{A}=\log 1 / \mathrm{T}=\log \mathrm{Po} / \mathrm{P}=\text { a.b.c }
$$

Os instrumentos são usualmente designados para registrar a energia transmitida em porcentagem de transmitância numa escala linear, mas pode também ser registrado em unidades de absorção em escala logarítmica.

Os espectrofotômetros de FTIR tem como princípio o interferômetro de Michelson, que é o núcleo de espectrômetros FTIR, e é utilisado para dividir um feixe de luz em dois, para que os caminhos dos dois feixes sejam diferentes. Em seguida, o interferômetro de Michelson recombina os dois feixes e os conduz para o detector, onde a diferença da intensidade destes dois feixes são medidos como uma função da diferença dos caminhos percorridos por cada feixe Esta diferença de caminho é chamada de diferença óptica de percurso (OPD -Optical Path Difference) (SAPTARI, 2003). O interferômetro está representado na figura 31, onde temos o esquema de um espectrofotômetro FTIR.

Figura 31. Diagrama simplificado do sistema óptico de um espectrômetro FTIR.

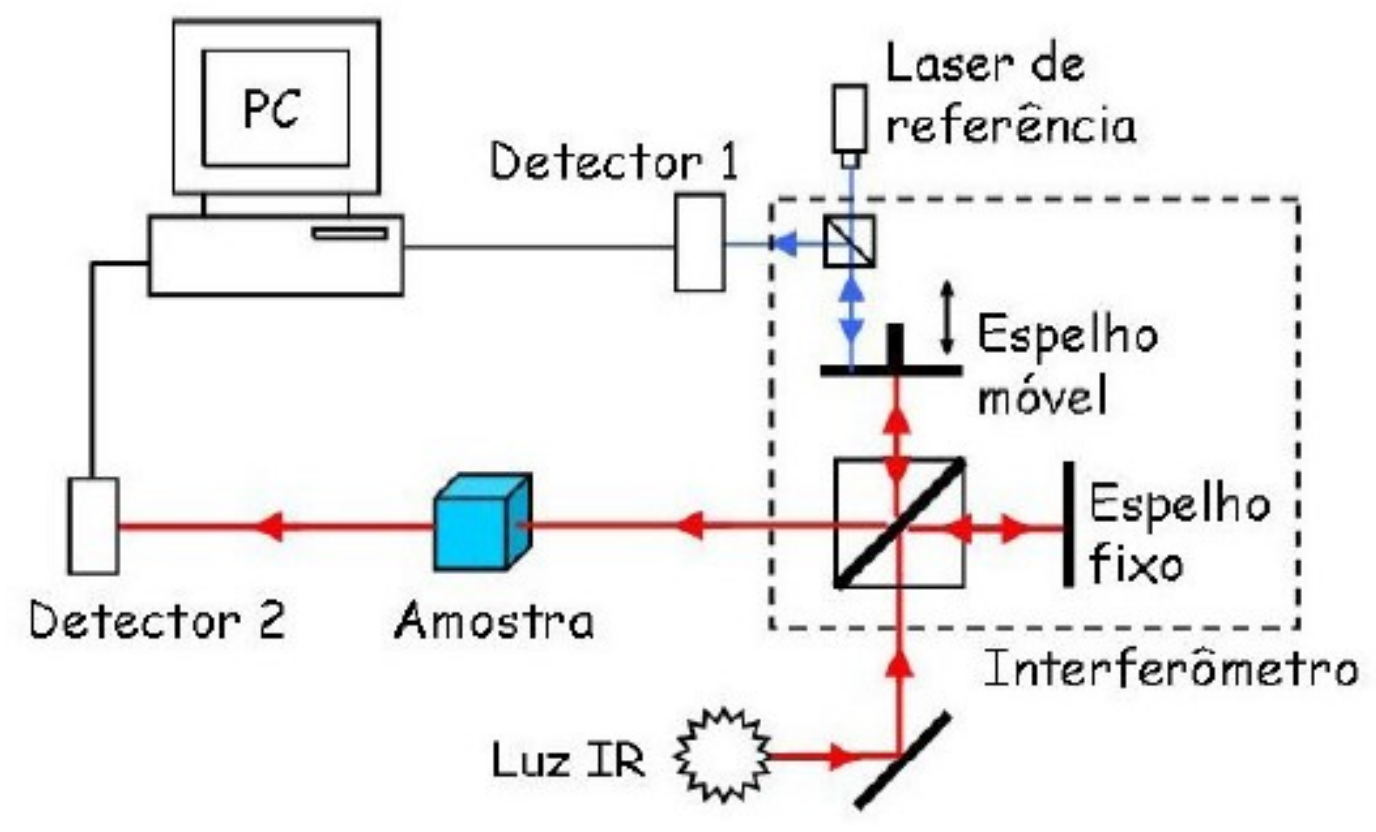


Fonte: Delgado, 2012.

Com as informações obtidas pelo detector do espectrofotômetro obtem-se um interferograma, que é um gráfico da intensidade do sinal em relação à diferença óptica de percurso.

A transformada de Fourier é um método matemático para transformar uma função em uma nova função e pode ser vista como a inversão da variável independente de uma função. Assim, a transformada de Fourier do interferograma pode ser visto como a inversão de OPD, cuja unidade de medida é centímetro, fazendo com que a inversão de OPD tenha como unidade $\mathrm{cm}^{-1}$, conhecida como número de onda (GRIFFITHS; HASETH, 2007). Depois da transformada de Fourier, um gráfico de intensidade de sinal em relação número de onda é produzido (este gráfico é o espectro de infravermelho).

Segundo Saptari (2003) as funções de onda dos feixes refletidos e transmitidos podem ser representados pela forma geral:

$$
\left.E_{1}=r t c E_{m} \times \cos v t-2 \pi k x\right)
$$

E tem-se que:

$$
\left.E_{1}=r t c E_{m} \times \cos [v t-2 \pi k(v x+\Delta d)]\right)
$$

Onde:

- $\Delta d=$ diferença de percurso,

- $r$ = reflectância (amplitude) do divisor de raios,

- $t=$ transmitância,

- $c=$ constante de polarização.

A função de onda da sua sobreposição com o detector resultante é representado como:

$$
E=E_{1}+E_{2}=2\left(r \times t \times c \times E_{m}\right) \times \cos (v t-2 \pi k x) \cos (\pi k \Delta d)
$$

Onde:

- $\quad E_{m}=$ amplitude 
- $\quad v=$ frequência

- $\mathrm{k}=$ número de onda da fonte de radiação infravermelha

A intensidade (I) detectada é a media de tempo de $E_{2}$ e é descrita como:

$$
I=4 r^{2} t^{2} c^{2} E_{m}^{2} \cos ^{2}(v t-2 \pi k x) \cos ^{2}(\pi k \Delta d)
$$

Uma vez que a média de tempo do primeiro termo cosseno é apenas $1 / 2$ (meio), tem-se em seguida:

$$
I=2 I(k) \cos ^{2}(\pi k \Delta d)
$$

E assim:

$$
I(\Delta d)=I(k)[1+\cos (2 \pi \mathrm{k} \Delta \mathrm{d})]
$$

Onde:

- $\quad I(k)=$ constante que depende apenas de $\mathrm{k}$

- $I(\Delta d)=$ interferograma.

A partir de $I(\Delta d)$ pode ser obtido $I(k)$ utilizando a transformada de Fourier:

$$
I(\Delta d)-I(\infty)=\int_{0}^{K_{m}} I(k) \cos (2 \pi k \Delta d) d k
$$

Tendendo $K_{m} \rightarrow \infty$, é possível escrever:

$$
I(k)=\int_{0}^{\infty}[I(\Delta d)-I(\infty)] \cos (2 \pi k \Delta d) d \Delta d
$$

As informações fisicamente medidas recebidas pelo detector produzem um interferograma, que fornece informações sobre uma mudança de percurso ao longo do tempo dentro da distância de varredura espelho (OPD). Portanto, o interferograma obtido no detector é um espectro no domínio do tempo. Este procedimento envolve a amostragem de cada 
posição, o que pode levar muito tempo se o sinal é pequeno e o número de frequências a ser amostrado é grande (BALL, 2006).

Em termos de frequência ordinária, $v$, a transformada de Fourier é dada por (frequência angular $\omega=s \pi v$ ) (SAPTARI, 2003):

$$
f(v)=\int_{-\infty}^{\infty} f(t) e^{-i 2 \pi v} d t
$$

A inversa da transformada de Fourier é dada por:

$$
f(v)=\int_{-\infty}^{\infty} f(t) e^{+i 2 \pi v t} d t
$$

O interferograma é transformado em um gráfico de espectro de absorção de raios infravermelhos que é normalmente plotado como intensidade de absorção ou porcentagem de transmitância versus comprimento de onda ou número de onda.

\subsection{Fluorescência de Raios $X$}

As análises científicas realizadas por metodologias físicas e químicas em diversos materiais permitem obter informações dos materiais existentes nestes, o processo de manufatura, os pigmentos utilizados, etc. Estas informações ajudam no entendimento do objeto e podem revelar informações sobre o processo de manufatura, o estado de conservação e em alguns casos também fornece dados para identificação do período histórico de produção (RIZZUTTO et al, 2007).

As análises não destrutivas onde não há digestão do objeto ou amostra possuem vantagens, pois podem preservar a amostra ou o objeto analisado.

A Fluorescência de Raios X (XRF - X-Ray Fluorescence) é uma técnica de análise não destrutiva, que vem sendo muito utilizada para investigar a composição elementar dos materiais presentes em determinados objetos (RIZZUTTO et al, 2007).

Segundo Pinto (2013), fluorescência é a emissão de radiação resultante da excitação de elétrons por uma radiação de energia superior àquela emitida. A radiação é emitida como resultado da transferência de elétrons entre diferentes níveis de energia. 
$\mathrm{Na}$ análise por fluorescência de Raios $\mathrm{X}$, os fótons de raios $\mathrm{X}$ de um tubo fonte de raios $\mathrm{X}$ interagem com os elétrons orbitais de um átomo de material do objeto a ser analisado, e são retirados de um orbital mais interno, criando uma vacância, promovendo estes elétrons para níveis excitados no rearranjo eletrônico. Esta vacância será preenchida por um elétron de um orbital mais externo e nesta transição emitem raios $\mathrm{X}$ característicos dos elementos presentes na amostra (RIZZUTTO et al, 2007). Por ser uma técnica de análise elementar, a Fluorescência de Raios X não identifica a composição química dos compostos presentes na amostra, apenas seus elementos constituintes.

\section{MATERIAIS E MÉTODOS}

\subsection{Materiais}

Para a realização dos ensaios foram utilizados tecidos contendo biocerâmica, todos disponíveis no mercado e clinicamente testados, além da utilização de um tecido que não contém biocerâmica a fim de comparar os resultados obtidos.

Os tecidos utilizados foram todos de malharia circular com ligamento de meia malha, compostos por poliamida e elastano. As características dos tecidos estão dispostas na tabela 5:

Tabela 5. Caracterização dos tecidos.

\begin{tabular}{|c|c|c|c|c|}
\hline & Composição & $\begin{array}{l}\text { Gramatura } \\
(\mathrm{g} / \mathrm{m} 2)\end{array}$ & $\begin{array}{l}\text { Título do fio } \\
\text { de Poliamida } \\
\text { (Tex) }\end{array}$ & $\begin{array}{l}\text { Título do fio } \\
\text { de Elastano } \\
\text { (Den) }\end{array}$ \\
\hline Tecido sem biocerâmica & $\begin{array}{l}90 \% \text { PA } \\
10 \% \text { EL }\end{array}$ & 360 & 20 & 65 \\
\hline $\begin{array}{l}\text { Tecido com biocerâmica incorporada à } \\
\text { matriz polimérica do fío }\end{array}$ & $\begin{array}{l}88 \% \text { PA } \\
12 \% \text { EL }\end{array}$ & 360 & 17 & 59 \\
\hline Tecido impregnado com biocerâmica & $\begin{array}{l}90 \% \text { PA } \\
10 \% \text { EL }\end{array}$ & 320 & 18 & 32 \\
\hline Tecido com deposição de biocerâmica & $\begin{array}{l}90 \% \mathrm{PA} \\
10 \% \mathrm{EL}\end{array}$ & 365 & 20 & 65 \\
\hline
\end{tabular}


Fonte: Renan Guazzelli Affonso, 2016.

Para a caracterização das amostras foram utilizadas as normas: método de pequenos comprimentos (ASTM D 1059) para a obtenção do título dos fios de poliamida, uma adaptação do método de título de elastano (NF G 18-001) utilizando um corpo de prova de 50 cm para obtenção do título dos fios de elastano, e o método de gramatura (ASTM D 3376) para obtenção dos valores de gramatura de cada tecido.

Uma amostra de $5 \times 3 \mathrm{~cm}$ de cada tecido foi utilizada no espectrofotômetro de infravermelhos. O espectrofotômetro utilizado foi o espectrofotômetro por transformada de Fourier (FTIR - Fourier Transform Infra Red) "Spectrum GX”, configurável para múltiplas faixas do espectro de radiação infravermelha.

Para as análises de fluorescência de raios $X$ utilizou-se um sistema portátil de Fluorescência de Raios X (XRF - X Ray Fluorescence), constituído por um tubo de raios X da Amptek ${ }^{\circledR}$, com filamento de Prata (voltagem $30 \mathrm{kV}$ e corrente de $5 \mu \mathrm{A}$ ), e um detector SiDrift também da Amptek ${ }^{\circledR}$.

\subsection{Métodos}

Primeiramente foi feita a calibragem do equipamento com o porta amostras para que não houvesse interferência do mesmo nos ensaios (O porta amostras é uma placa de alumínio onde há um buraco por onde passa o feixe de raios infravermelhos dentro do espectrofotômetro. Ele serve somente para manter a amostra numa posição adequada, permitindo que o feixe passe pela amostra). Para cada amostra foram feitos dois testes no equipamento, um sem aquecimento e outro com aquecimento. Cada teste faz 32 medições da amostra, portanto, somente o que foi percebido pelo espectrofotômetro nas 32 medições será expresso no resultado do teste.

Após a calibragem foi feito o teste da amostra sem biocerâmica e sem aquecimento, em seguida, para simular a ação do tecido junto ao corpo, a amostra sem biocerâmica foi aquecida em uma chapa metálica a $50^{\circ} \mathrm{C}$, durante 5 minutos, juntamente com o porta amostras (a fim de que o mesmo ajudasse nas medições, evitando a perda de calor excessiva e prejudicando o resultado dos testes) e colocada no espectrofotômetro para o segundo teste. Para controlar a temperatura de aquecimento foi utilizado um béquer de vidro com água e um 
termômetro, para indicar a temperatura. O procedimento foi repetido em todos os tecidos contendo biocerâmica descritos na tabela 5 . A temperatura de $50^{\circ} \mathrm{C}$ foi determinada a partir de diversas tentativas com temperaturas mais baixas, pois assim com o tempo de retirada do tecido da chapa metálica até a amostra ser colocada no porta amostras e no espectrofotômetro, a temperatura da amostra já havia diminuído consideravelmente, sendo assim, com uma temperatura de aquecimento de $50^{\circ} \mathrm{C}$ a temperatura final da amostra ao ser colocada no espectrofotômetro no momento do teste era suficiente para obter resultados claros. Caso as amostras fossem aquecidas a $37^{\circ} \mathrm{C}$, temperatura do corpo humano, a temperatura final na hora do teste seria muito inferior, não caracterizando uma simulação da ação do tecido junto ao corpo. A figura 32 apresenta um fluxograma do procedimento de medição das amostras no espectrofotômetro de raios infravermelhos.

Figura 32. Fluxograma do experimento para a medição das amostras no espectrofotômetro FTIR.

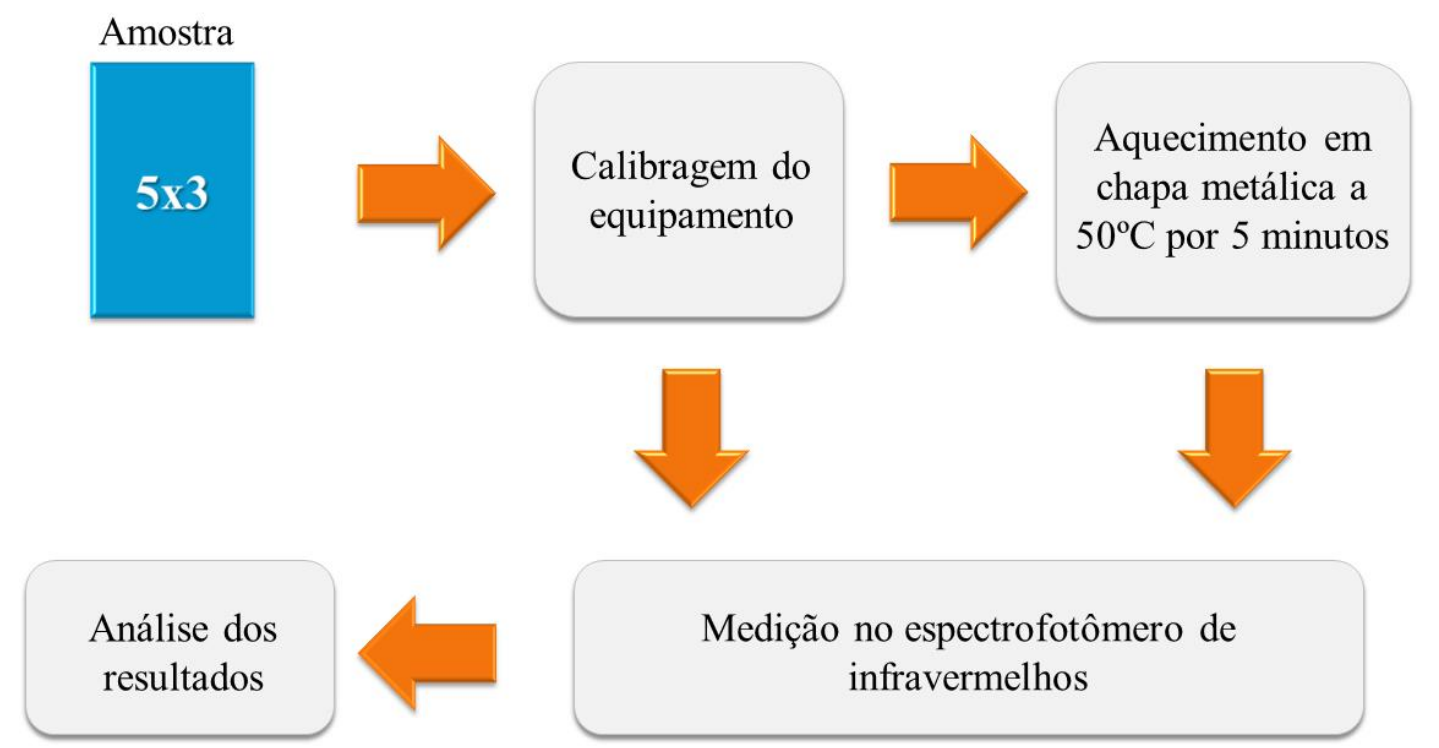

Fonte: Renan Guazzelli Affonso, 2016.

Outras tentativas para o aquecimento das amostras foram realizadas, como aquecimento com uma lâmpada ou até mesmo um secador de cabelos, porém os resultados obtidos não foram satisfatórios, sendo o aquecimento realizado na chapa metálica com o porta 
amostras o que obteve melhor resultado, sendo assim o método escolhido para a realização do trabalho.

A figura 33 mostra o espectrofotômetro utilizado para a realização dos ensaios e o interior do espectrofotômetro, indicando onde é colocado o porta amostras para a medição no aparelho.

Figura 33. Espectrofotômetro utilizado no experimento e interior do espectrofotômetro. 


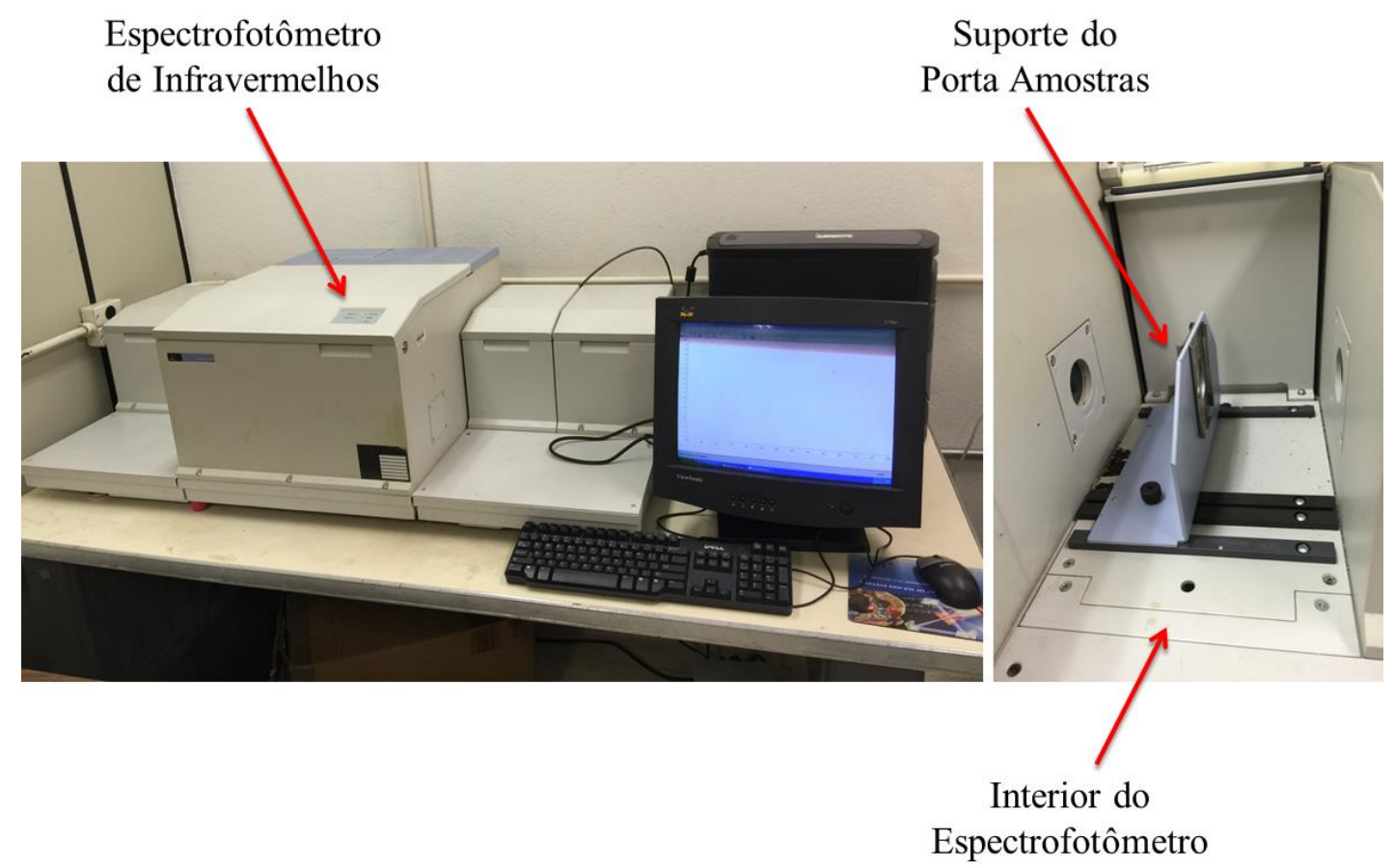

Fonte: Renan Guazzelli Affonso, 2016.

A figura 34 mostra a chapa metálica utilizada para aquecer as amostras, juntamente com o porta amostras utilizado. O béquer com água e um termômetro foi utilizado para controlar a temperatura. 
Figura 34. Chapa metálica utilizada para aquecer as amostras com o porta amostras utilizado no experimento.

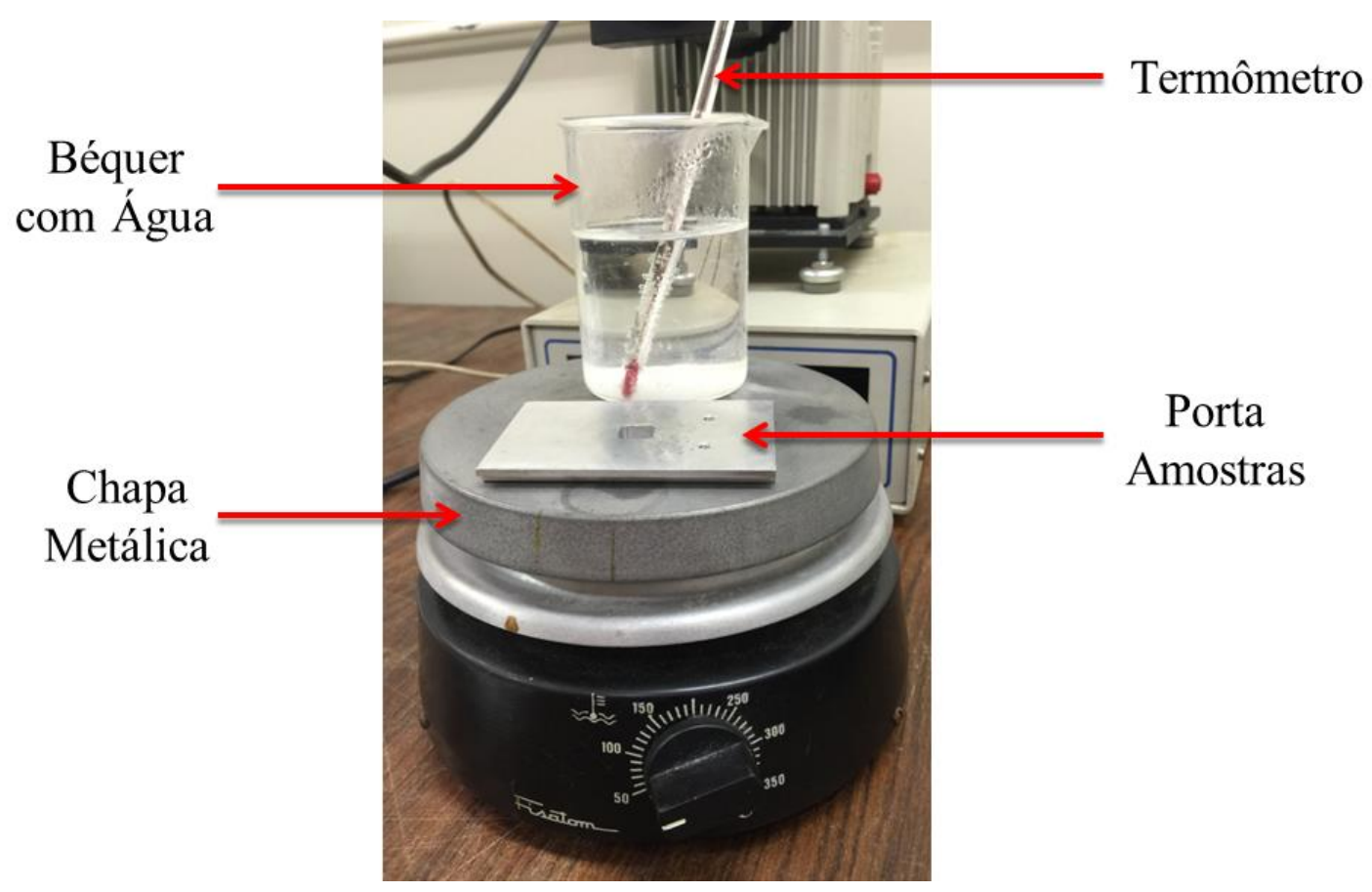

Fonte: Renan Guazzelli Affonso, 2016.

Como saída foram obtidos gráficos de porcentagem de Transmitância em função do Número de Onda, expresso em $\mathrm{cm}^{-1}$, que foram manipulados com a ajuda do software OriginPro.

Após as medições realizadas no espectrofotômetro de infravermelhos, foi realizado um teste de fluorescência de raios X com o sistema portátil de Fluorescência de Raios X. Durante as medidas o sistema de XRF é posicionado próximo a amostra sem tocá-la e nem causar-lhe nenhum tipo de dano.

A figura 35 mostra o sistema de Fluorescência de Raios X utilizado para a realização dos testes de fluorescência de raios $\mathrm{X}$ das amostras. 
Figura 35. Sistema de Fluorescência de Raios X utilizado no experimento.

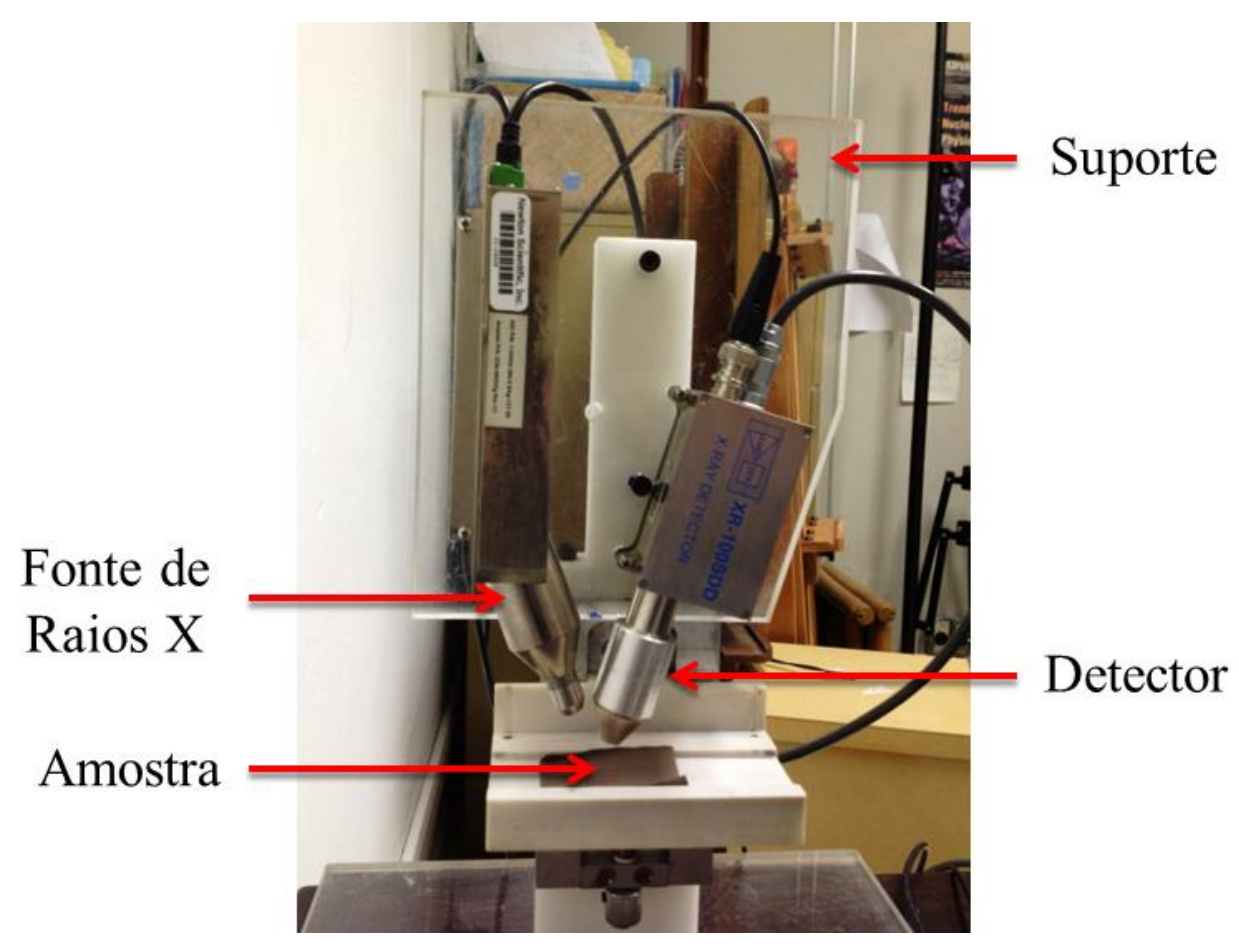

Fonte: Renan Guazzelli Affonso, 2016.

A fonte de raios $\mathrm{X}$ irá incidir um feixe de raios $\mathrm{X}$ na amostra, onde a interação do feixe com a amostra será percebida pelo detector de raios X. 


\section{RESULTADOS E DISCUSSÃO DOS ENSAIOS}

\subsection{Resultados da Espectrofotometria de Raios Infravermelhos}

Após os ensaios realizados no espectrofotômetro FTIR (medição das amostras com e sem aquecimento no espectrofotômetro) foi obtido o gráfico do tecido sem biocerâmica, onde é possível verificar o espectro de emissão através da figura 36 (todos os gráficos foram gerados com a utilização do software OriginPro).

Figura 36. Espectro de emissão do tecido sem biocerâmica aquecido e não aquecido.

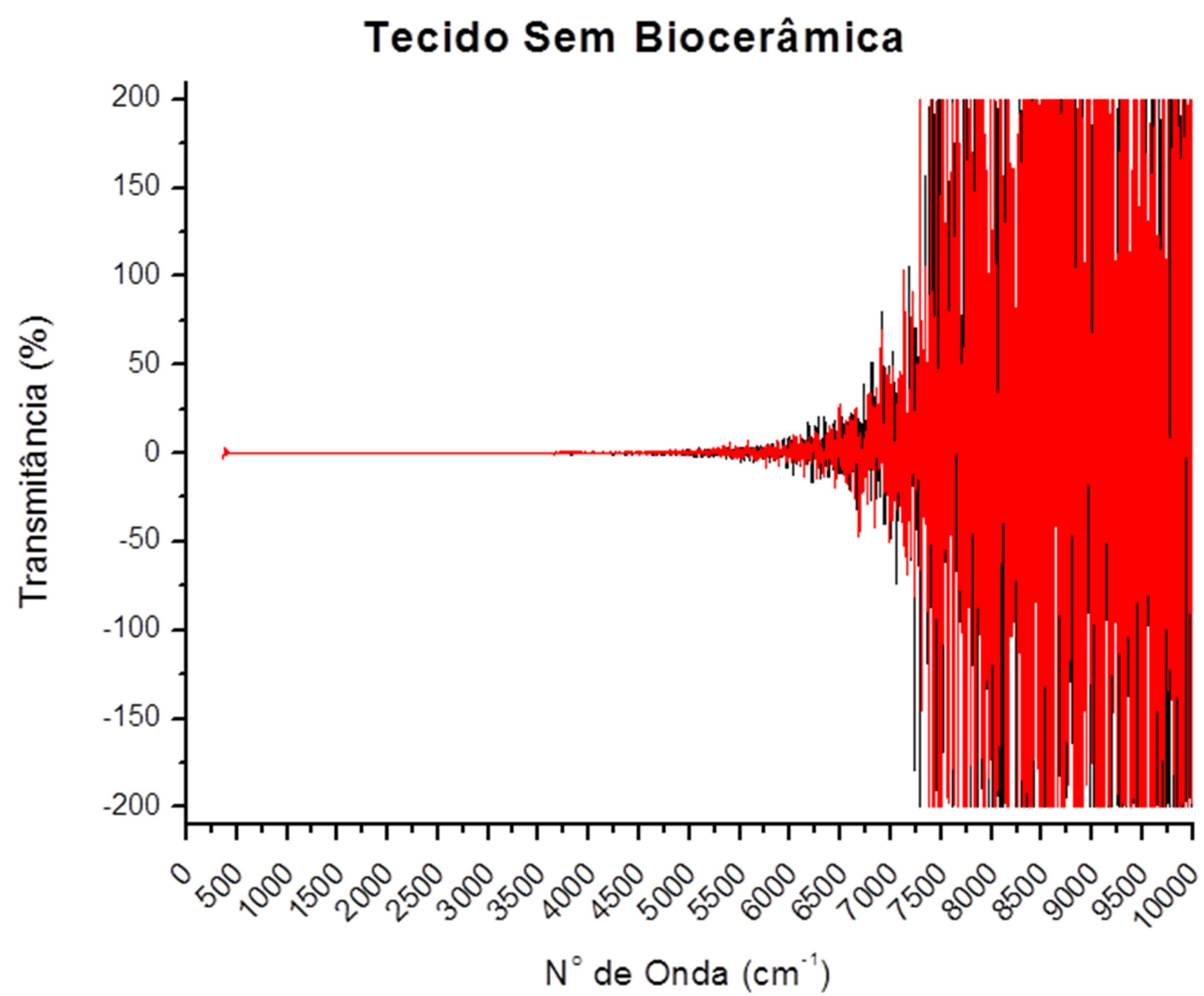

Sem Aquecimento Com Aquecimento

Fonte: Renan Guazzelli Affonso, 2016.

Pode-se observar que a partir do número de onda $7500 \mathrm{~cm}^{-1}$ a relação sinal-ruído fica muito grande, impossibilitando conclusões nessa faixa de emissão, por isso essa região será descartada nos próximos gráficos. Para uma melhor análise dos resultados obtidos, o espectro do tecido com aquecimento foi deslocado para cima (este processo foi realizado para todas as 
amostras, portanto os gráficos obtidos pelo espectrofotômetro serão apresentados com o espectro da amostra aquecida deslocada), conforme observado na figura 37.

Figura 37. Espectro de emissão do tecido sem biocerâmica, aquecido e não aquecido, com deslocamento.

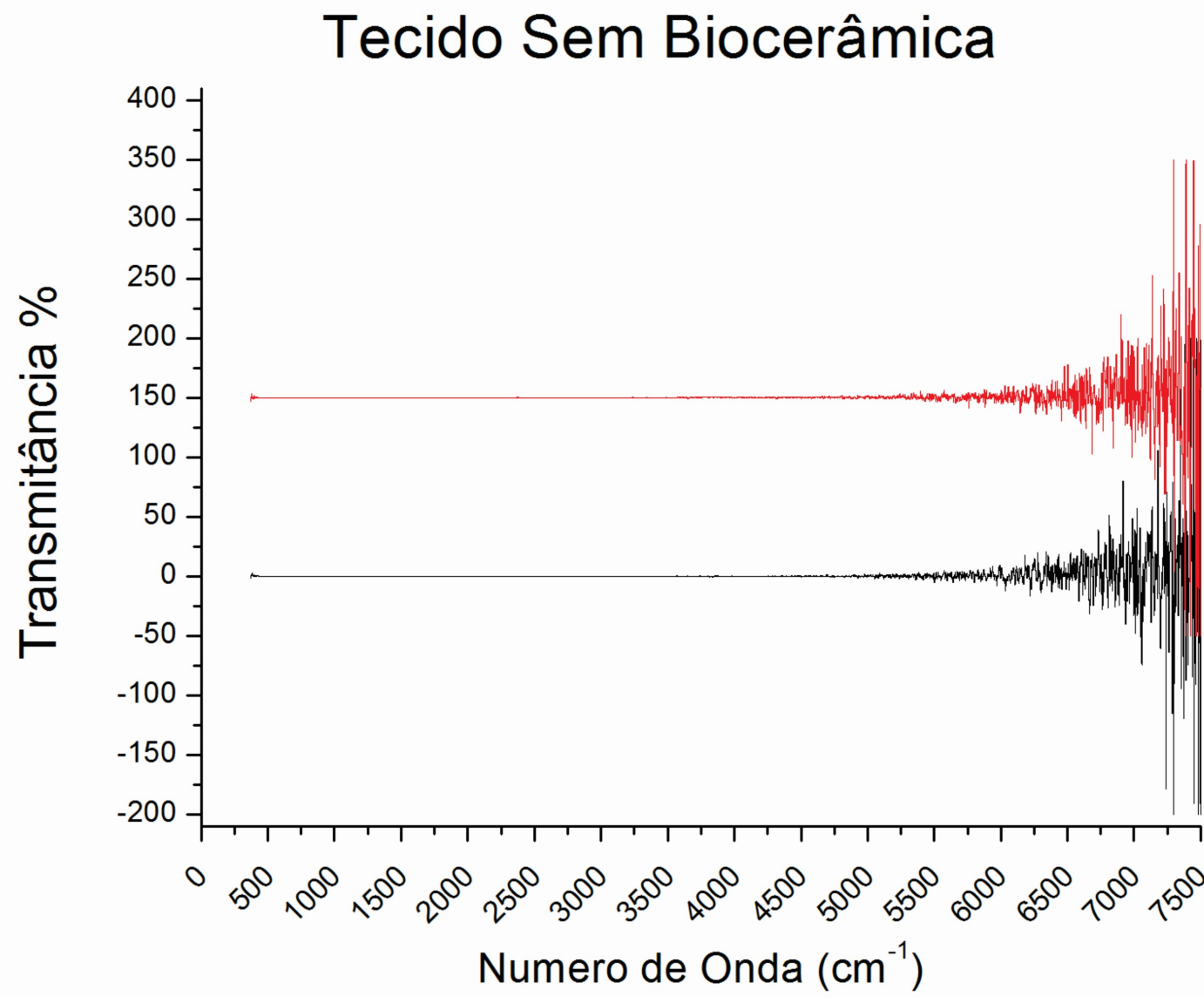

Fonte: Renan Guazzelli Affonso, 2016.

O que caracteriza uma emissão de raios infravermelhos por parte da amostra aquecida é a presença de um pico de emissão no gráfico do espectro do tecido. Um pico de emissão foge ao padrão (desenho) do gráfico obtido com a amostra sem aquecimento, podendo ser notado facilmente.

Observando o espectro de emissão do tecido sem biocerâmica não foi encontrado nenhum pico significativo que diferencie a amostra aquecida da sem aquecimento (a evolução do espectro gerado com o aquecimento da amostra se assemelha muito ao espectro da amostra sem aquecimento), portando conclui-se que não há nenhuma emissão do tecido sem biocerâmica ao ser aquecido. 
Após a realização dos ensaios com o tecido com biocerâmica incorporada à matriz polimérica do fio, o gráfico apresentado na figura 38, com o espectro de emissão das amostras, foi obtido.

Figura 38. Espectro de emissão do tecido com biocerâmica incorporada à matriz polimérica do fio, aquecido e não aquecido, com deslocamento.

Tecido com Biocerâmica Incorporada à Matriz Polimérica do Fio

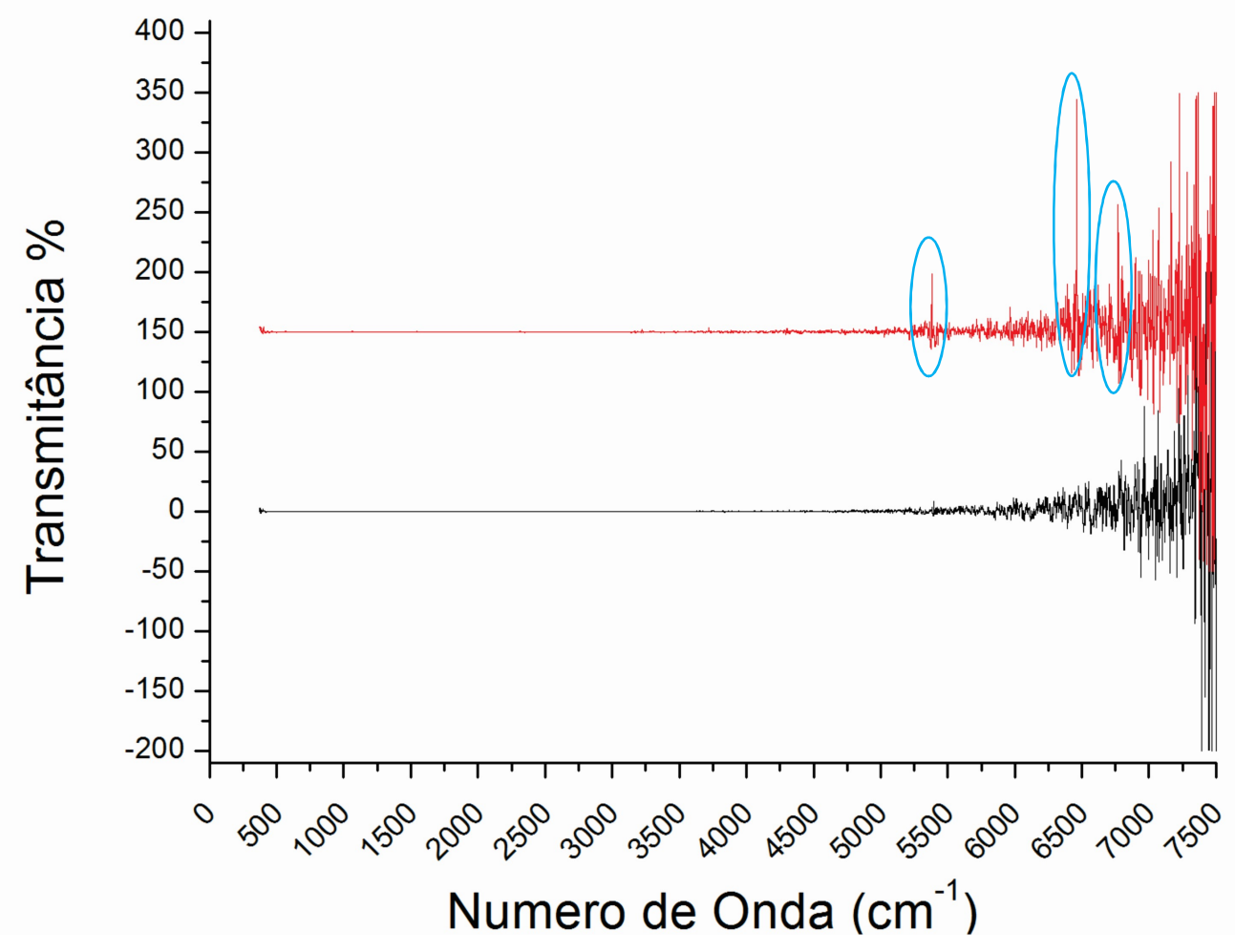

Sem Aquecimento

Com Aquecimento

Fonte: Renan Guazzelli Affonso, 2016.

Observando o espectro de emissão do tecido com biocerâmica incorporado à matriz polimérica do fio foram encontrados três picos significativos que diferenciam a amostra aquecida da sem aquecimento. O primeiro pico de emissão da amostra aquecida que se diferencia da sem aquecimento se encontra no número de onda $5397 \mathrm{~cm}^{-1}$, o segundo se encontra em $6476 \mathrm{~cm}^{-1}$ e o terceiro em $6785 \mathrm{~cm}^{-1}$. Portanto, pela presença de picos significativos no espectro de emissão da amostra aquecida, que diferem do espectro da não aquecida, conclui-se que há emissão do tecido quando aquecido. 
Em seguida, após a realização dos ensaios com o tecido com biocerâmica impregnada, foi obtido o gráfico com o espectro de emissão das amostras, apresentado na figura 39.

Figura 39. Espectro de emissão do tecido com biocerâmica impregnada, aquecido e não aquecido, com deslocamento.

\section{Tecido Impregnado com Biocerâmica}

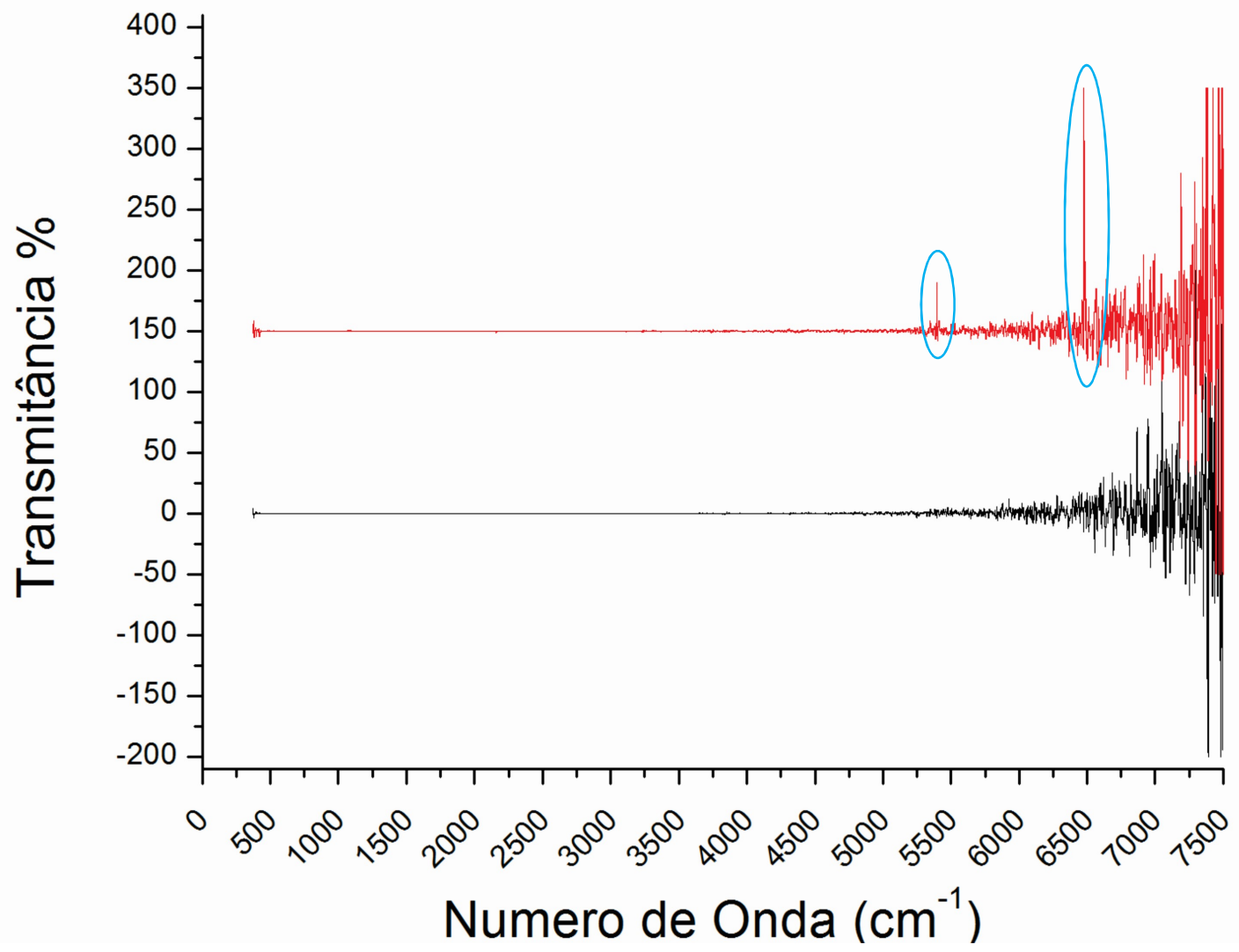

Fonte: Renan Guazzelli Affonso, 2016.

Ao observar o espectro de emissão do tecido com biocerâmica impregnada, foram encontrados dois picos significativos que diferenciam a amostra aquecida da sem aquecimento. O primeiro pico de emissão se encontra no número de onda $5397 \mathrm{~cm}^{-1}$, o segundo pico se encontra em $6476 \mathrm{~cm}^{-1}$. Portando conclui-se que há emissão do tecido quando aquecido.

Após a realização dos ensaios com o tecido com deposição de biocerâmica, foi obtido o gráfico com o espectro de emissão das amostras, apresentado na figura 40 . 
Figura 40. Espectro de emissão do tecido com deposição de biocerâmica, aquecido e não aquecido, com deslocamento.

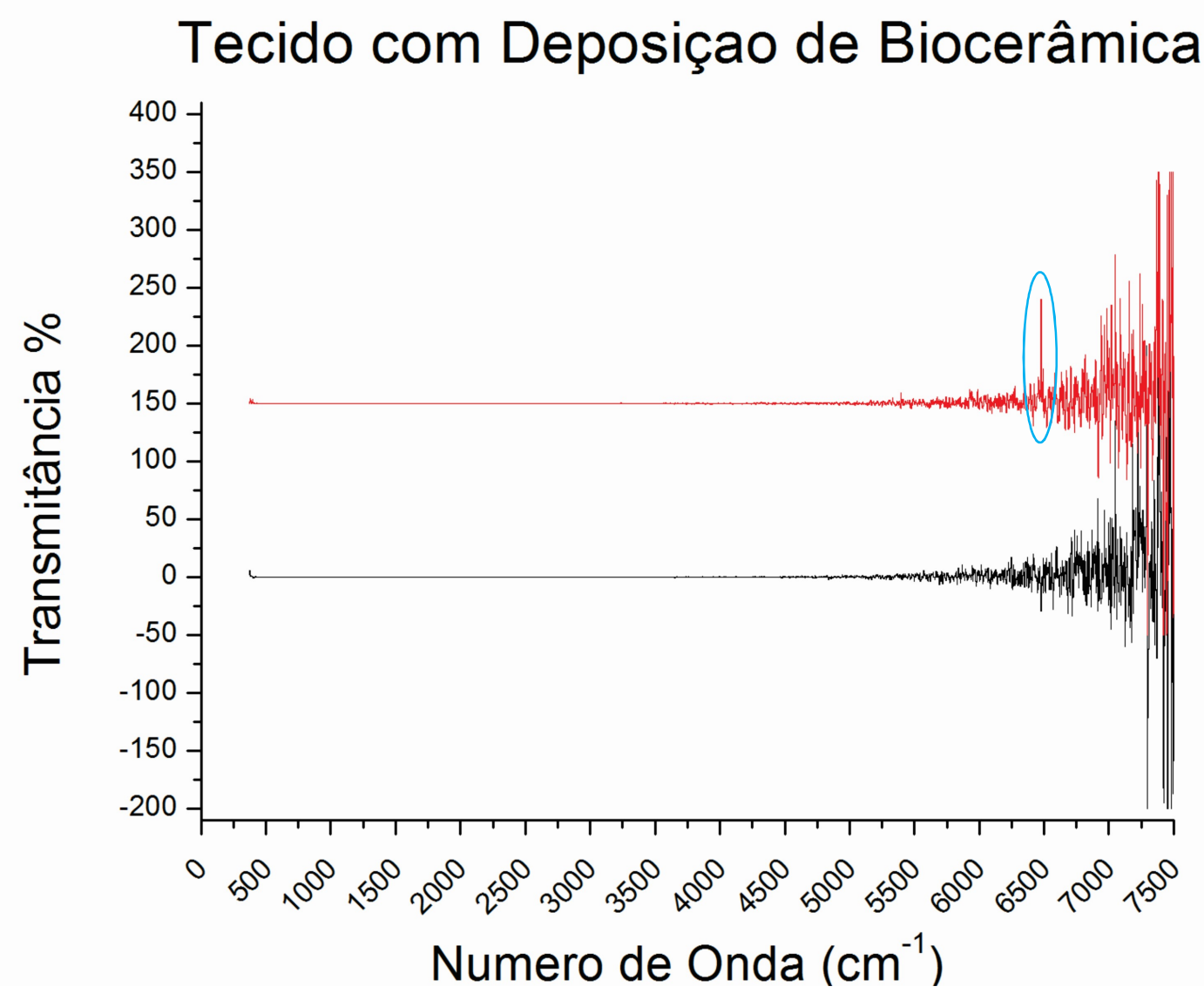

Fonte: Renan Guazzelli Affonso, 2016.

Ao observar o espectro de emissão do tecido com deposição de biocerâmica, apenas um pico significativo, que diferencia a amostra aquecida da sem aquecimento, foi encontrado. O pico de emissão se encontra no número de onda $6476 \mathrm{~cm}^{-1}$. Portando, conclui-se que há emissão do tecido quando aquecido.

A emissividade dos tecidos não é expressa pela altura do pico de emissão encontrado nos espectros das amostras, e sim pela área embaixo da curva deste pico. Para calcular a área embaixo da curva de cada pico de emissão uma curva gaussiana foi ajustada a cada pico de emissão. 
Para o ajuste da cada curva gaussiana foi utilizada a equação 18 , fornecida pelo software OriginPro (o software ajusta a curva gaussiana eutomaticamente a cada pico de emissão).

$$
y=y_{0}+\frac{A}{w \sqrt{\pi / 2}} e^{-2 \frac{\left(x-x_{C}\right)^{2}}{w^{2}}}
$$

Para o cálculo da área embaixo da curva foram utilizados os valores adquiridos pelos parâmetros pré-estabelecidos da curva gaussiana em cada pico. Estes parâmetros são apresentados na figura 41 .

Figura 41. Parâmetros para cálculo da área embaixo da curva gaussiana ajustada a cada pico de emissão do espectro infravermelho.

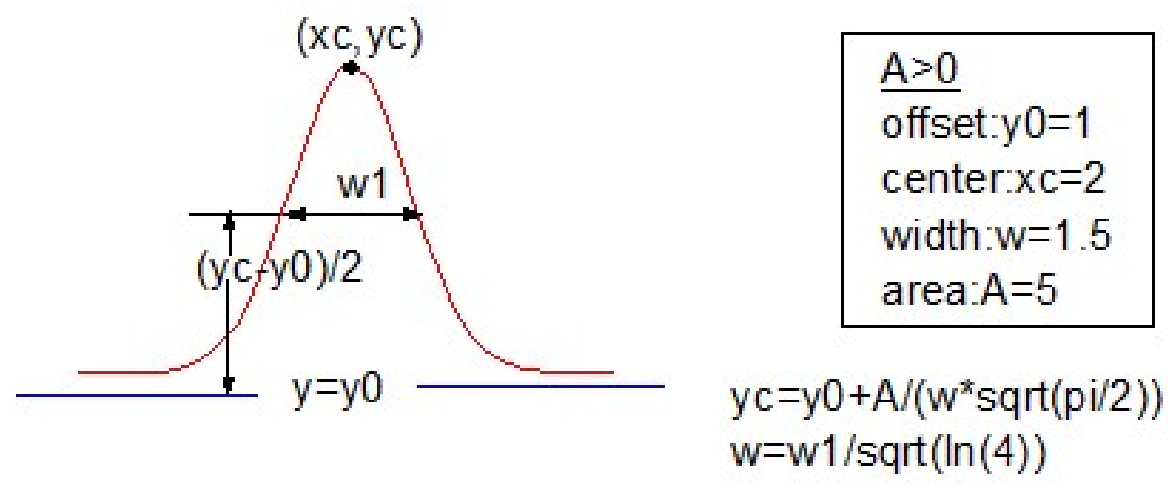

Fonte: Software OriginPro

O ajuste da curva gaussiana para o primeiro pico de emissão do tecido com biocerâmica incorporada à matriz polimérica do fio é apresentado na figura 42. 
Figura 42. Curva Gaussiana ajustada ao primeiro pico do espectro de emissão do tecido com biocerâmica incorporada à matriz polimérica do fio, quando aquecido.

\section{Tecido com Biocerâmica Incorporada à Matriz Polimérica do Fio}

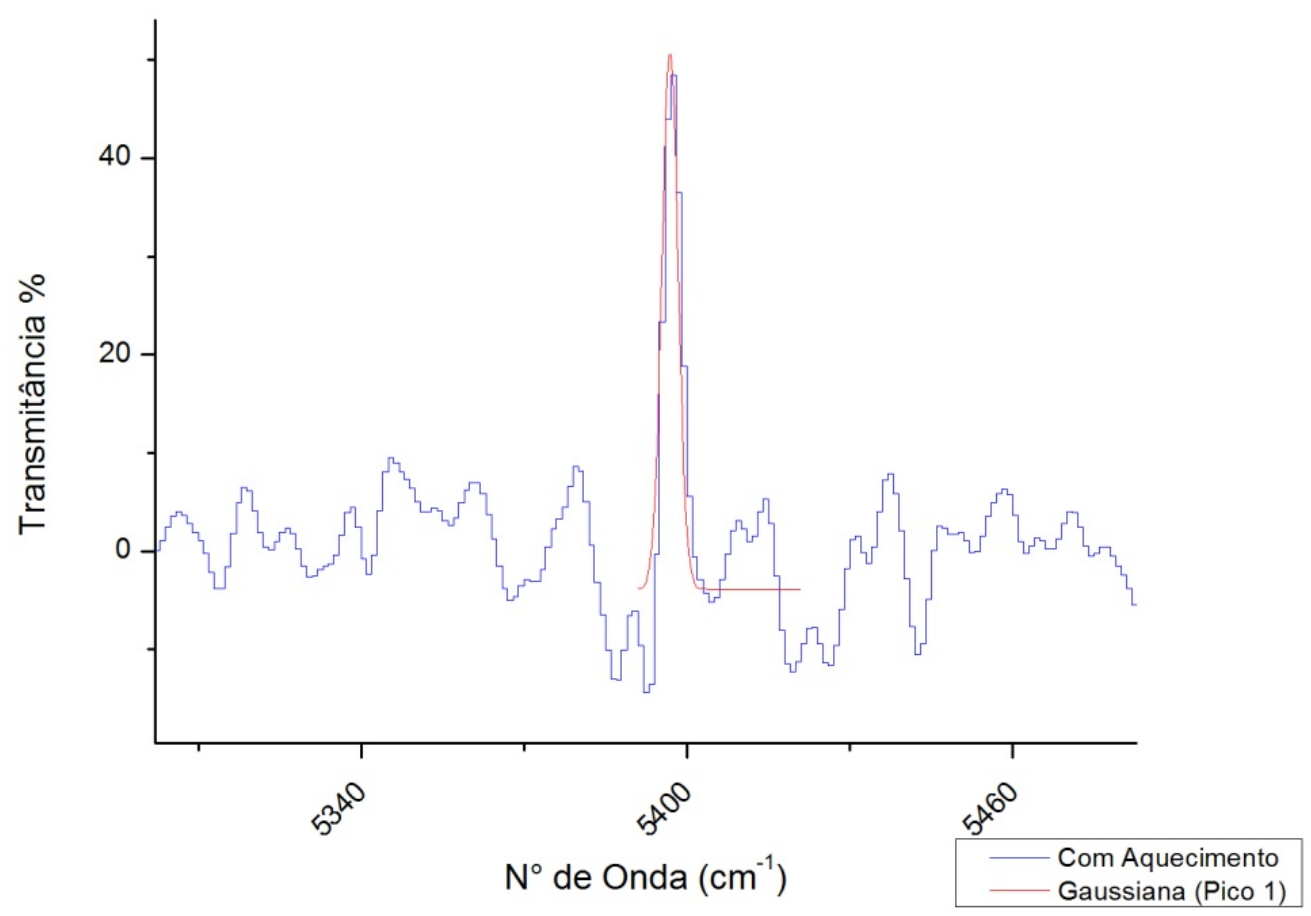

Fonte: Renan Guazzelli Affonso, 2016.

Após o ajuste da curva gaussiana para o primeiro pico de emissão do tecido com biocerâmica incorporada à matriz polimérica do fio, uma tabela contendo os parâmetros calculados com o ajuste da curva gaussiana foi obtida, e é apresentada na tabela 6 . 
Tabela 6. Resultado dos cálculos obtidos através do ajuste da curva gaussiana para o primeiro pico de emissão do tecido com biocerâmica incorporada à matriz polimérica do fio, quando aquecido.

\begin{tabular}{|c|c|c|c|}
\hline Equation & \multicolumn{3}{|c|}{$\mathrm{y}=\mathrm{y} 0+\left(\mathrm{A} /\left(\mathrm{w}^{*} \mathrm{sqrt}(\mathrm{PI} / 2)\right)\right)^{*} \exp \left(-2^{*}((\mathrm{x}-\mathrm{xc}) / \mathrm{w})^{\wedge} 2\right)$} \\
\hline Adj. R-Square & 0,94253 & & \\
\hline & Peak 1 & Value & Standard Error \\
\hline & yo & $-7,70 \mathrm{E}+06$ & $2,47 E+06$ \\
\hline & xc & $5,39 E+09$ & 121529,1937 \\
\hline & w & $3,26 \mathrm{E}+06$ & 311801,485 \\
\hline & A & $2,05 E+14$ & $2,62 E+13$ \\
\hline & sigma & $1,63 E+06$ & \\
\hline & FWHM & $3,84 \mathrm{E}+06$ & \\
\hline & Height & $5,77 E+07$ & \\
\hline
\end{tabular}

Fonte: Software OriginPro

O ajuste da curva gaussiana para o segundo pico de emissão do tecido com biocerâmica incorporada à matriz polimérica do fio é apresentado na figura 43 . 
Figura 43. Curva Gaussiana ajustada ao segundo pico do espectro de emissão do tecido com biocerâmica incorporada à matriz polimérica do fio, quando aquecido.

Tecido com Biocerâmica Incorporada à Matriz Polimérica do Fio

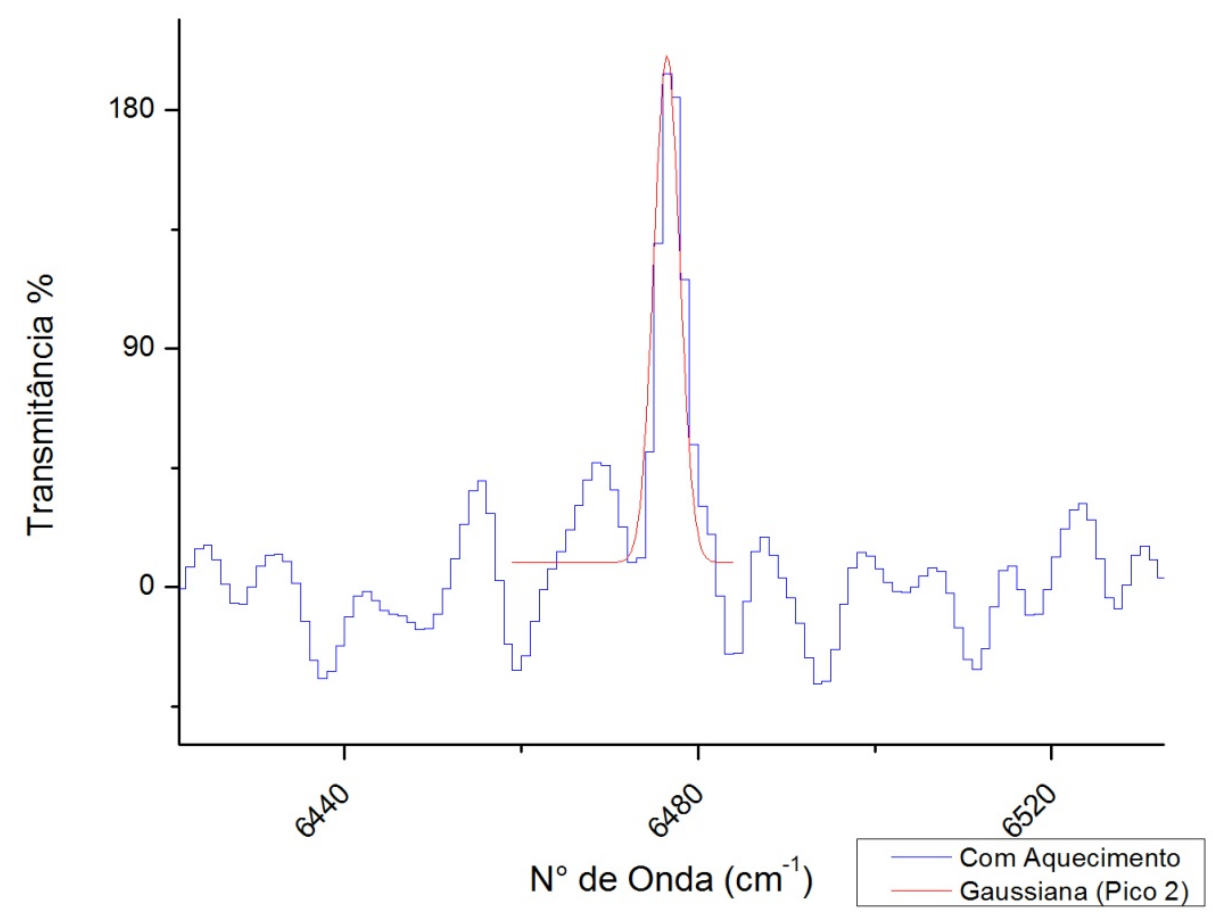

Fonte: Renan Guazzelli Affonso, 2016.

A tabela contendo os parâmetros calculados com o ajuste da curva gaussiana para o segundo pico de emissão do tecido com biocerâmica incorporada à matriz polimérica do fio, quando aquecido, é apresentada na tabela 7. 
Tabela 7. Resultado dos cálculos obtidos através do ajuste da curva gaussiana para o segundo pico de emissão do tecido com biocerâmica incorporada à matriz polimérica do fio, quando aquecido.

\begin{tabular}{|c|c|c|c|}
\hline Equation & \multicolumn{3}{|c|}{$\mathrm{y}=\mathrm{y} 0+\left(\mathrm{A} /\left(\mathrm{w}^{*} \operatorname{sqrt}(\mathrm{PI} / 2)\right)\right)^{*} \exp \left(-2^{*}((\mathrm{x}-\mathrm{xc}) / \mathrm{w})^{\wedge} 2\right)$} \\
\hline Adj. R-Square & 0,96938 & & \\
\hline & Peak 2 & Value & Standard Error \\
\hline & yo & $1,49 \mathrm{E}+08$ & $6,73 E+06$ \\
\hline & xc & $6,47 E+09$ & 87104,29125 \\
\hline & w & $3,16 E+06$ & 229348,5555 \\
\hline & A & $7,00 \mathrm{E}+14$ & $6,76 \mathrm{E}+13$ \\
\hline & sigma & $1,58 \mathrm{E}+06$ & \\
\hline & FWHM & $3,72 E+06$ & \\
\hline & Height & $1,98 \mathrm{E}+08$ & \\
\hline
\end{tabular}

Fonte: Software OriginPro

O ajuste da curva gaussiana para o terceiro pico de emissão do tecido com biocerâmica incorporada à matriz polimérica do fio é apresentado na figura 44 . 
Figura 44. Curva Gaussiana ajustada ao terceiro pico do espectro de emissão do tecido com biocerâmica incorporada à matriz polimérica do fio, quando aquecido.

Tecido com Biocerâmica Incorporada à Matriz Polimérica do Fio

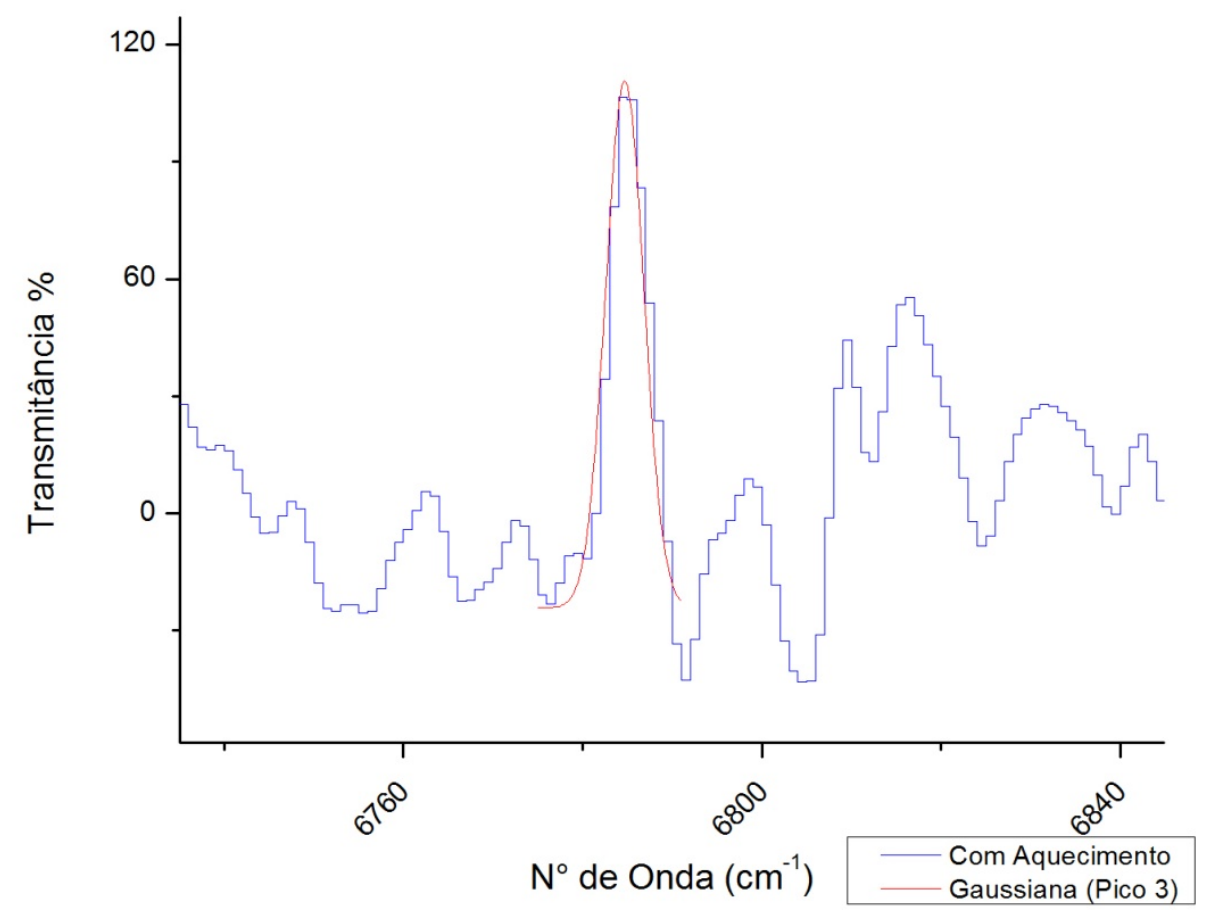

Fonte: Renan Guazzelli Affonso, 2016.

A tabela contendo os parâmetros calculados com o ajuste da curva gaussiana para o terceiro pico de emissão do tecido com biocerâmica incorporada à matriz polimérica do fio, quando aquecido, é apresentada na tabela 8. 
Tabela 8. Resultado dos cálculos obtidos através do ajuste da curva gaussiana para o terceiro pico de emissão do tecido com biocerâmica incorporada à matriz polimérica do fio, quando aquecido.

\begin{tabular}{|c|c|c|c|}
\hline Equation & \multicolumn{3}{|c|}{$\mathrm{y}=\mathrm{y} 0+\left(\mathrm{A} /\left(\mathrm{w}^{*} \operatorname{sqrt}(\mathrm{PI} / 2)\right)\right)^{*} \exp \left(-2^{*}((\mathrm{x}-\mathrm{xc}) / \mathrm{w})^{\wedge} 2\right)$} \\
\hline Adj. R-Square & 0,96383 & & \\
\hline & Peak 3 & Value & Standard Error \\
\hline & yo & $1,25 \mathrm{E}+08$ & $4,38 \mathrm{E}+06$ \\
\hline & $\mathbf{x c}$ & $6,78 \mathrm{E}+09$ & 109459,8329 \\
\hline & w & $4,28 \mathrm{E}+06$ & 291777,1266 \\
\hline & A & $7,19 E+14$ & $5,91 \mathrm{E}+13$ \\
\hline & sigma & $2,14 \mathrm{E}+06$ & \\
\hline & FWHM & $5,04 \mathrm{E}+06$ & \\
\hline & Height & $1,35 E+08$ & \\
\hline
\end{tabular}

Fonte: Software OriginPro

O ajuste da curva gaussiana para o primeiro pico de emissão do tecido com biocerâmica impregnada é apresentado na figura 45. 
Figura 45. Curva Gaussiana ajustada ao primeiro pico do espectro de emissão do tecido com biocerâmica impregnada, quando aquecido.

\section{Tecido com Biocerâmica Impregnada}

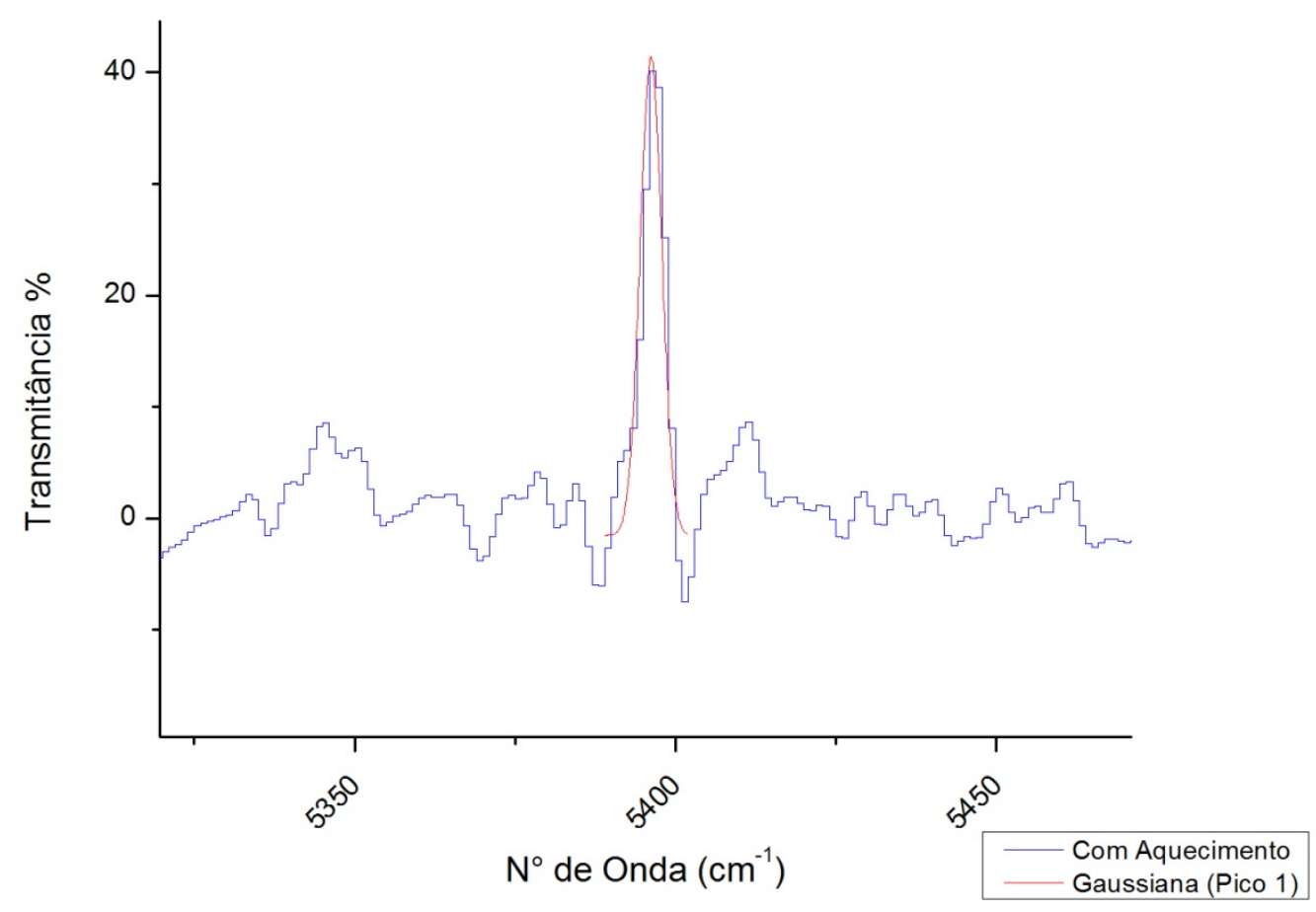

Fonte: Renan Guazzelli Affonso, 2016.

Após o ajuste da curva gaussiana para o primeiro pico de emissão do tecido com biocerâmica impregnada, uma tabela contendo os parâmetros calculados com o ajuste da curva gaussiana foi obtida, sendo apresentada na tabela 9 . 
Tabela 9. Resultado dos cálculos obtidos através do ajuste da curva gaussiana para o primeiro pico de emissão do tecido com biocerâmica impregnada, quando aquecido.

\begin{tabular}{|c|c|c|c|}
\hline Equation & \multicolumn{3}{|c|}{$y=y 0+\left(A /\left(w^{*} \operatorname{sqrt}(P I / 2)\right)\right)^{*} \exp \left(-2^{*}((x-x c) / w)^{\wedge} 2\right)$} \\
\hline Adj. R-Square & 0,92171 & & \\
\hline & Peak 1 & Value & Standard Error \\
\hline & yo & $1,48 \mathrm{E}+08$ & $2,00 E+06$ \\
\hline & xc & $5,39 E+09$ & 145193,1152 \\
\hline & w & $3,39 E+06$ & 363954,755 \\
\hline & A & $1,81 \mathrm{E}+14$ & $2,25 E+13$ \\
\hline & sigma & $1,70 E+06$ & \\
\hline & FWHM & $4,00 E+06$ & \\
\hline & Height & $4,30 E+07$ & \\
\hline
\end{tabular}

Fonte: Software OriginPro

O ajuste da curva gaussiana para o segundo pico de emissão do tecido com biocerâmica impregnada é apresentado na figura 46. 
Figura 46. Curva Gaussiana ajustada ao segundo pico do espectro de emissão do tecido com biocerâmica impregnada, quando aquecido.

\section{Tecido com Biocerâmica Impregnada}

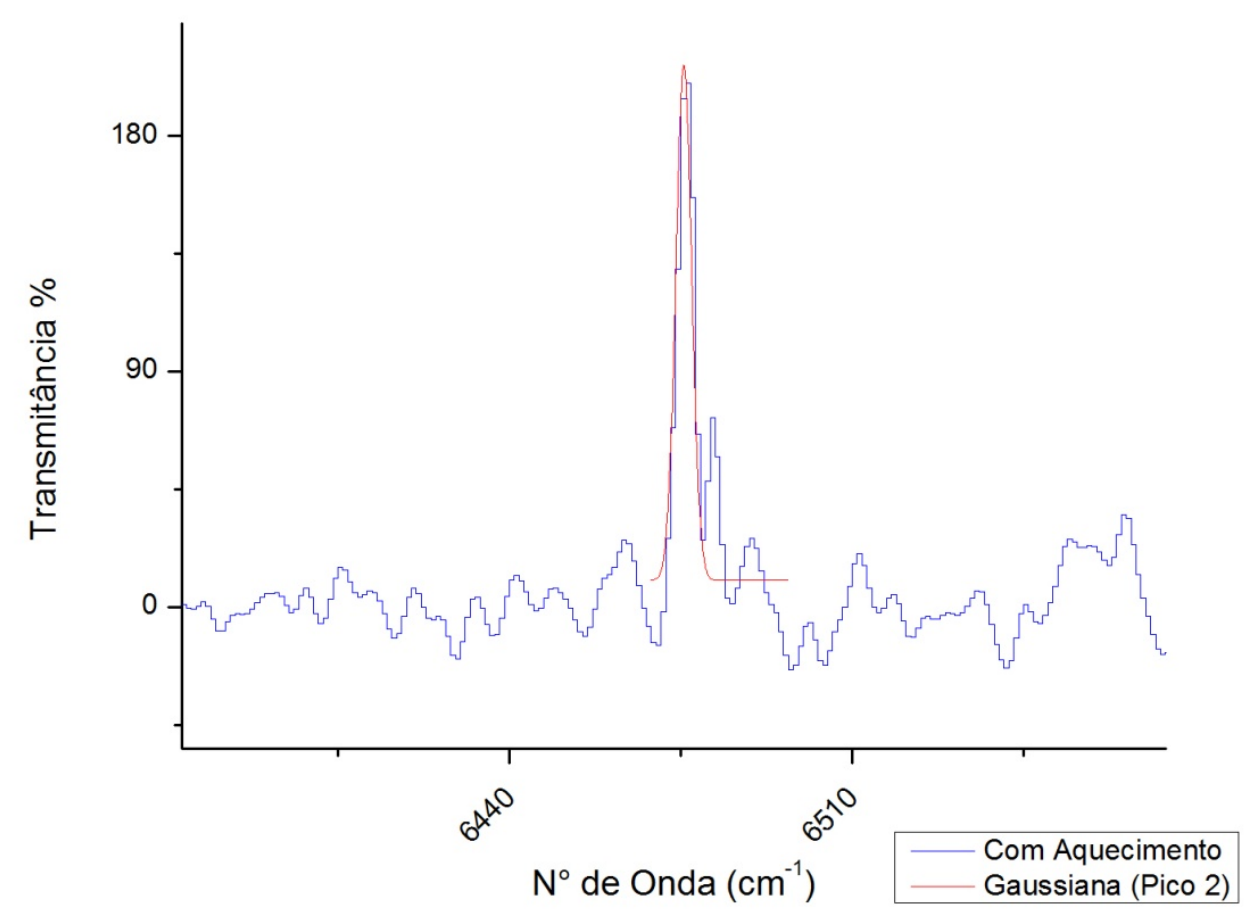

Fonte: Renan Guazzelli Affonso, 2016.

A tabela contendo os parâmetros calculados com o ajuste da curva gaussiana para o segundo pico de emissão do tecido com biocerâmica impregnada, quando aquecido, é apresentada na tabela 10 . 
Tabela 10. Resultado dos cálculos obtidos através do ajuste da curva gaussiana para o segundo pico de emissão do tecido com biocerâmica impregnada, quando aquecido.

\begin{tabular}{|c|c|c|c|}
\hline Equation & \multicolumn{3}{|c|}{$\mathrm{y}=\mathrm{y} 0+\left(\mathrm{A} /\left(\mathrm{w}^{*} \operatorname{sqrt}(\mathrm{PI} / 2)\right)\right)^{*} \exp \left(-2^{*}((\mathrm{x}-\mathrm{xc}) / \mathrm{w})^{\wedge} 2\right)$} \\
\hline Adj. R-Square & 0,86799 & & \\
\hline & Peak 2 & Value & Standard Error \\
\hline & yo & $1,72 \mathrm{E}+08$ & $8,83 E+06$ \\
\hline & $\mathbf{x c}$ & $6,47 E+09$ & 171626,9498 \\
\hline & w & $2,99 \mathrm{E}+06$ & 395740,1339 \\
\hline & A & $8,05 E+14$ & $9,96 \mathrm{E}+13$ \\
\hline & sigma & $1,50 E+06$ & \\
\hline & FWHM & $3,52 E+06$ & \\
\hline & Height & $1,90 \mathrm{E}+08$ & \\
\hline
\end{tabular}

Fonte: Software OriginPro

O ajuste da curva gaussiana para o pico de emissão do tecido com deposição de biocerâmica é apresentado na figura 47. 
Figura 47. Curva Gaussiana ajustada ao pico do espectro de emissão do tecido com deposição de biocerâmica, quando aquecido.

\section{Tecido com Deposiçao de Biocerâmica}

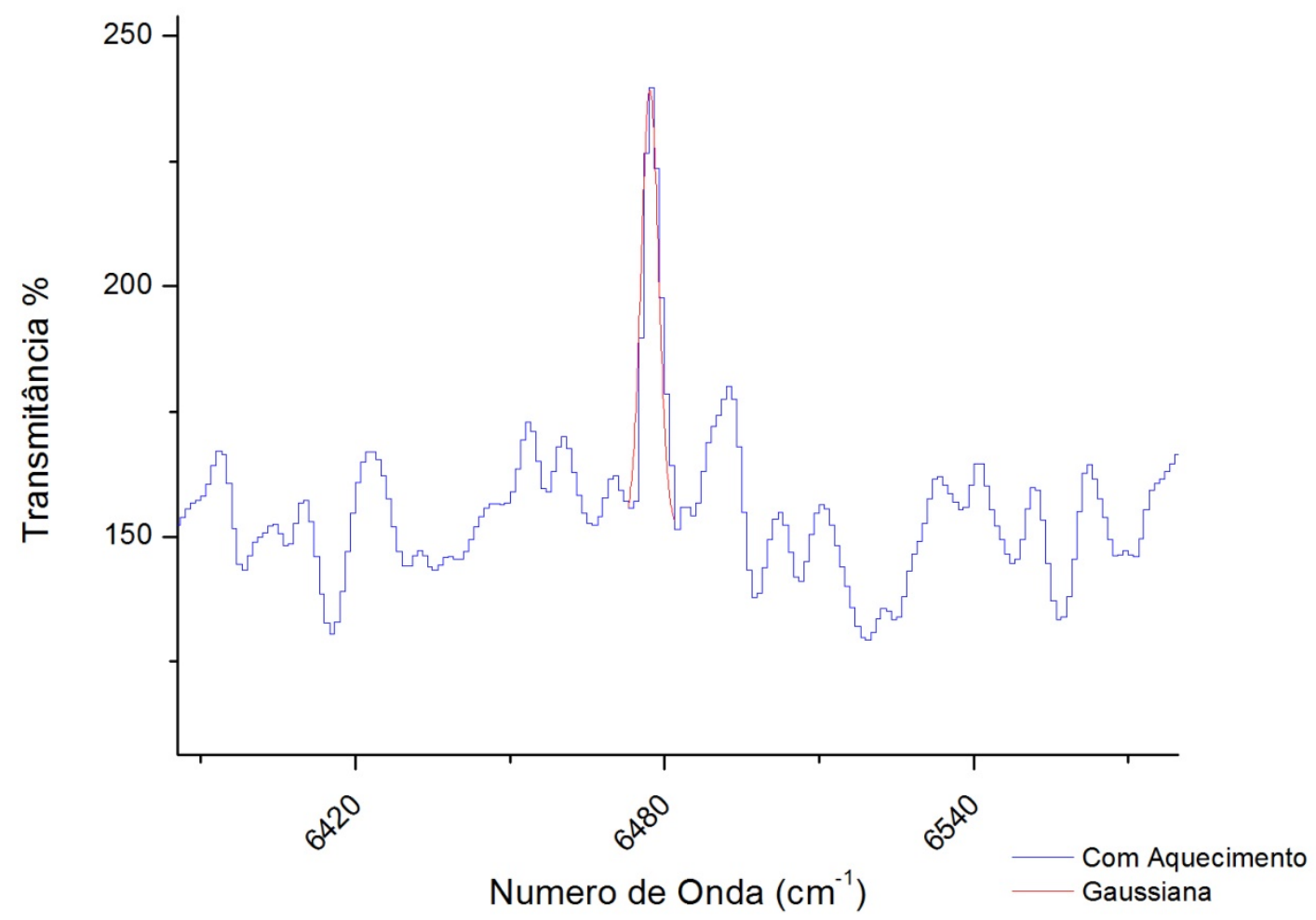

Fonte: Renan Guazzelli Affonso, 2016.

A tabela contendo os parâmetros calculados com o ajuste da curva gaussiana para o pico de emissão do tecido com deposição de biocerâmica, quando aquecido, é apresentada na tabela 11 . 
Tabela 11. Resultado dos cálculos obtidos através do ajuste da curva gaussiana para o pico de emissão do tecido com deposição de biocerâmica, quando aquecido.

\begin{tabular}{|c|c|c|c|}
\hline Equation & \multicolumn{3}{|c|}{$\mathrm{y}=\mathrm{y} 0+\left(\mathrm{A} /\left(\mathrm{w}^{*} \operatorname{sqrt}(\mathrm{PI} / 2)\right)\right)^{*} \exp \left(-2^{*}((\mathrm{x}-\mathrm{xc}) / \mathrm{w})^{\wedge} 2\right)$} \\
\hline Adj. R-Square & 0,97227 & & \\
\hline & Peak 1 & Value & Standard Error \\
\hline & yo & $4,12 E+06$ & $2,46 E+06$ \\
\hline & $\mathbf{x c}$ & $6,47 E+09$ & 83201,20803 \\
\hline & w & $3,23 E+06$ & 209381,4145 \\
\hline & A & $3,47 E+14$ & $2,60 \mathrm{E}+13$ \\
\hline & sigma & $1,62 E+06$ & \\
\hline & FWHM & $3,81 E+06$ & \\
\hline & Height & $8,57 E+07$ & \\
\hline
\end{tabular}

Fonte: Software OriginPro

Para uma melhor visualização dos valores de áreas obtidos com o ajuste das curvas gaussianas para cada pico de emissão dos tecidos, quando aquecidos, foi feito um gráfico apenas com o número de onda versus a contagem de área de cada, expresso na figura 48 . O eixo y do gráfico é expresso em unidades de área (área embaixo da curva de cada pico de emissão), pois a intenção é analisar o gráfico qualitativamente. Quanto maior a contagem de área, maior a emissão por parte do tecido. 
Figura 48. Contagem de área de cada pico para os diferentes tipos de tecido, quando aquecido.

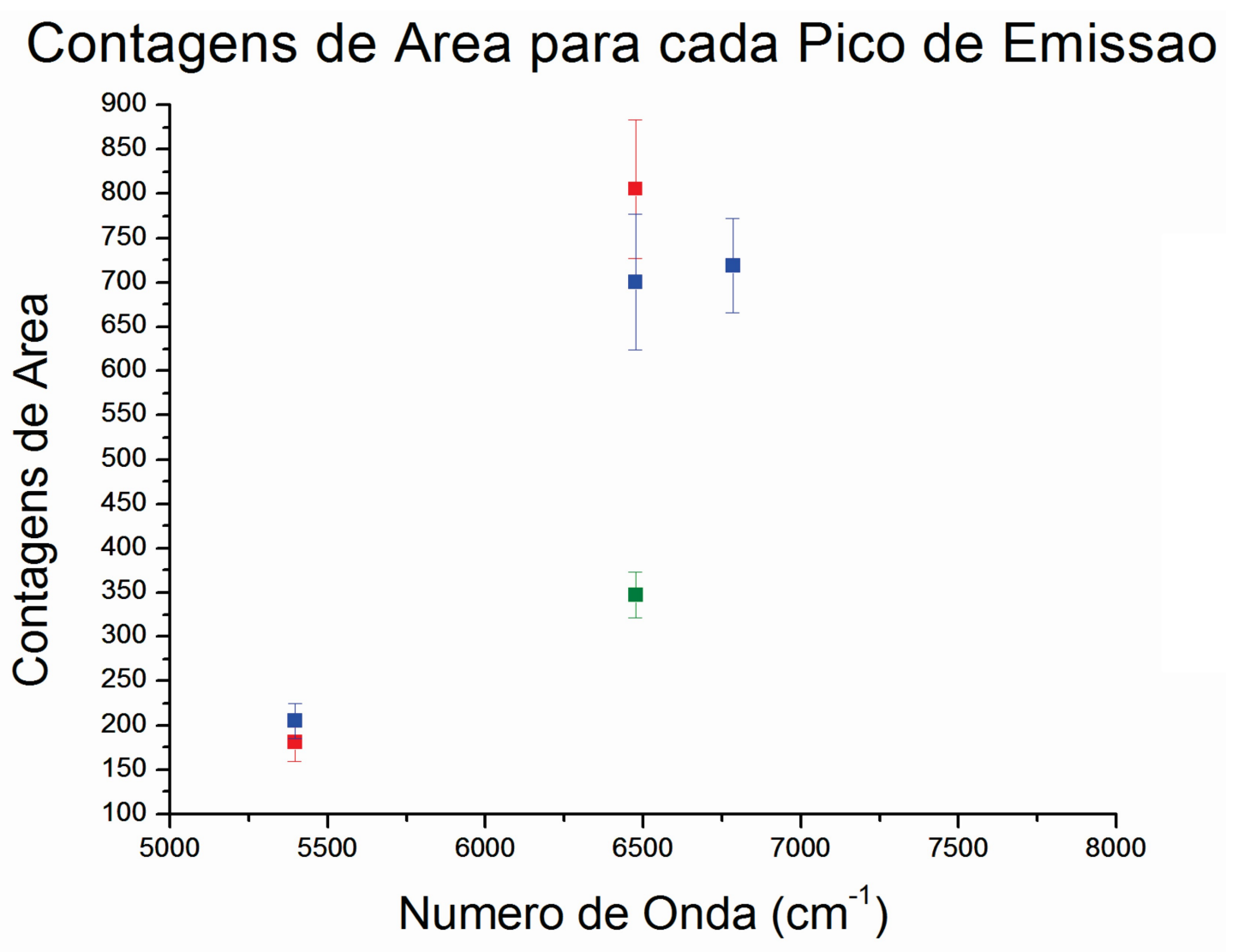

- Tecido com Biocerâmica Incorporada à Matriz Polimérica do Fio

Tecido Impregnado com Biocerâmica

Tecido com Deposição de Biocerâmica

Fonte: Renan Guazzelli Affonso, 2016.

De modo a esclarecer em que faixa de comprimento de onda encontram-se as emissões dos tecidos os dados de contagens de área foram dispostos na tabela 12, contendo a faixa de número de onda das emissões e seu respectivo comprimento de onda. 
Tabela 12. Comparativo de contagens de área para cada pico de emissão dos diferentes tecidos em função com número de onda e comprimento de onda.

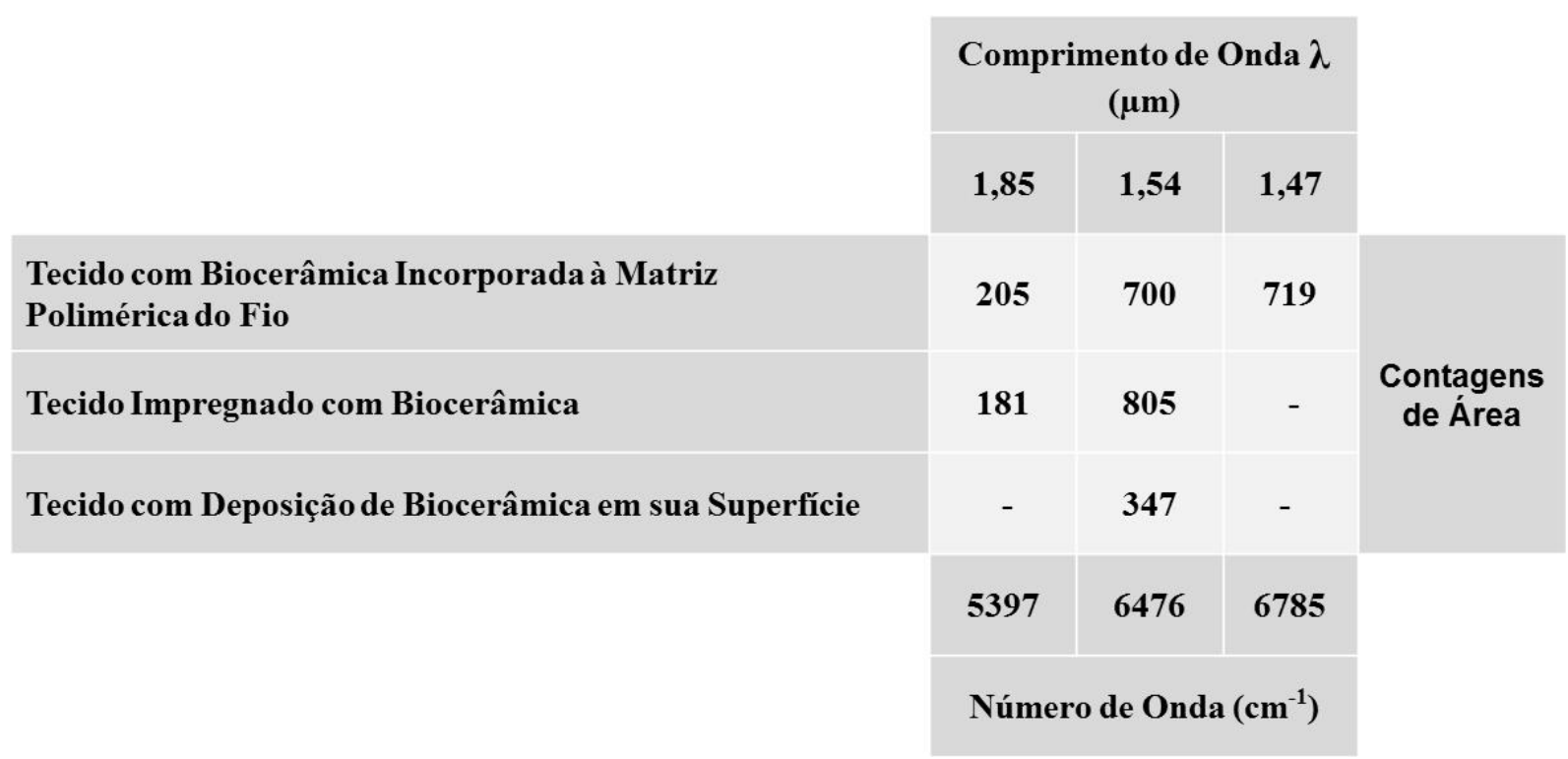

Fonte: Renan Guazzelli Affonso, 2016.

Como pode-se observar na tabela 12, o tecido com mais emissões é o com biocerâmica incorporada à matriz polimérica do fio, seguido pelo tecido impregnado com biocerâmica e por fim o tecido com deposição de biocerâmica.

Ao analisar as emissões em função do comprimento de onda onde elas ocorrem, podese notar que todas acontecem na faixa de $1,47 \mu \mathrm{m}$ a $1,85 \mu \mathrm{m}$. Esta faixa de comprimento de onda encontrada está dentro da região de raios infravermelhos médios (mais próximos da região de infravermelhos próximos), e não de raios infravermelhos longos, como foi encontrado na maior parte das bibliografias analisadas para o desenvolvimento deste estudo. 


\subsection{Resultados da Fluorescência de Raios X}

De modo a verificar os elementos que compõem os tecidos e a fim de justificar a diferença da emissão de raios infravermelhos entre os mesmos, os tecidos foram analisados pela técnica de XRF (Fluorescência de Raios X).

Cada teste foi realizado em dois pontos diferentes de cada amostra. Os resultados obtidos nos testes (repetidos) foram iguais, garantindo a reprodutibilidade do ensaio.

Nesta análise foram utilizados os diferentes tecidos contendo biocerâmica, objetos deste estudo, com o objetivo de identificar os elementos químicos presentes bem como suas semelhanças e/ou diferenças. Um espectro de FRX (gráfico de contagens de raios X emitidos pelo material analisado por energia dos raios X) permite identificar os elementos químicos presentes na amostra analisada e a quantidade deste elemento é determinada pela área embaixo da curva do pico do elemento identificado, que é proporcional à sua concentração presente no pigmento. $\mathrm{O}$ elemento $\mathrm{K}$ (potássio) pode estar presente nas amostras, mas em pouca quantidade o que dificulta sua caracterização.

Para a realização dos testes os parâmetros utilizados no sistema de fluorescência de raios $\mathrm{X}$ foram: tensão de $30 \mathrm{KV}$, corrente de $50 \mu \mathrm{A}$ e tempo ajustado de 250 segundos.

O espectro obtido após o ensaio de fluorescência de raios $\mathrm{X}$ da amostra do tecido com biocerâmica incorporada à matriz polimérica do fio é apresentado na figura 49 . 
Figura 49. Gráfico de contagens de raios $\mathrm{X}$ emitidos pelo tecido com biocerâmica incorporada à matriz polimérica do fio.

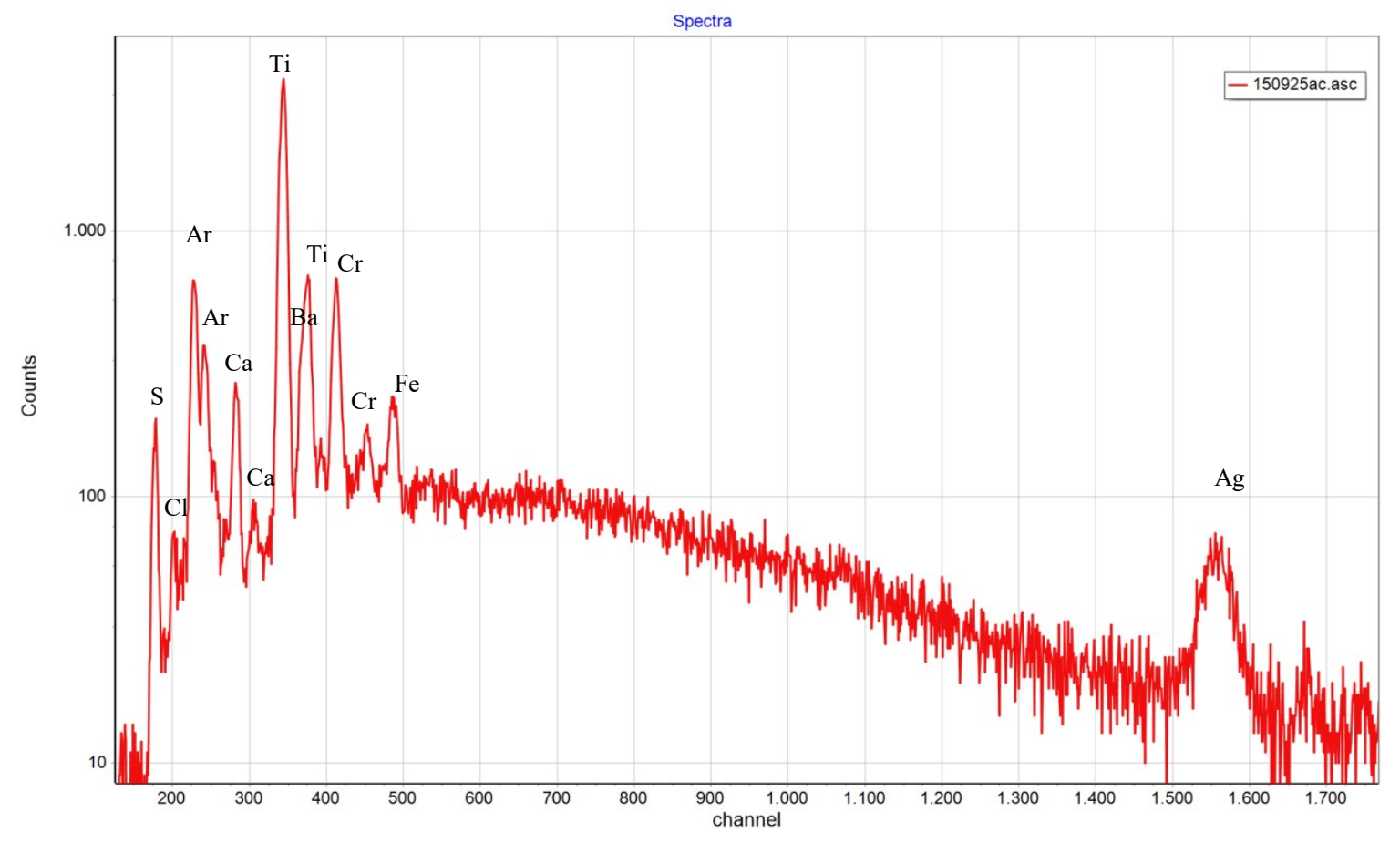

Fonte: Sistema FRX

Os elementos identificados na amostra do tecido com biocerâmica incorporada à matriz polimérica do fio são: $\mathrm{S}, \mathrm{Cl}, \mathrm{Ca}, \mathrm{Ti}, \mathrm{Cr}, \mathrm{Fe}$ e $\mathrm{Ba}$. Os elementos $\mathrm{Ar}$ e $\mathrm{Ag}$ são elementos do arranjo experimental e não da amostra analisada.

Os nomes dos elementos químicos encontrados nas amostras nos ensaios de fluorescência de raios X são apresentados na tabela 13. 
Tabela 13. Nomes dos elementos químicos encontrados nas medições com o sistema FRX.

\begin{tabular}{|c|c|}
\hline \multicolumn{2}{|c|}{ Nome dos elementos químicos } \\
\hline $\mathrm{Si}$ & Silício \\
\hline $\mathrm{S}$ & Enxofre \\
\hline $\mathrm{Cl}$ & Cloro \\
\hline $\mathrm{Ca}$ & Cálcio \\
\hline $\mathrm{Ti}$ & Titânio \\
\hline $\mathrm{Cr}$ & Cromo \\
\hline $\mathrm{Fe}$ & Ferro \\
\hline $\mathrm{Zn}$ & Zinco \\
\hline $\mathrm{Sr}$ & Estrôncio \\
\hline $\mathrm{Zr}$ & Zircônio \\
\hline
\end{tabular}

\begin{tabular}{|c|c|}
\hline Ar & Argônio do ar \\
\hline $\mathbf{A g}$ & Prata do tubo de RX \\
\hline
\end{tabular}

Fonte: Renan Guazzelli Affonso, 2016.

A tabela 14 apresenta as áreas obtidas no espectro apresentado na figura 49.

Tabela 14. Áreas relativas a cada elemento encontrado no espectro da amostra de tecido com biocerâmica incorporada à matriz polimérica do fio.

\begin{tabular}{|c|c|c|c|c|}
\hline \multicolumn{5}{|c|}{ Tecido com Biocerâmica Incorporada à Matriz } \\
Polimérica do Fio \\
\hline Elemento & Z & Energia & Area & incA \\
\hline $\mathrm{Si}$ & 14 & 1,74 & 0 & 0 \\
\hline $\mathrm{S}$ & 16 & 2,307 & 1183 & 36 \\
\hline $\mathrm{Cl}$ & 17 & 2,622 & 351 & 31 \\
\hline $\mathrm{Ca}$ & 20 & 3,691 & 1309 & 58 \\
\hline $\mathrm{Ti}$ & 22 & 4,509 & 33198 & 201 \\
\hline $\mathrm{Cr}$ & 24 & 5,412 & 5628 & 94 \\
\hline $\mathrm{Fe}$ & 26 & 6,399 & 1713 & 73 \\
\hline $\mathrm{Zn}$ & 30 & 8,631 & 0 & 0 \\
\hline $\mathrm{Sr}$ & 38 & 14,142 & 0 & 0 \\
\hline $\mathrm{Zr}$ & 40 & 15,746 & 0 & 0 \\
\hline $\mathrm{Ba}$ & 56 & 4,464 & 1623 & 94 \\
\hline
\end{tabular}

Fonte: Sistema FRX 
O espectro obtido após o ensaio de fluorescência de raios $\mathrm{X}$ da amostra do tecido com biocerâmica impregnada é apresentado na figura 50 .

Figura 50. Gráfico de contagens de raios X emitidos pelo tecido com biocerâmica impregnada.

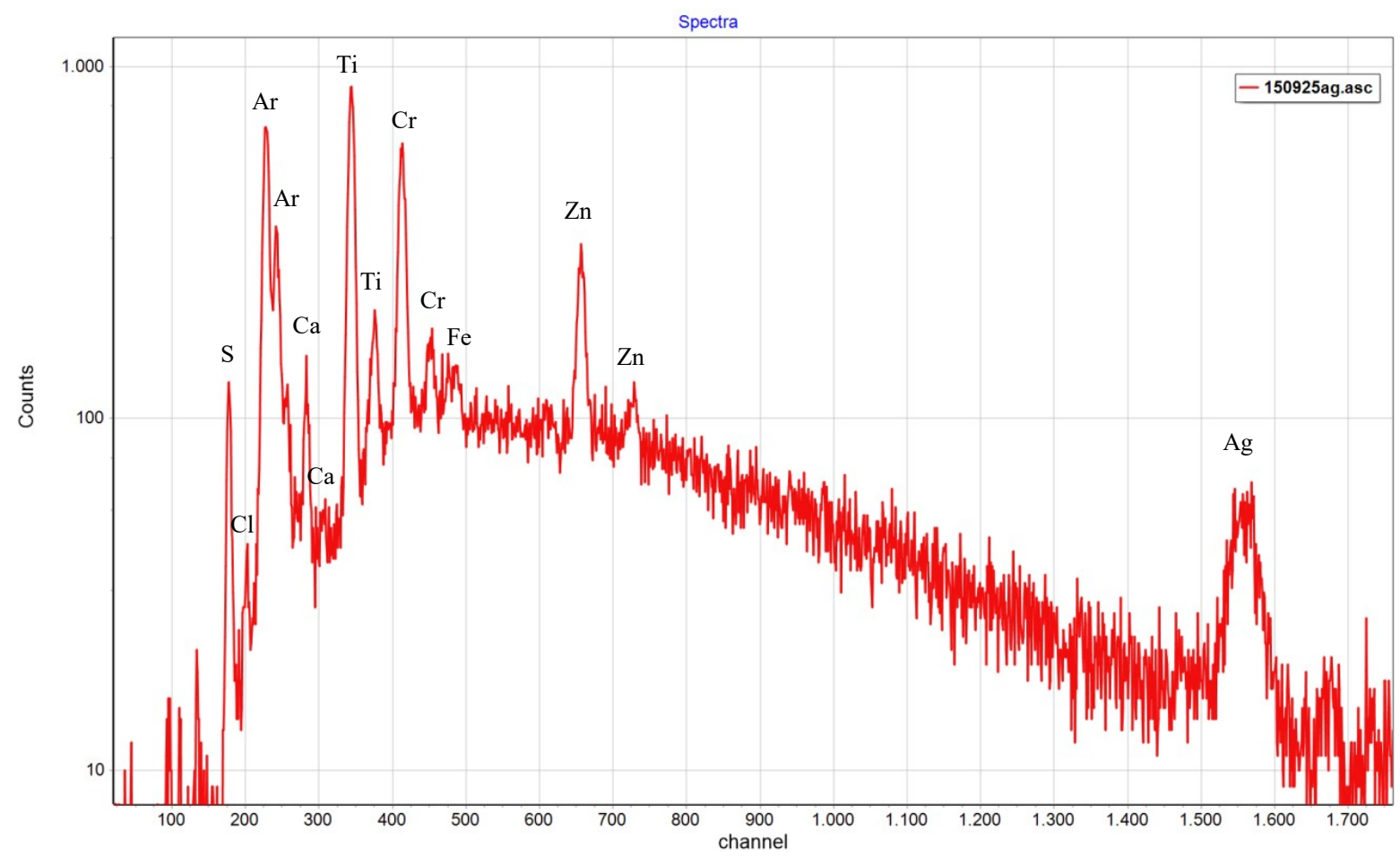

Fonte: Sistema FRX

Os elementos identificados na amostra do tecido com biocerâmica impregnada são: S, Cl, Ca, Ti, Cr, Fe e Zn. Os elementos Ar e Ag são elementos do arranjo experimental e não da amostra analisada.

A tabela 15 apresenta as áreas obtidas no espectro apresentado na figura 50. 
Tabela 15. Áreas relativas a cada elemento encontrado no espectro da amostra de tecido com biocerâmica impregnada.

\begin{tabular}{|c|c|c|c|c|}
\hline \multicolumn{5}{|c|}{ Tecido com Biocerâmica Impregnada } \\
\hline Elemento & Z & Energia & A & incA \\
\hline $\mathrm{Si}$ & 14 & 1,74 & 79 & 15 \\
\hline $\mathrm{S}$ & 16 & 2,307 & 759 & 30 \\
\hline $\mathrm{Cl}$ & 17 & 2,622 & 169 & 26 \\
\hline $\mathrm{Ca}$ & 20 & 3,691 & 236 & 45 \\
\hline $\mathrm{Ti}$ & 22 & 4,509 & 8071 & 96 \\
\hline $\mathrm{Cr}$ & 24 & 5,412 & 5841 & 92 \\
\hline $\mathrm{Fe}$ & 26 & 6,399 & 722 & 64 \\
\hline $\mathrm{Zn}$ & 30 & 8,631 & 2834 & 113 \\
\hline $\mathrm{Sr}$ & 38 & 14,142 & 0 & 0 \\
\hline $\mathrm{Zr}$ & 40 & 15,746 & 0 & 0 \\
\hline $\mathrm{Ba}$ & 56 & 4,464 & 0 & 0 \\
\hline
\end{tabular}

Fonte: Sistema FRX

Nota-se que diferentemente da amostra de tecido com biocerâmica incorporada à matriz polimérica do fio, esta apresenta Si, porém não apresenta $\mathrm{Ba}$.

$\mathrm{O}$ espectro obtido após o ensaio de fluorescência de raios $\mathrm{X}$ da amostra do tecido com deposição de biocerâmica é apresentado na figura 51 . 
Figura 51. Gráfico de contagens de raios X emitidos pelo tecido com deposição de biocerâmica.

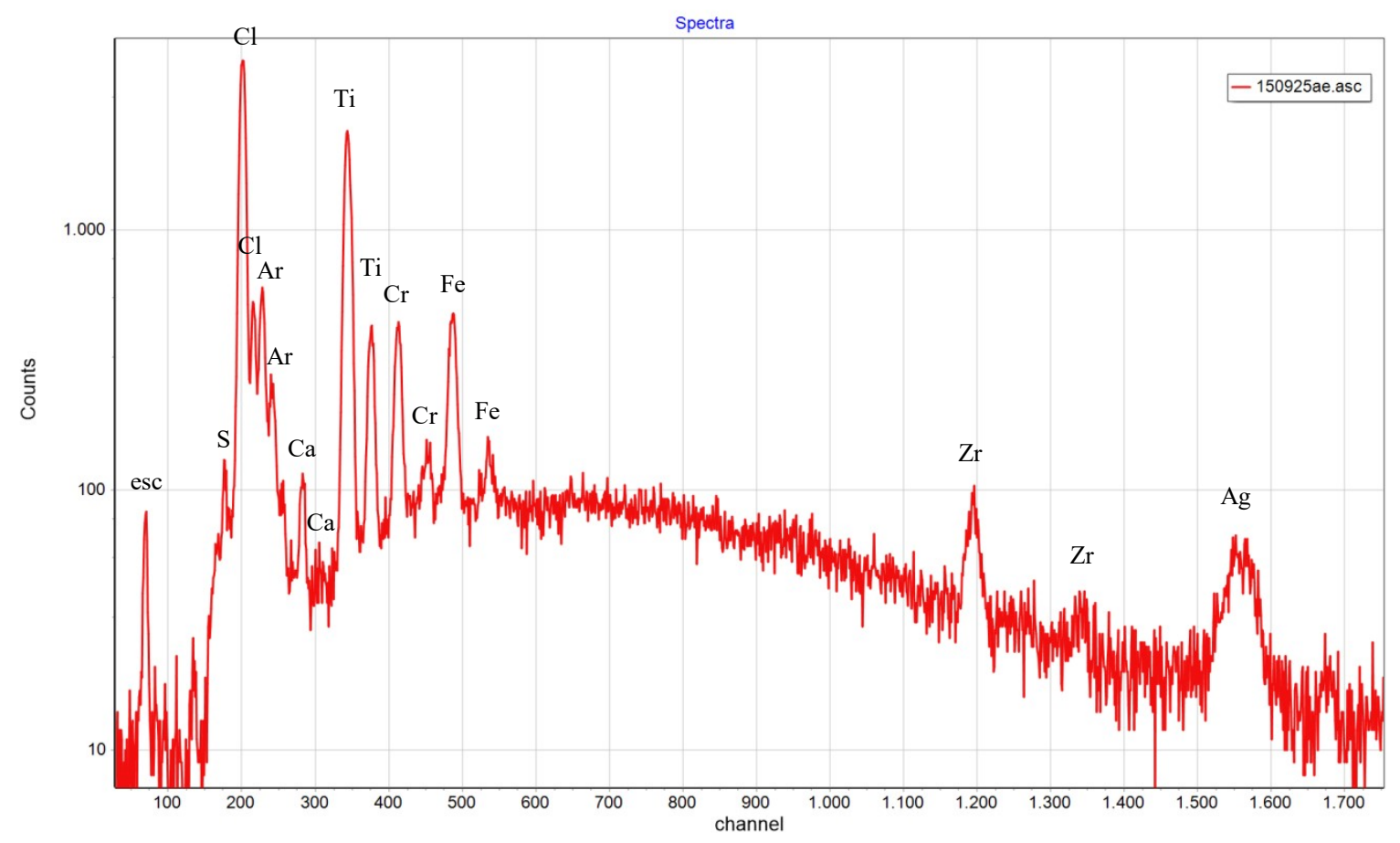

Fonte: Sistema FRX

Os elementos identificados na amostra do tecido com deposição de biocerâmica são: $\mathrm{S}, \mathrm{Cl}, \mathrm{Ca}, \mathrm{Ti}, \mathrm{Cr}, \mathrm{Fe}$ e Zr. Os elementos Ar e Ag são elementos do arranjo experimental e não da amostra analisada.

A tabela 16 apresenta as áreas obtidas no espectro apresentado na figura 51. 
Tabela 16. Áreas relativas a cada elemento encontrado no espectro da amostra de tecido com deposição de biocerâmica.

\begin{tabular}{|c|c|c|c|c|}
\hline \multicolumn{5}{|c|}{ Tecido com Deposição de Biocerâmica } \\
\hline Elemento & Z & Energia & A & incA \\
\hline $\mathrm{Si}$ & 14 & 1,74 & 0 & 0 \\
\hline $\mathrm{S}$ & 16 & 2,307 & 886 & 38 \\
\hline $\mathrm{Cl}$ & 17 & 2,622 & 31325 & 167 \\
\hline $\mathrm{Ca}$ & 20 & 3,691 & 259 & 43 \\
\hline $\mathrm{Ti}$ & 22 & 4,509 & 22179 & 145 \\
\hline $\mathrm{Cr}$ & 24 & 5,412 & 4026 & 79 \\
\hline $\mathrm{Fe}$ & 26 & 6,399 & 4773 & 87 \\
\hline $\mathrm{Zn}$ & 30 & 8,631 & 0 & 0 \\
\hline $\mathrm{Sr}$ & 38 & 14,142 & 0 & 0 \\
\hline $\mathrm{Zr}$ & 40 & 15,746 & 1063 & 74 \\
\hline $\mathrm{Ba}$ & 56 & 4,464 & 0 & 0 \\
\hline
\end{tabular}

Fonte: Sistema FRX

Nota-se que diferentemente das outras amostras previamente apresentadas, a amostra do tecido com deposição de biocerâmica apresenta Zr.

$\mathrm{O}$ espectro obtido após o ensaio de fluorescência de raios $\mathrm{X}$ da amostra do tecido sem biocerâmica é apresentado na figura 52. 
Figura 52. Gráfico de contagens de raios X emitidos pelo tecido sem biocerâmica.

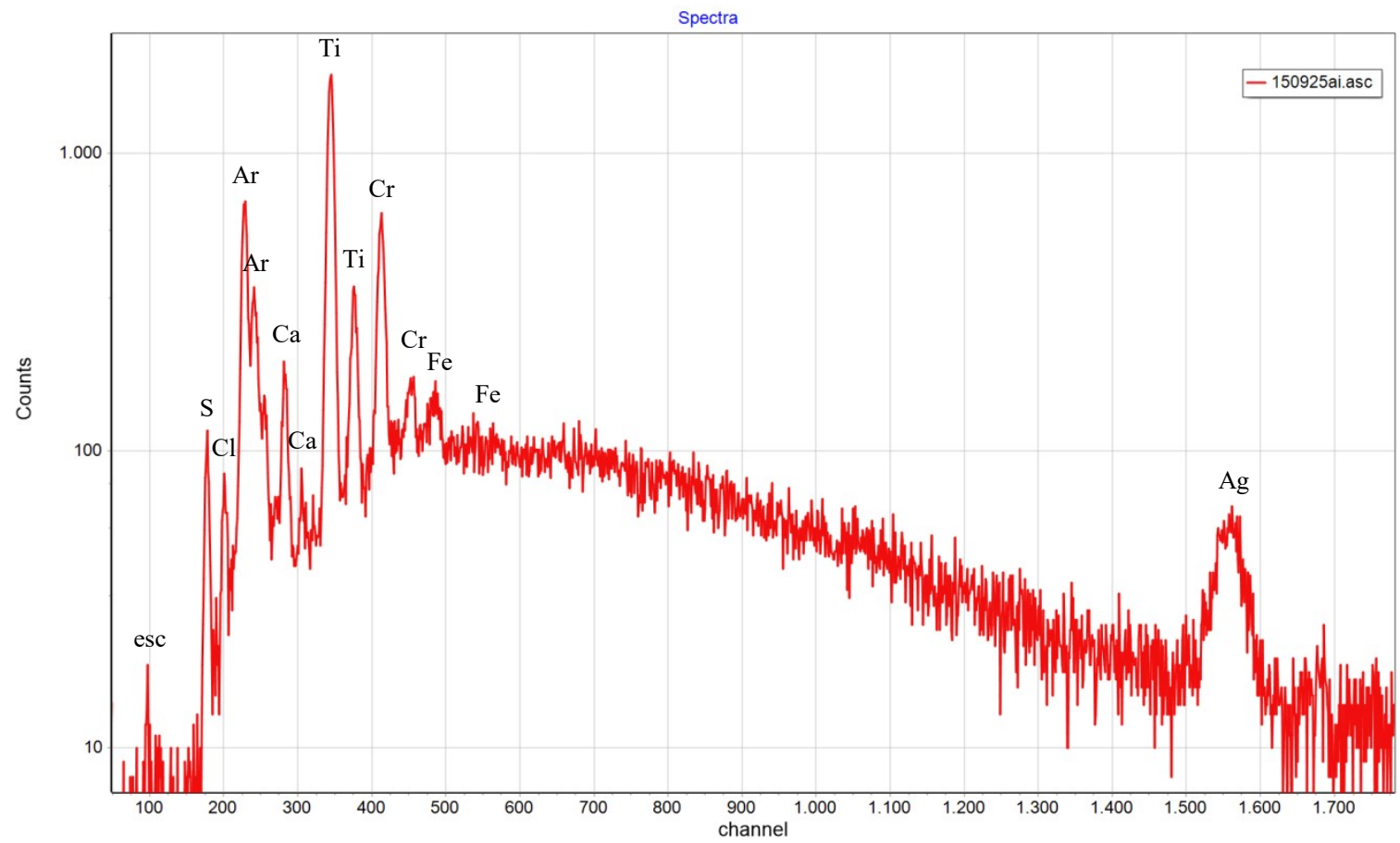

Fonte: Sistema FRX

Os elementos identificados na amostra do tecido com deposição de biocerâmica são: $\mathrm{S}, \mathrm{Cl}, \mathrm{Ca}, \mathrm{Ti}, \mathrm{Cr}$ e Fe. Os elementos Ar e Ag são elementos do arranjo experimental e não da amostra analisada.

A tabela 17 apresenta as áreas obtidas no espectro apresentado na figura 52. 
Tabela 17. Áreas relativas a cada elemento encontrado no espectro da amostra de tecido sem biocerâmica.

\begin{tabular}{|c|c|c|c|c|}
\hline \multicolumn{5}{|c|}{ Tecido sem Biocerâmica } \\
\hline Elemento & Z & Energia & $A$ & incA \\
\hline $\mathrm{Si}$ & 14 & 1,74 & 0 & 0 \\
\hline$S$ & 16 & 2,307 & 639 & 28 \\
\hline $\mathrm{Cl}$ & 17 & 2,622 & 410 & 30 \\
\hline $\mathrm{Ca}$ & 20 & 3,691 & 740 & 50 \\
\hline $\mathrm{Ti}$ & 22 & 4,509 & 16664 & 129 \\
\hline $\mathrm{Cr}$ & 24 & 5,412 & 5595 & 91 \\
\hline $\mathrm{Fe}$ & 26 & 6,399 & 839 & 65 \\
\hline $\mathrm{Zn}$ & 30 & 8,631 & 0 & 0 \\
\hline $\mathrm{Sr}$ & 38 & 14,142 & 0 & 0 \\
\hline $\mathrm{Zr}$ & 40 & 15,746 & 0 & 0 \\
\hline $\mathrm{Ba}$ & 56 & 4,464 & 0 & 0 \\
\hline
\end{tabular}

Fonte: Sistema FRX

Não foi encontrado Zr, Zn, Sr, Si ou Ba, na amostra sem biocerâmica.

As amostras foram novamente testadas, desta vez utilizando um filtro no feixe de raios $\mathrm{X}$ (chapa de alumínio com tungstênio), para baixar o limite de detecção do aparelho. O uso de filtros no sistema de XRF permite evidenciar elementos de baixa concentração que estejam na região de mais alta energia.

A figura 53 apresenta o espectro obtido ao realizar o teste com a amostra com biocerâmica incorporada à matriz polimérica do fio. 
Figura 53. Gráfico de contagens de raios $\mathrm{X}$ emitidos pelo tecido com biocerâmica incorporada à matriz polimérica do fio, com filtro.

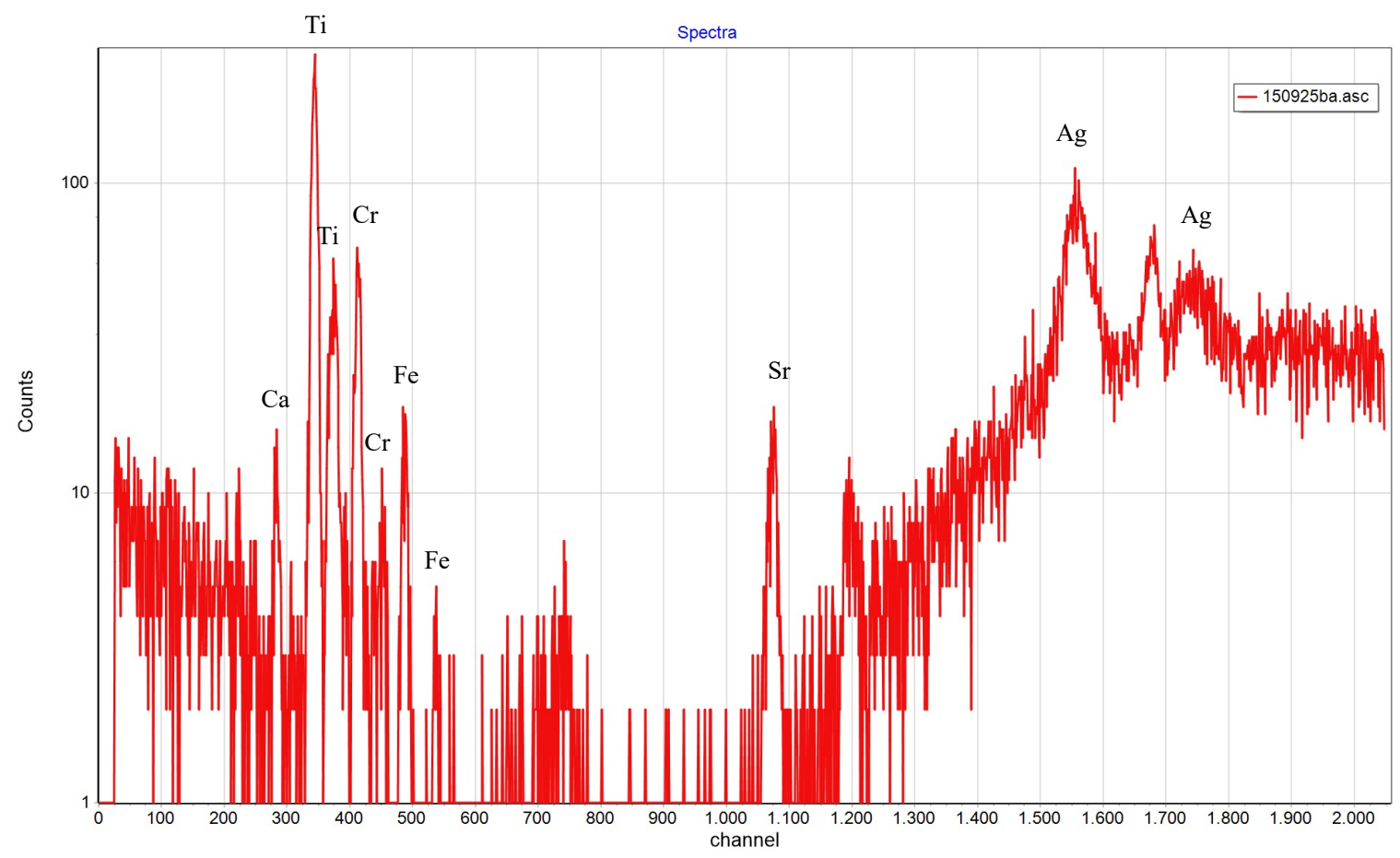

Fonte: Sistema FRX

Os elementos identificados na amostra do tecido com biocerâmica incorporada à matriz polimérica do fio são: $\mathrm{Ca}, \mathrm{Ti}, \mathrm{Cr}, \mathrm{Fe}$ e $\mathrm{Sr}$. O elemento Ag é um elemento do arranjo experimental e não da amostra analisada.

A figura 54 apresenta o espectro obtido ao realizar o teste com a amostra com biocerâmica impregnada. 
Figura 54. Gráfico de contagens de raios X emitidos pelo tecido com biocerâmica impregnada, com filtro.

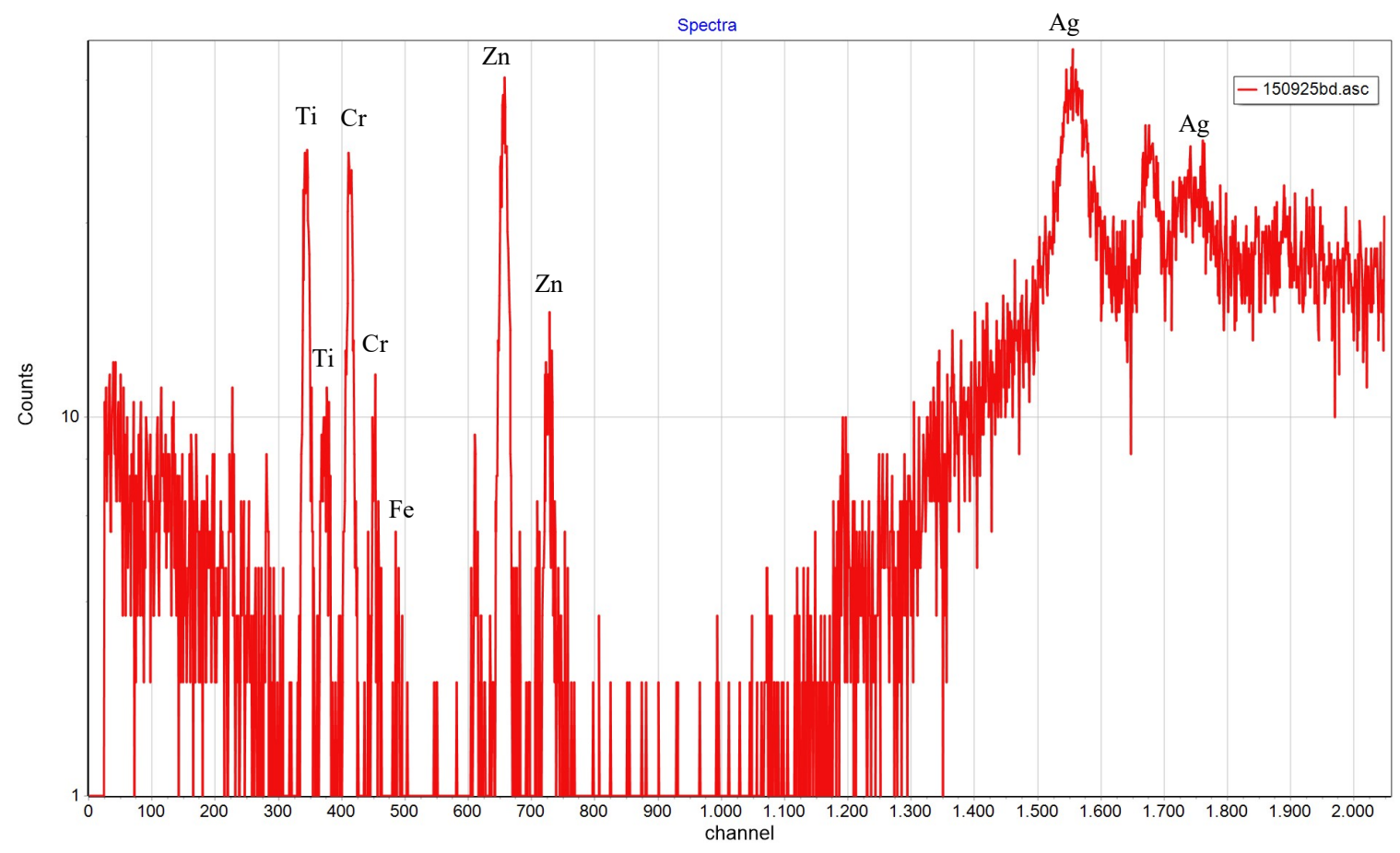

Fonte: Sistema FRX

Os elementos identificados na amostra do tecido com biocerâmica impregnada são: Ti, $\mathrm{Cr}, \mathrm{Fe}$ e $\mathrm{Zn}$. O elemento Ag é um elemento do arranjo experimental e não da amostra analisada.

A figura 55 apresenta o espectro obtido ao realizar o teste com a amostra com deposição de biocerâmica. 
Figura 55. Gráfico de contagens de raios X emitidos pelo tecido com deposição de biocerâmica, com filtro.

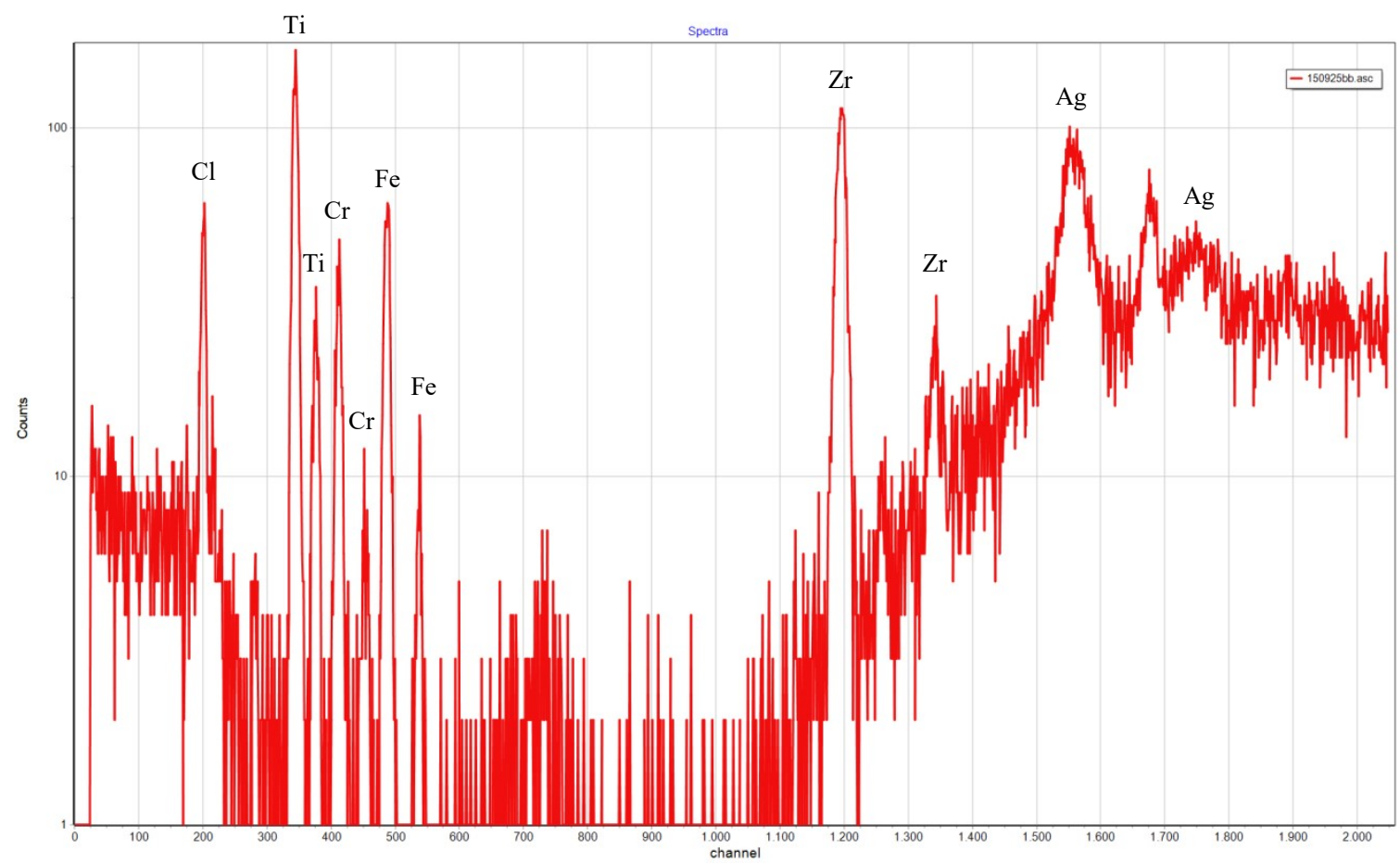

Fonte: Sistema FRX

Os elementos identificados na amostra do tecido com deposição de biocerâmica são: $\mathrm{Cl}, \mathrm{Ti}, \mathrm{Cr}, \mathrm{Fe}$ e $\mathrm{Zr}$. O elemento Ag é um elemento do arranjo experimental e não da amostra analisada.

A figura 56 apresenta o espectro obtido ao realizar o teste com a amostra sem biocerâmica. 
Figura 56. Gráfico de contagens de raios X emitidos pelo tecido sem biocerâmica, com filtro.

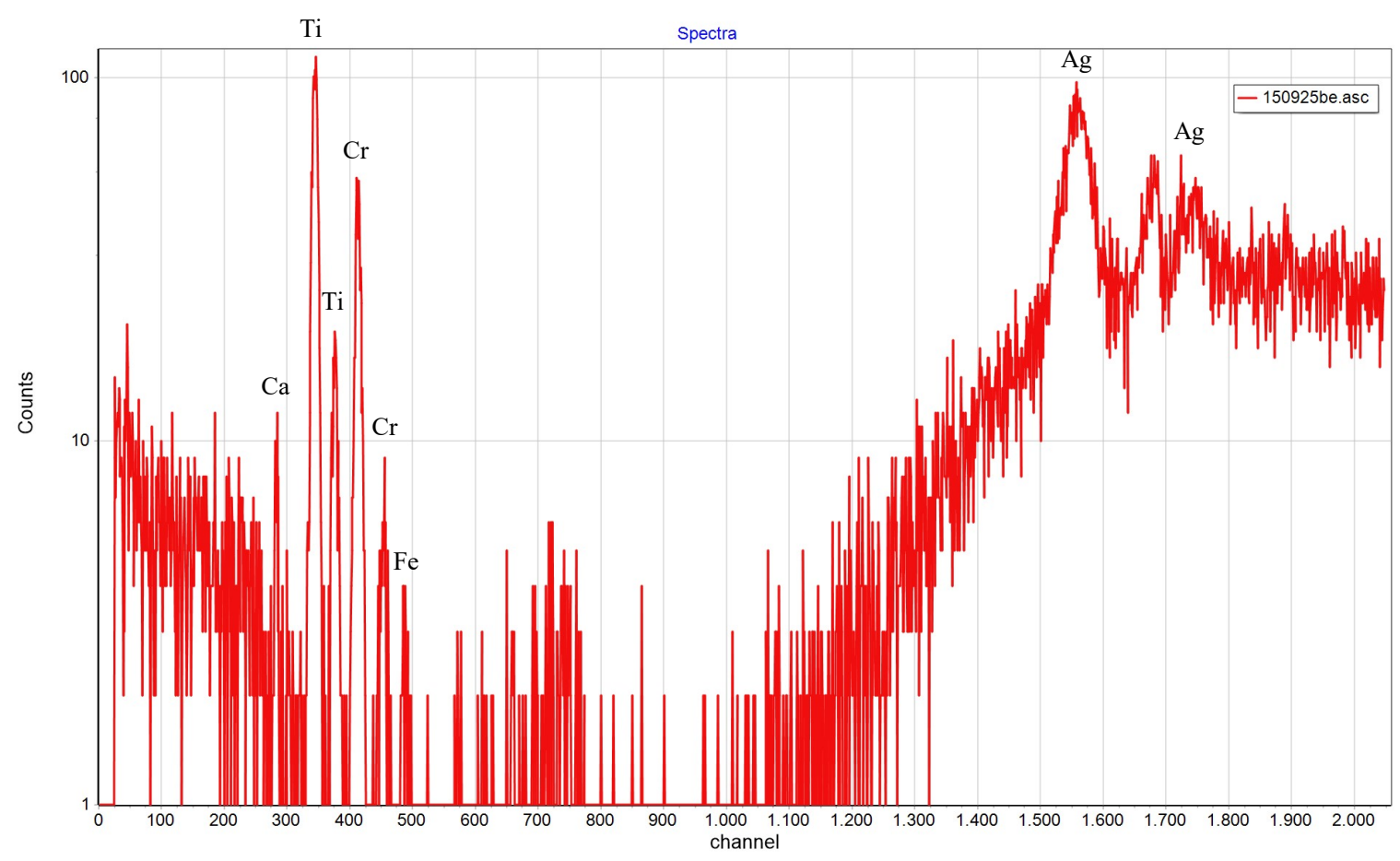

Fonte: Sistema FRX

Os elementos identificados na amostra do tecido com deposição de biocerâmica são: $\mathrm{Ca}, \mathrm{Ti}, \mathrm{Cr}$ e Fe. O elemento Ag é um elemento do arranjo experimental e não da amostra analisada.

Os elementos químicos encontrados nas medições das amostras com a utilização do filtro no sistema FRX são apresentados na tabela 18. 
Tabela 18. Áreas relativas a cada elemento encontrado no espectro das diferentes amostras analisadas, com filtro no sistema FRX.

\begin{tabular}{|c|c|}
\hline \multicolumn{1}{|c|}{} & \\
\hline Elemento & $\mathbf{Z}$ \\
\hline $\mathrm{Si}$ & 14 \\
\hline $\mathrm{S}$ & 16 \\
\hline $\mathrm{Cl}$ & 17 \\
\hline $\mathrm{Ca}$ & 20 \\
\hline $\mathrm{Ti}$ & 22 \\
\hline $\mathrm{Cr}$ & 24 \\
\hline $\mathrm{Fe}$ & 26 \\
\hline $\mathrm{Zn}$ & 30 \\
\hline $\mathrm{Sr}$ & 38 \\
\hline $\mathrm{Zr}$ & 40 \\
\hline $\mathrm{Ba}$ & 56 \\
\hline
\end{tabular}

\begin{tabular}{|c|c|}
\hline $\begin{array}{c}\text { Tecido Biocerâmica } \\
\text { Matriz do Fio }\end{array}$ \\
\hline Área & inc A \\
\hline 0 & 0 \\
\hline 9 & 10 \\
\hline 18 & 10 \\
\hline 83 & 11 \\
\hline 2059 & 48 \\
\hline 510 & 22 \\
\hline 166 & 12 \\
\hline 0 & 0 \\
\hline 252 & 16 \\
\hline 114 & 21 \\
\hline 154 & 18 \\
\hline
\end{tabular}

\begin{tabular}{|c|c|}
\hline \multicolumn{2}{|c|}{$\begin{array}{c}\text { Tecido Biocerâmica } \\
\text { Impregnada }\end{array}$} \\
\hline Área & incA \\
\hline 0 & 0 \\
\hline 15 & 9 \\
\hline 10 & 9 \\
\hline 24 & 7 \\
\hline 505 & 20 \\
\hline 463 & 18 \\
\hline 26 & 3 \\
\hline 931 & 26 \\
\hline 0 & 0 \\
\hline 0 & 0 \\
\hline 0 & 0 \\
\hline
\end{tabular}

\begin{tabular}{|c|c|}
\hline \multicolumn{2}{|c|}{$\begin{array}{c}\text { cecido Deposição de } \\
\text { Biocerâmica }\end{array}$} \\
\hline Área & incA \\
\hline 0 & 0 \\
\hline 33 & 11 \\
\hline 427 & 22 \\
\hline 25 & 8 \\
\hline 1472 & 34 \\
\hline 402 & 19 \\
\hline 647 & 23 \\
\hline 0 & 0 \\
\hline 0 & 0 \\
\hline 1955 & 44 \\
\hline 0 & 0 \\
\hline
\end{tabular}

\begin{tabular}{|c|c|}
\hline \multicolumn{2}{|c|}{$\begin{array}{c}\text { Tecido sem } \\
\text { Biocerâmica }\end{array}$} \\
\hline Área & incA \\
\hline 0 & 0 \\
\hline 8 & 10 \\
\hline 10 & 9 \\
\hline 38 & 9 \\
\hline 1052 & 29 \\
\hline 499 & 19 \\
\hline 38 & 5 \\
\hline 0 & 0 \\
\hline 0 & 0 \\
\hline 0 & 0 \\
\hline 0 & 0 \\
\hline
\end{tabular}

Fonte: Sistema FRX

Nota-se que as amostras do tecido com biocerâmica incorporada à matriz polimérica do fio e a amostra do tecido com deposição de biocerâmica apresentam $\mathrm{Zr}$, sendo que a primeira destas apresenta o elemento em baixa concentração.

A amostra com biocerâmica incorporada à matriz polimérica do fio é a única a apresentar os elementos $\mathrm{Sr}$ e $\mathrm{Ba}$, e a amostra com biocerâmica impregnada, a única a apresentar Zn.

Todas as amostras apresentam $\mathrm{S}, \mathrm{Cl}, \mathrm{Ca}, \mathrm{Ti}, \mathrm{Cr}$ e $\mathrm{Fe}$. As amostras que contém algum tipo de emissão de raios infravermelhos quando aquecidas (verificadas anteriormente pela espectroscopia de infravermelhos) possuem $\mathrm{Zn}, \mathrm{Sr}, \mathrm{Zr}$ ou $\mathrm{Ba}$, elementos que não estão presentes na amostra que não apresenta emissão quando aquecida (sem biocerâmica). Estes elementos presentes somente nas amostras com presença de emissão de raios infravermelhos podem ser os responsáveis pela emissão.

A diferença de composição de cada amostra afirma a diferença de emissividade de raios infravermelhos por parte das amostras, quando aquecidas. 


\section{CONCLUSÕES}

Ao encontrar picos de emissão nas amostras aquecidas, se conclui que é possível sim medir a emissividade de raios infravermelhos de tecidos contendo biocerâmica, através da utilização de um espectrofotômetro de infravermelhos FTIR, simulando a ação do tecido junto ao corpo.

As informações contidas na bibliografia encontrada a respeito da emissão de raios infravermelhos, por parte de tecidos contendo biocerâmica, divergem dos resultados obtidos, quando se trata do comprimento de onda dos raios infravermelhos emitidos pelos tecidos. A bibliografia diz que tecidos contendo biocerâmica emitem raios infravermelhos longos, quando aquecidos (em contato com o corpo), e nos resultados obtidos constatou-se que os raios infravermelhos emitidos pelos tecidos estão na faixa de infravermelhos médios (beirando a faixa de infravermelhos próximos), portanto não se confirmou a teoria apresentada pela bibliografia.

O fato dos tecidos emitirem raios infravermelhos médios, quando aquecidos, em lugar de emitir infravermelhos longos, pode ser um ponto positivo, pois os raios infravermelhos médios penetram mais fundo na pele do que os longos.

Através da fluorescência de raios $\mathrm{X}$ pode-se verificar que, pelo fato dos tecidos contendo biocerâmica apresentarem diferentes elementos químicos em sua composição, cada tecido tem uma emissão característica de raios infravermelhos quando aquecidos.

\section{SUGESTÃO DE TRABALHOS FUTUROS.}

Para trabalhos futuros sugiro a construção de um equipamento com controle total de temperatura, capaz de aquecer a amostra no interior do espectrofotometro de raios infravermelhos (sem interferir no receptor de raios infravermelhos). Com isso seria possível analisar em qual faixa de temperatura a biocerâmica começa a ser excitada e emitir raios infravermelhos. 


\section{REFERÊNCIAS}

ABRAFAS, Disponível em: www.abrafas.org.br, Acesso em: Fev 2016.

ALFIERI, P. Tecnologia das Fibras Têxteis I e II; Centro Universitário da FEI, 2012a.

ALFIERI, P. Acabamentos Físicos, Físico-químicos Têxteis e Processos de Lavanderia; Centro Universitário da FEI, 2012 b.

ALFIERI, P. Tecnologia da Texturação e Fios Recobertos - Partes 1 e 2; Centro Universitário da FEI, 2013.

ANDRADE, L. E. C.; KAYSER, C. Estudo dos efeitos de um tecido emissor de infravermelho longo sobre a microcirculação em pacientes com fenômeno de Raynaud; UNIFESP, São Paulo, 2012.

ASTM D 1059 Yarn number based on short-length speciments; American Society for Testing Materials, Annual book of ASTM standards, West Conshohocken, 2006).

ASTM D 3776 Mass per unit area (weight) of woven fabric; American Society for Testing Materials, Annual book of ASTM standards, West Conshohocken, 2006).

BALL, D. W. Field Guide to Spectroscopy; SPIE Publication, Bellingham, 2006.

BASTOS, T. Uso da tecnologia têxtil FIR para melhoria do desempenho esportivo; XXV CNTT, São Paulo, 2013.

BEZERRA, A. F.; CONRADO, L. A. L. Bioestimulação com infravermelho na melhora da qualidade de vida de indivíduos. Rev. Laser Dental Show, São Paulo, 2003.

CARTER, C. B. ; NORTON, M. G . Ceramic Materials: Science and Engineering; Springer, 2007. 
CHURCHILL, P. K. Human Thermal Environments : The Principles and the Practice ; Taylor \& Francis, 2003.

CONMETRO (conselho nacional de metrologia, normalização e qualidade Industrial). Resolução n. ${ }^{\circ}$ 02, de 6 de maio de 2008, Governo Federal, 2008.

CONRADO, L. A. L. Tecidos com biocerâmica emissor de infravermelho na bioestimulação celular; IP\&D - UNIVAP, São Paulo, 2000.

CONRADO, L. A. L. Ação da radiação infravermelha sobre os tecidos; Arq. Ciências e Saúde Unipar, São Paulo, 2004.

CORBMAN, B. P. Textiles: Fiber to Fabric. Mc Graw-Hill. Bronx Community College, New York, 1975.

CYAN, N. K. Y. Investigation of Thermal Functional Performance and Infrared Radiation Properties of Camisole Incorporated With IR Coating; Institute of Textiles \& Clothing; Hong Kong, 2012.

DELGADO, A. O. Processos de Modificação Molecular em Polímeros Irradiados com Feixe de Íons; Instituto de Física da Universidade de São Paulo (USP), São Paulo, 2012.

DOVER, J. S.; PHILLIPS, T. J.; ARNDT, K. A. Cutaneous affect and therapeutic uses of heat with emphasis on infrared radiation; American Academy of Dermatology, 1989.

DYER, J. Infrared Functional Textiles; AgResearch Ltd, Nova Zelândia, 2011.

ELSNER, P.; HIPLER, U. C. Biofunctional Textiles and the Skin; Karger Publishers, Suiça, 2006.

EP 6.0 (European Pharmacopoeia); Absorption Spectrophotometry, Infrared; 2008. 
FIORINI, E. J. Fourier Transform Infrared Spectroscopy - FTIR; Faculdade de Engenharia Elétrica da Universidade Estadual de Campinas, Campinas, 2000.

GRIFFITHS, P. R.; HASETH, J. H. Fourier Transform Infrared Spectrometry; John Wiley \& Sons, Hoboken, 2007.

HEARLE, J. W. S.; HOLLICK, L.; WILSON, D. K. Yarn Texturing Technology; Woodhead Publishing Limited, Inglaterra, 1ª edição, 2001.

HÓLMER, I. How is Performance in the Heat Affected by Clothing?; Faculty of Engineering, Lund University, Suécia, 2008.

HU, J. Characterization of Sensory Comfort of Apparel Products; The Hong Kong Polytechnic University, Hong Kong, 2006.

HU, J. Y.; LI, Y.; YEUNG, K. W.; WANG, S. X. Characterization of Thermal Radiation Properties of Polymeric Materials; Polymer Testing Vol. 25, No 5, 2006.

INOUE, S.; KABAYA, M. Biological activities caused by infra-red radiation; Int. J Biometeorol, 1989.

KARACHI, T. S. Innovation in Textiles: Trends and Challenges; CMRI, University of Bolton, UK, Megatex 2008.

KLOCK, U.; ANDRADE, A. S.; HERNANDEZ, J. A; MUÑIZ, G. I. B. Química da Madeira; Universidade Federal do Paraná, Curitiba, 2005.

KNIGHT, R. D. Physics for Scientists and Engineers: A Strategic Approach; AddisonWesley, San Francisco, Canadá, 2004.

LI, Y. The Science of Clothing Comfort; Textile Progress, Vol. 31, The Textile Institute, 2001 . 
LI, Y.; WU, D. X.; HU, J. Y.; WANG, S. X. Novel Infrared Radiation Properties of Cotton Fabric Coated With Nano Zn/ZnO Particles; The Hong Kong Polytechnic University, Hong Kong, 2007.

LUO, J.; MAO, A.; LI, Y.; WANG, R.; XIONG, Y. Ano Innovative Engineering Design Framework of Digital Clothing for Superior Thermal Performance; Journal of Information \& Computational Science, 2011.

MACEDO, A. M. K. S. Análise de Malhas; Instituto Federal de Santa Catarina, Santa Catarina, $1^{\text {a }}$ edição, 2009.

NETO, A. P. P. Fibras têxteis. Senai Cetiq, Rio de Janeiro, 1996, v.1 e v.2

NF G 18-001 Fils élastiques á base de polyisoprène naturel ou synthétique Determination des dimensions et de 1 amasse linéique (méthode A); Association Française de Normalisation, Recuel de normes françaises des textiles, Paris, 1983.

OGULATA, R. T. The Effect of Thermal Insulation of Clothing on Human Thermal Comfort; Fibres \& Textiles in Eastern Europe, Vol. 15, 2007.

PAiVA, M. B.; EMANUEL, A. F.; MAGNO, R. S. M. Processo de Fiação; Natal-RN, 2010.

PARK, C. H.; SHIM, M. H.; SHIM, H. S. Effect of Ceramics on the Physical and Thermophysiological Performance of Warm-up Suit; Textile Research Journal, 79: 1557, 2009.

PINTO, H. P. F. Três Estratégias para Análise Quantitativa ou Qualitativa por Espectroscopia de Fluorescência de Raios X por Energia Dispersiva; Universidade de São Paulo, São Paulo, 2013.

RIZZUTTO, M. A.; TABACNIKS, M. H.; ADDED, N.; BARBOSA, M. D. L.; CURADO, J. F.; PASCHOLATI, P. R.; NEVES, G.; LIMA, S. C.; MELO, H. G.; NEIVA, A. C. Pixe Externo para Análise de Objetos de Arte e Arqueologia; Revista brasileira de arqueometria, restauração e conservação, Volume 1, 2007.

ROMERO, L. L.; VIEIRA, J. O. W. M.; MARTINS, R. F.; MEDEIROS, L. A. R. Área de Operações Industriais: Malharias; Brasil, dezembro de 1994. 
SADOV, F.; KORCHAGIN, M.; MATETSKY, A. Chemical Technology of Fibrous Materials; MIR Publishers, Moscow, 1973.

SAPTARI, V. Fourier-Transform Spectroscopy Instrumentation Engineering; SPIE Publication, Bellingham, 2003.

SHYR, T.; XU, W.; YAO, M. Textiles' Properties in the Infrared Irradiation; Textile Research Journal, 77: 513, 2007.

SMITH, B. C, Fundamentals of Fourier Transform Infrared Spectroscopy; CRC, Boca Raton, 1996.

SONG, Q.; HU, J.; XING, J.; YUEN, M.; YAO, B.; LI, Y. Evaluation of IR Radiation Performances of Composite MicroPCMs Incorporated with Silver Nano Particles; Hong Kong, 2008.

SPENCER, D. J. Knitting Technology - A comprehensive handbook and practical guide; Woodhead Publishing Limited, Cambridge, Inglaterra, $3^{\mathrm{a}}$ edição, 2001.

THOMAS, B. et al. The Fiber Year, Oerlikon Textile, GmbH \& Co. KG, 2010.

WAINWRIGHT, M. Therapeutic applications of near-infrared dyes; Liverpool John Moores University, Liverpool, UK, 2010.

WU, H.; FAN, J.; QUIN, X.; ZHANG, G. Thermal Radiative Properties of Electrospun Superfine Fibrous PVA Films; Materials Letters, Vol. 62, Peer Reviewed Journal, 2008.

YANG, W.; HU, J.; HAN, Y.; LI, Y. Relationships Between Fabric Thermal Radiation Properties and Warmth Keeping Performance; Hong Kong, 2008.

YU, C. Z.; WANG, G. Z.; MA, X. Y.; WANG, R. Compound Powders of Nano ZrO2 and TiO2 and Warm Keeping of Leather; Leather Science and Engineering, Vol. 17, 2007. 